\title{
A NOVEL APPROACH TO INTEGRATING DESIGN INTO MANUFACTURING AND MATERIALS EDUCATION THROUGH THE FABRICATION OF A SCALE MODEL CANNON
}

\author{
A Thesis \\ by \\ JEREMY L. WEINSTEIN \\ Submitted to the Office of Graduate Studies of \\ Texas A\&M University \\ in partial fulfillment of the requirements for the degree of \\ MASTER OF SCIENCE
}

May 2003

Major Subject: Mechanical Engineering 


\title{
A NOVEL APPROACH TO INTEGRATING DESIGN INTO MANUFACTURING AND MATERIALS EDUCATION THROUGH THE FABRICATION OF A SCALE MODEL CANNON
}

\author{
A Thesis \\ by \\ JEREMY L. WEINSTEIN \\ Submitted to Texas A\&M University \\ in partial fulfillment of the requirements \\ for the degree of \\ MASTER OF SCIENCE
}

Approved as to style and content by:

\begin{tabular}{cc}
\hline $\begin{array}{c}\text { Richard Griffin } \\
\text { (Chair of Committee) }\end{array}$ & $\begin{array}{c}\text { Terry Creasy } \\
\text { (Member) }\end{array}$ \\
\hline $\begin{array}{c}\text { James Yao } \\
\text { (Member) }\end{array}$ & Rita Caso \\
& (Member) \\
\hline & \\
\hline John Weese & \\
(Department Head) &
\end{tabular}

May 2003

Major Subject: Mechanical Engineering 


\begin{abstract}
A Novel Approach to Integrating Design into Manufacturing and Materials

Education through the Fabrication of a Scale Model Cannon. (May 2003)

Jeremy L. Weinstein, B.S., Texas Tech University

Chair of Advisory Committee: Dr. Richard Griffin
\end{abstract}

There has been a continuous push among industry, educators, and accreditation organizations to infiltrate all levels of engineering education with design skills development instruments. At Texas A\&M University there was the unique opportunity to modify a manufacturing and materials laboratory with this ideal in mind. Prior to 2001 the materials and manufacturing laboratories were independent initiatives. Recently, these courses have been combined into one entity. It was proposed that if these two courses integrated fully under the umbrella of one project, that the students would better understand the nature of product development in design and that this simple change would result in a higher level of learning.

The proposed manufacturing and materials selection project was a 1/8th scale replica of a $12 \mathrm{lb}$. Civil War Napoleon cannon in a field mount. The product was selected due to its ease of manufacture and potential for utilizing a sufficient variety of materials during development. The development of the product followed a simple timeline. Initially, students took an existing model and used it to develop working drawings. Next the barrel material was selected by examining the performance of two materials using common testing methods. Selected materials were then subjected to heat treatment. Once the material processing was complete, manual machining, CNC machining, welding and a novel rapid manufacturing approach were used to produce the cannons. The cannons were then tested and destroyed for metallographic examination.

A quasi-experimental two by two factorial design was used to evaluate the effects of the innovative laboratory treatment compared with the effects of standard laboratory treatment. Assessment was performed using two instruments. These 
instruments consisted of three student surveys and two open-ended qualitative essays graded for depth of learning using analytic rubrics. Preliminary results indicate that the students are highly enthused by the new class. Analysis of the open-ended qualitative essays indicate that the students in the treatment, or project-based, laboratory performed at an equal level to those in the non-treatment, or control group. 


\section{ACKNOWLEDGMENTS}

I would like to thank Richard Griffin for his help and guidance in the development of this unique project. I would also like to thank members of the Mechanical Engineering Department and Texas A\&M who had a hand in the execution of the laboratory and assessment tools: Alan Wolfenden, Rita Caso, Jim Sajewski, Mike Walker, and Johnny Hallford. Finally, the help of Lindsay Plesko has been instrumental in my continued hunt for this elusive goal. 


\section{TABLE OF CONTENTS}

ABSTRACT …....................................................................................

ACKNOWLEDGMENTS .................................................................. v

TABLE OF CONTENTS ...................................................................... vi

LIST OF FIGURES …..................................................................... viii

LIST OF TABLES ...............................................................................

CHAPTER

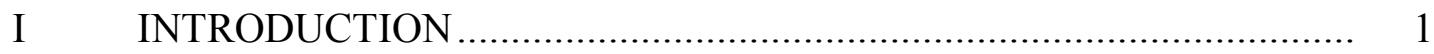

Literature Review ......................................................... 2

Objectives................................................................. 4

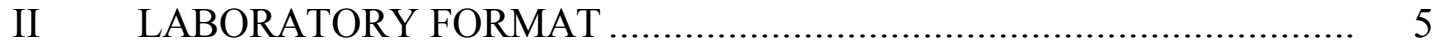

Project Development ................................................. 5

Laboratory Structure ...................................................... 14

III ASSESSMENT TOOLS .......................................................... 30

Surveys ................................................................... $\quad 30$

Essays ....................................................................... 33

First Essay Development................................................... 33

Second Essay Development ................................................ 37

Rubrics ...................................................................... 40

Rubric 1 ................................................................. 40

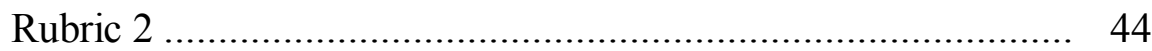

IV $\quad$ RESULTS AND DISCUSSION ................................................. 49

First Survey ........................................................... 49

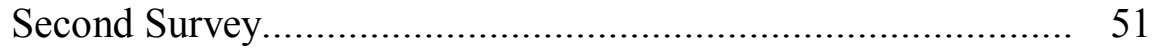

Final Survey .............................................................. 52 
CHAPTER

Peer Review . 54

Essays .................................................................... 55

V CONCLUSIONS AND RECOMMENDATIONS ............................. 59

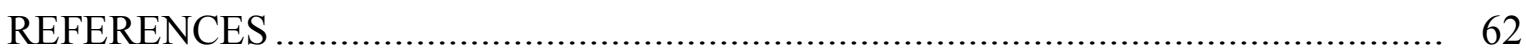

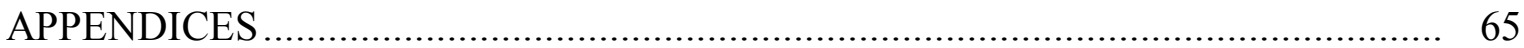

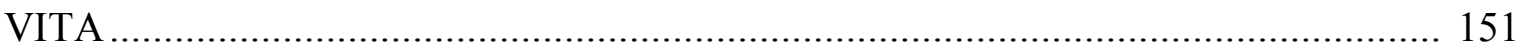




\section{LIST OF FIGURES}

FIGURE $\quad$ Page

$1 \quad$ Assembled Cannon Produced in Laboratory ...................................... 5

$2 \quad$ Dimensions of a 12lb. Civil War Napoleon Cannon ............................... 7

3 Drawing of the Cannon Barrel as Employed in the Laboratory................. 8

$4 \quad$ Drawing of the Trunion Used in Cannon Assembly.............................. 9

$5 \quad$ Drawing of the Wheel Used in Cannon Assembly ............................... 10

$6 \quad$ Drawing of the Trail Piece as Used in the Cannon Laboratory .................. 11

$7 \quad$ The Axle as Used in the Laboratory ............................................. 12

$8 \quad$ Drawing of the Cheek Pieces as Used in the Laboratory ....................... 13

$9 \quad$ Example Cannon with Original Cheek Configuration .......................... 13

$10 \quad$ Arrangement of the Metrology and Tolerance Assignment .................... 17

11 Details of the Materials Testing Laboratory ..................................... 18

12 Requirements for the Aging, Hardness, and Heat Treatment Laboratory.. 20

13 Requirements for the Injection Molding Tensile Test Laboratory ........... 21

14 The Manual Machining Assignment .............................................. 22

15 Requirements for the CNC Machining Laboratory ........................... 24

$16 \quad$ Rapid Prototyping and Casting Assignment .................................. 26

17 Requirements for the Welding and Brazing Assignment ..................... 28

18 Metallography Assignment for the Cannon Laboratory ......................... 29 
FIGURE $\quad$ Page

19 Problem Statement from the First Essay Assessment ........................... 33

$20 \quad$ First Question from the First Essay Assessment ............................... 34

$21 \quad$ Second Question from the First Essay Assessment.............................. 34

22 Third Question from the First Essay Assessment.............................. 35

23 Fourth Question from the First Essay Assessment............................ 35

$24 \quad$ Fifth Question from the First Essay Assessment ............................... 36

25 Sixth Question from the First Essay Assessment ............................... 36

26 Seventh Question from the First Essay Assessment........................... 36

27 Background Information for the Second Essay Assessment .................. 37

$28 \quad$ First Question Second Essay Assessment ..................................... 37

29 Second Question Second Essay Assessment................................... 38

$30 \quad$ Third Question Second Essay Assessment ..................................... 38

31 Fourth Question Second Essay Assessment..................................... 39

32 Seventh Question Second Essay Assessment.................................. 39

33 Analytic Assessment Tool for Essay 1 Question 1 ............................. 40

34 Analytic Assessment Tool for Essay 1 Question 2 ............................. 41

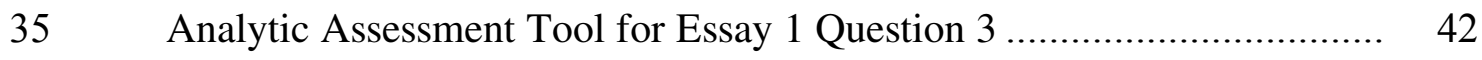

$36 \quad$ Analytic Assessment Tool for Essay 1 Question 4 .............................. 42

37 Analytic Assessment Tool for Essay 1 Question 5 ............................. 43

38 Analytic Assessment Tool for Essay 1 Question 6 .............................. 43 
FIGURE $\quad$ Page

39 Analytic Assessment Tool for Essay 1 Question 7 ............................. 44

$40 \quad$ Analytic Assessment Tool Question 1 Essay 2 ............................... 45

$41 \quad$ Analytic Assessment Tool Question 2 Essay 2 ................................. 46

$42 \quad$ Analytic Assessment Tool Question 3 Essay 2 ............................... 46

$43 \quad$ Assessment Tool Questions 4, 5, 6 Essay 2 .................................... 43

$44 \quad$ Analytic Assessment Tool Question 7 Essay 2 ................................. 48

$45 \quad$ Students' Completed Cannon Assemblies ......................................... 59 


\section{LIST OF TABLES}

TABLE

Page

$1 \quad$ List of Materials Available for Selection in Question 2 ...................... 38

2 Average Results of Students from the Cannon Laboratory: Initial

Survey .............................................................................. 49

3 Initial Measure of the Students' Interest in the Project Laboratory............ 50

$4 \quad$ Initial Survey Results Non-Cannon Section ................................... 51

5 Average Results of Students from the Cannon Laboratory: Final Survey . 52

6 Average Results of Students from the Non-Cannon Laboratory: Final

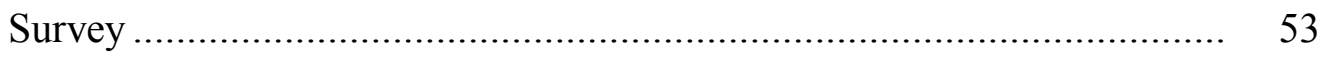

$7 \quad$ Final Measure of the Students' Interest in the Project Laboratory............ 53

$8 \quad$ Statistical Analysis of Students' Background ................................... 56

$9 \quad$ Analysis of Score Reliability ...................................................... 57

10 Evaluation of the Significance of Differences in the Course Metrics......... 57 


\section{CHAPTER I}

\section{INTRODUCTION}

Beginning in the summer of 2001 the mechanical engineering 310 manufacturing laboratory and the MEEN 340 materials laboratory were combined to form the current MEEN 360 laboratory ${ }^{1}$. This move was prompted by the need to optimize the current undergraduate degree format in Mechanical Engineering. The format for this new class was created through a combination of existing laboratory assignments. Formerly, both MEEN 310 and MEEN 340 laboratories were organized to achieve certain goals within their particular area of specialization. The new combined laboratory maintains the same independent approaches, but could be improved to achieve higher cognitive levels.

At the time of the new laboratory's development it seemed sufficient to simply combine the most important assignments from the two laboratories. This approach appeared to preserve valuable topics while discarding those assignments that apparently lacked enough importance to be maintained. In many ways this decision was the correct one. The topics that were lost did not necessarily negate the full development of the students within the areas of manufacturing and materials, but the lack of continuity of the students' immersion within these particular fields, necessitated by the patchwork interspersion of the various assignments, has created an environment where students will be unable to fully understand the link between these two fields.

Progressive research in cognitive methods of learning demanded a more studentoriented pedagogy of course content. Any course format concerned with good teaching must have the following elements:

- Instructional methods that facilitate student involvement

- The right content

- Instructional strategies that maximize teaching efficiency and student learning

- Good attitudes on the part of the teacher and student

The journal model is the Journal of Engineering Education. 
- Promotion of life long learning skills ${ }^{2}$

Many of these elements are addressed automatically or within the course through student teacher interaction; however, instructional methodology and strategy are fertile grounds for continued research and innovation. It has been shown that when a student is engaged in authentic activities in a context relevant to their interest that learning is fostered $^{3}$. This would seem to indicate that if an educator is interested in a student oriented approach to education the affected course should be modeled on a projectoriented approach.

A project-oriented approach considered within the context of an engineering education would demand an additional consideration of design-oriented models. ABET accreditation curriculum criteria for 2002-03 requires that mechanical engineering graduates have the ability to demonstrate proficiency in the area of design and realization of mechanical systems ${ }^{4}$. This proficiency is often relegated to the province of Capstone design courses. Capstone projects are typically industry or faculty directed open-ended problems. To truly emulate the experience of design, these projects must follow this model, but the development of design skills cannot be an all or nothing approach. Stepby-step projects are required that result in success to allow students to feel and understand the process of design ${ }^{5}$.

The MEEN 360 laboratory consisted of a variety of course content from the previous two laboratories. What is required is a course format, which addresses the potentials of this new laboratory. There is a movement within education to organize a course around projects, which internally address the knowledge requirements of the course. ABET requires, that courses incorporate design elements within projects. It is suggested that MEEN 360 laboratory be built on a project, which will take the form of a black powder cannon based on a $1 / 8^{\text {th }}$ scale replica of a 12 lb. Civil War Napoleon Cannon in a field mount.

\section{Literature Review}

Education is a fertile field for research. Topics range from how students learn, to how to assess what students learn, to what might be the best format for education, the variety is almost endless, but the field of engineering education is not as broad. Research in engineering education combines the traditional field of education with the additional 
complexity of technical topics. Educational research is not a field commonly associated with knowledge of engineering topics. The current state of engineering education requires research by those with the technical expertise to teach this subject ${ }^{6}$.

The topic of this thesis touches on a variety of categories in constant consideration in the field of engineering education: cognitive methods, cooperative learning, problem based learning, project based learning, hierarchy of knowledge, design education, assessment techniques, etc. There was room within the topic of materials and manufacturing education to address all these concerns, but the focus of this thesis centers around a comparison of assignment-based education with project-based education with an additional emphasis on teaching design in a step-by-step process.

In the past teaching design through projects has infiltrated curriculums in a variety of fashions. Basic design courses independent of hard technical calculation have become part of an introduction to engineering at this university and at others ${ }^{7}$. This approach has also been modified for application with topics such as materials and manufacturing and introduced at later periods in students' development ${ }^{8}$. Qualitative assessment of these integrated approaches as compared with more traditional formats has already been done ${ }^{9}$. What remained was integration of these approaches within a laboratory format and more specifically to find if students could achieve a greater level of knowledge under this modified format than the existing one.

Comparison implies assessment and assessment requires validated testing methods to assure that experimental conclusions were consistent with existing research and flexible enough to be applied to a wide range of courses. The proposed assessment methods were student perception surveys to determine the acceptability of the new approach to students and open-ended qualitative essays to determine the level of cognition the students developed in the new course. Student perception surveys are an existing medium currently employed within the department of mechanical engineering and developed to a higher level, more suitable to this experiment, as employed in the ENGR 213 course, the prerequisite for MEEN 360. Rubric style essays, to determine the knowledge level of students, are not commonly employed within the department, but they do have valid precedent within the context of educational research in other disciplines $^{10}$. 


\section{Objectives}

Educational motivation and student interest are difficult to capture. Only a small number of students are directly interested in increasing the depth of their education ${ }^{11}$. It is simply that the job experience that motivates a professional in the pursuit of their field is seldom found in a student. On the whole students have little practice in the field of engineering and even less information from which to assign a value to the knowledge being presented to them in a course. In essence, a source of motivation was required that was common to engineering students prior to completing their degree. If one looks into the background of engineering students one is likely to find a fascination with mechanical systems independent of the profession of engineering, but important in the students' initial selection of a field of study. The cannon project, beyond simply forming an excellent tie-in with existing course goals, also acted as a stimulating theme for the course $^{12}$. To prove the value of this project a comparative evaluation of students' depth of learning and satisfaction with this new approach was made within the existing MEEN 360 program. 


\section{CHAPTER II}

\section{LABORATORY FORMAT}

\section{Project Development}

The selection of a black powder cannon based on a $1 / 8^{\text {th }}$ scale replica of a $12 \mathrm{lb}$, Civil War Napoleon Cannon in a field mount, shown in Figure 1, was motivated by its

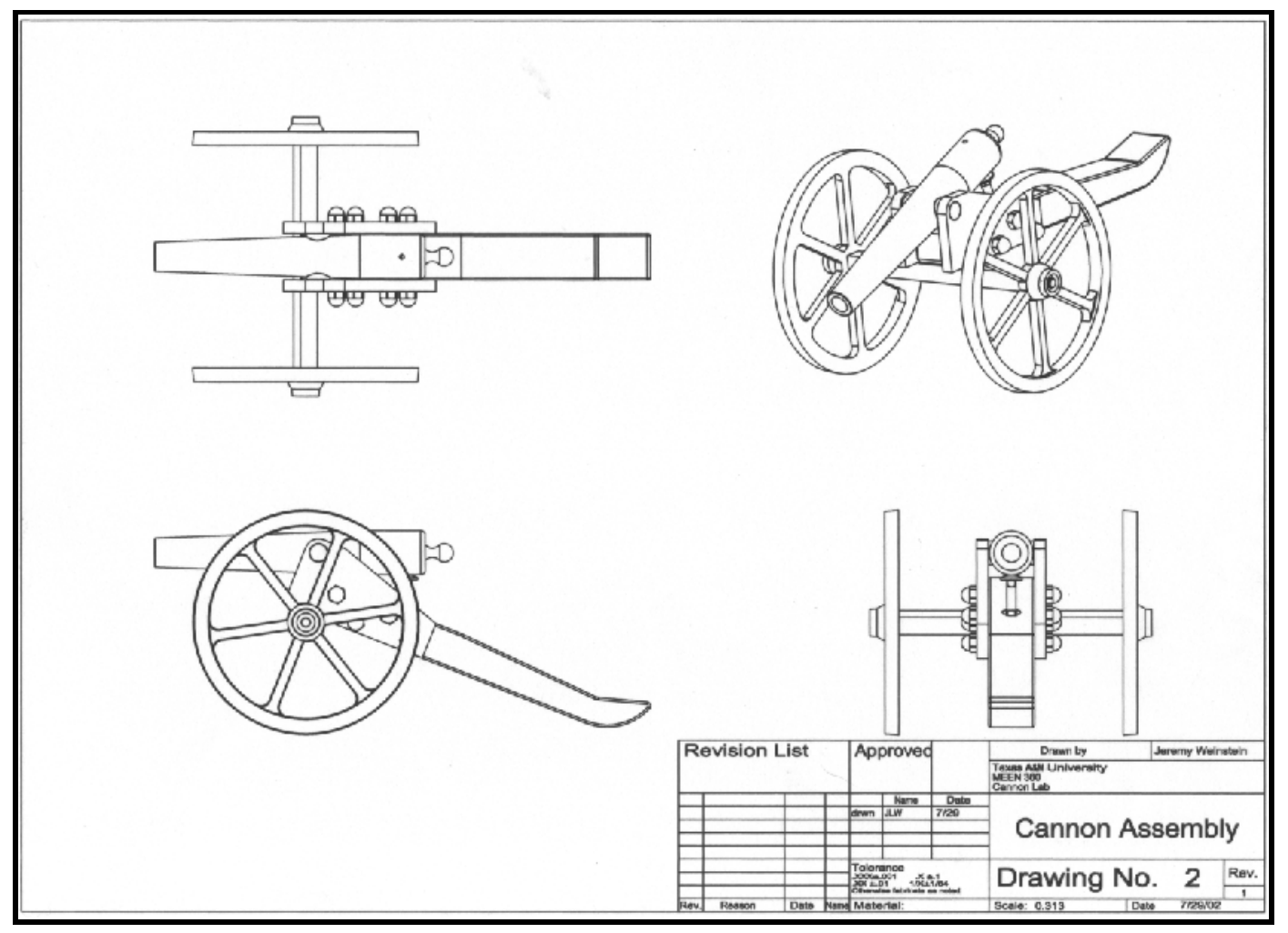

Figure 1. Assembled Cannon Produced in Laboratory

ability to meet the following criteria:

- The individual parts of the project must each act as a goal to the various experiments performed throughout the semester.

- The project needs to be easily fabricated with the available equipment such that it can be produced with each part taking no more than three hours.

- The parts need to be technically simple such that students can learn the required manufacturing techniques while producing the parts. 
- The individual parts which comprise the whole must suggest the manufacturing solutions available within the laboratory.

- A variety of materials must be employed in the construction of the project.

- The project must capture the student's interest by its nature.

- There needs to be potential for expansion upon the current project to address rising technologies.

Many project ideas were considered prior to selecting the cannon model: sterling engines, SI engines, steam engines, model airplanes, model cars, etc. The difficulty with the majority of potential projects stems from their complexity. The complexity of assembly, design, manufacture, and material selection of many potential projects voids the time limits given by the laboratory environment. The ideas inherent in their production seemed to be untenable within the restriction of the laboratory. Ultimately the decision was made to produce a cannon. There is a great deal of historical context involved with the selection of the cannon. Development of the cannon, much like other tools, has roughly paralleled the development of metals and metallurgical techniques ${ }^{13}$. Historically the cannon was one the first engineered products to employ the theory of elasticity in its improvement. In 1860 William Armstrong used the derivations of Lame to reduce cannon weight and improve accuracy through stress analysis ${ }^{13,14}$. The simple geometry of the cannon represents physical potential for analysis as in the study of mechanics, dynamics, fatigue, and fracture. Additionally, the variety of materials brass, bronze, cast iron, and steel used to manufacture cannon in its self suggests a comparison of performance characteristics using materials test methods employed in the laboratory. Cannons are a common object of fabrication for technical schools and hobbyists. Preliminary verbal surveying of students in the prior semesters suggested a positive view of this as a project. Last, cannons come in a variety of configurations which enable the rapid modification of existing designs to fit the needs of the course.

The model of cannon chosen was an 1857 Napoleon in a field mount. The cannon was an extremely significant gun during the Civil $\mathrm{War}^{15}$ and is commonly seen in battlefield re-creations. There is an existing trade in models, full size reproductions, historical documentation, and museum pieces. This quantity of data allows for ease of adaptation to the needs of the laboratory. The cannon and field mount as used in the 
Civil War consists of five basic pieces: the barrel, the axle, the wheels, cheek pieces, and trail. These individual pieces are relatively simple and can be fabricated with the equipment available in the laboratory. Dimensions of the various parts were estimated from information obtained from historical texts ${ }^{16}$. The bore of the 12-lb. Napoleon Cannon was scaled to fit a 50-caliber ball round. The size of the revised bore was used to correct the dimensions of the entire project. The resulting size fit within the parameters of the available fabrication equipment and the cost was not prohibitive.

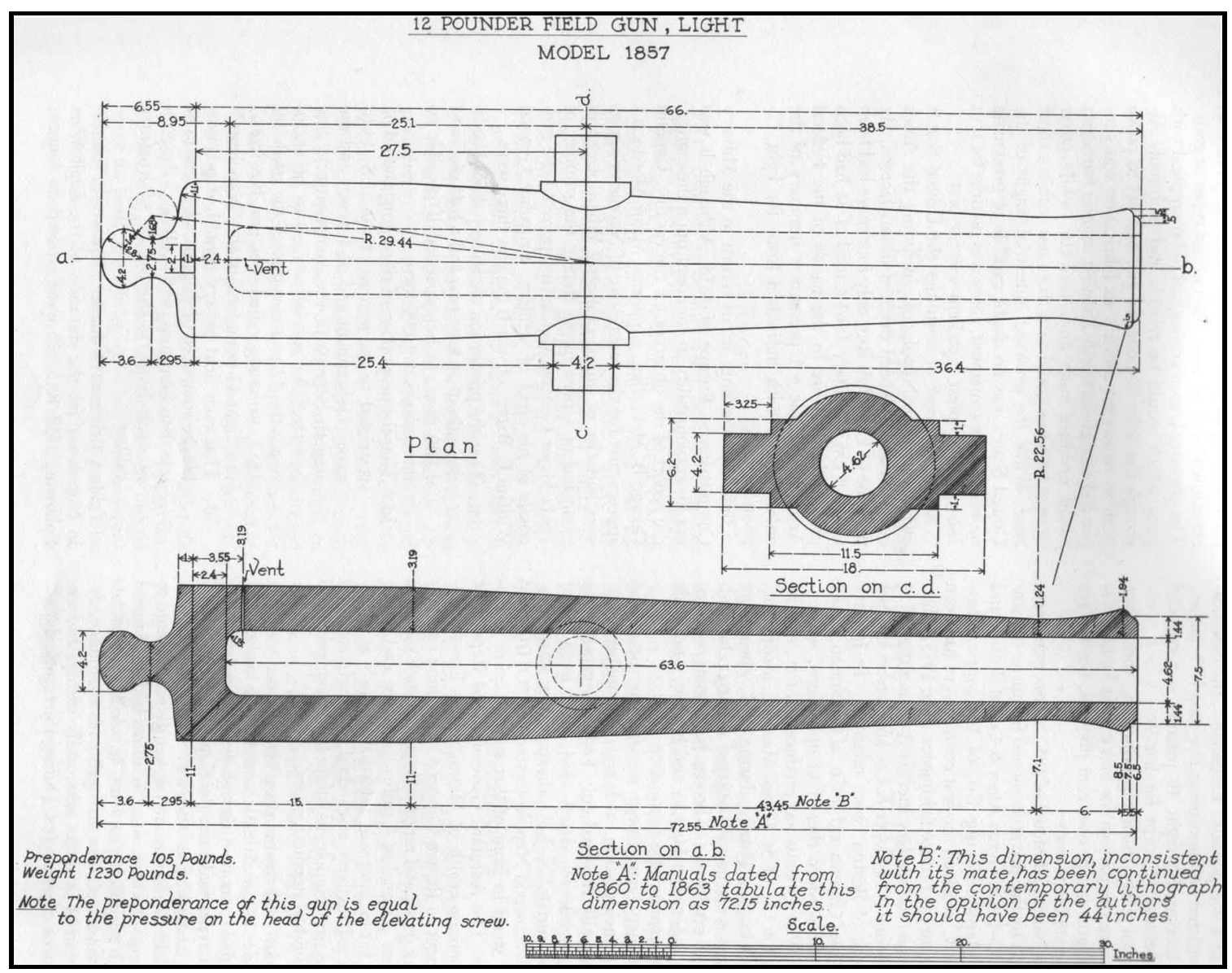

Figure 2. Dimensions of a 12lb. Civil War Napoleon Cannon

The majority of the fabrication and materials testing in the laboratory centers on the treatment and manufacture of the barrel. The barrel was designed using a modification of the drawing given below, Figure 2. The dimensions of the barrel were 
developed using a proportion based on a $0.500 \mathrm{in}$. bore. The drawing of the cannon can be seen below, Figure 3. All major elements of the 1857 Napoleon are incorporated into

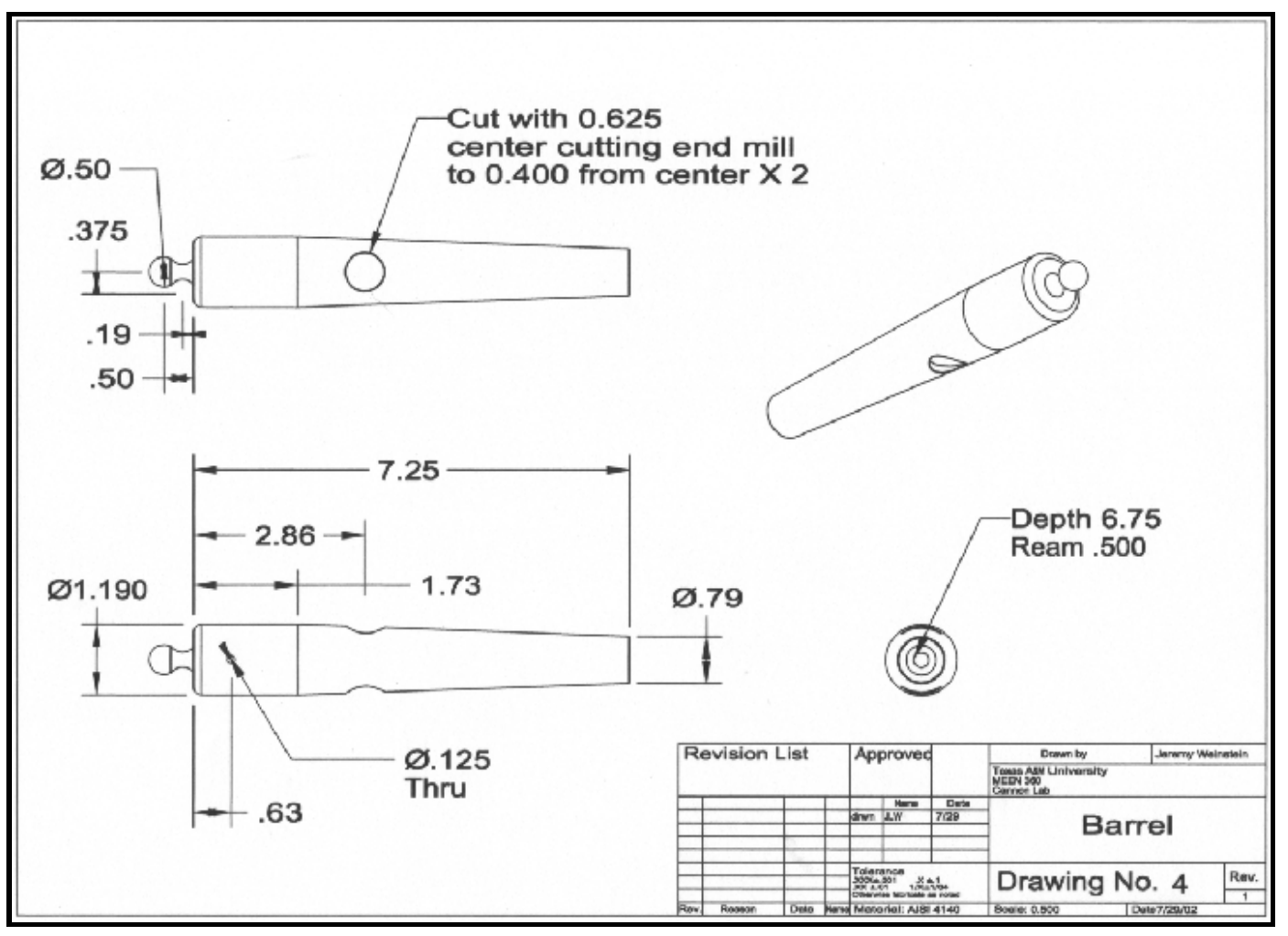

Figure 3. Drawing of the Cannon Barrel as Employed in the Laboratory

the design of the cannon with the exclusion of decorative elements. The final model of the cannon closely parallels that of existing field pieces from the time ${ }^{16}$. The material selected for the construction of the cannon was AISI 4140. The selection of this material serves many purposes. It closely follows the materials commonly used to manufacturer the guns on modern artillery ${ }^{17}$. It can be easily quenched to produce a martensitic structure. It can then be tempered to maintain high yield strength with equally high toughness. It is easily attainable and simple to machine.

The next part of the cannon assembly is the trunions. The function of the trunion is to act as a balance point and pivot to allow for elevation of the cannon in the cheek pieces. The design of the trunion for the model cannon is shown in Figure 4. The 


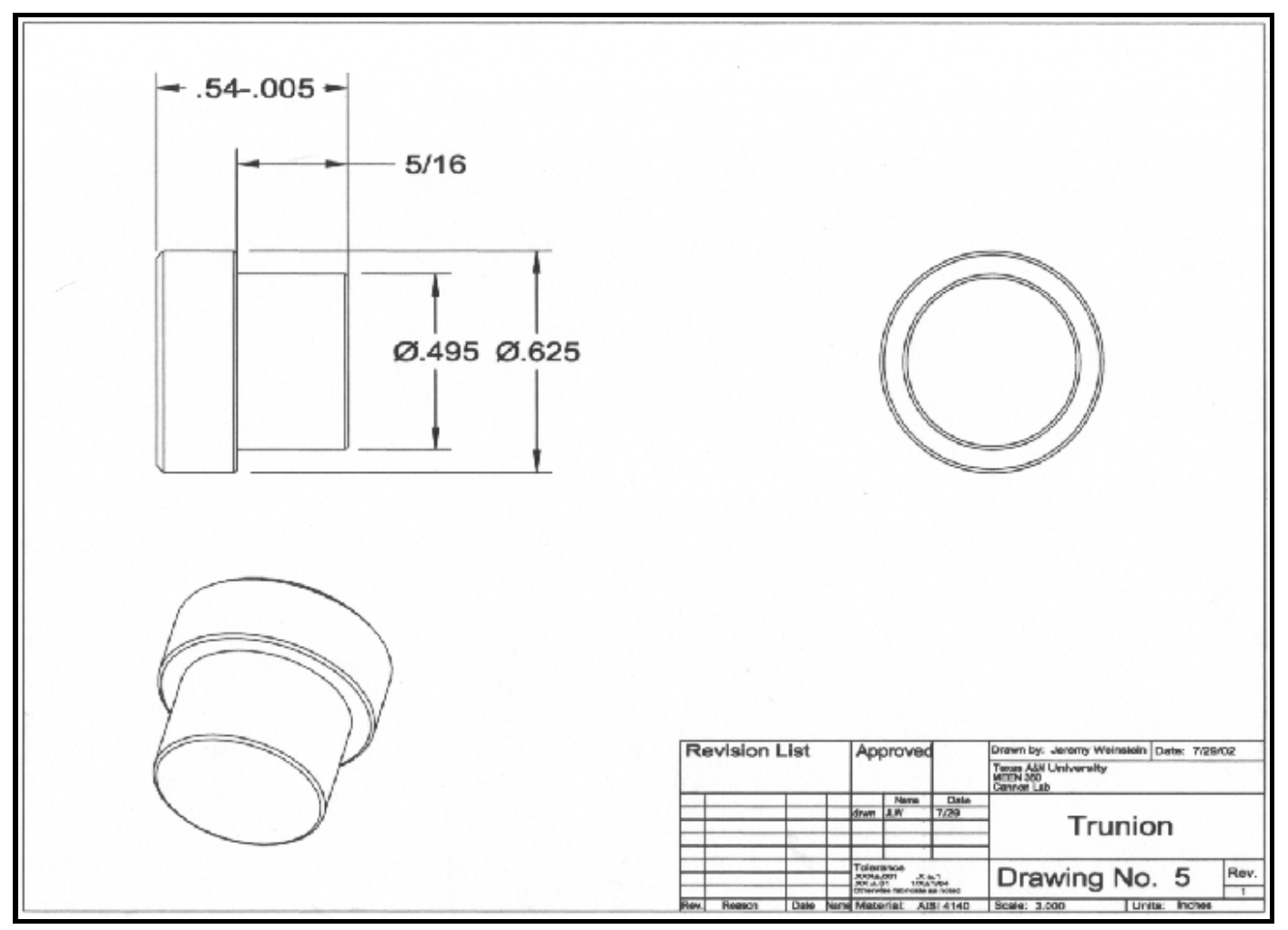

Figure 4. Drawing of the Trunion Used in Cannon Assembly

trunions are independent of the body of the barrel and must be assembled to it. This differs from the schematic of the cannon shown in Figure 2. This exception was made to allow the barrel to be easily machined on the lathe and to enable the use of a joining operation during the performance of the laboratory. The trunions were brazed on to the cannon as the final step in barrel construction prior to reaming the barrel to the correct size. The material selected for the trunions was AISI 1040. The variation in material between the barrel and the trunion served many purposes. It shows the capability of brazing to join differing steels of carbon content $>0.35 \%$ at room temperature without pre-heat. The choice of material also serves as a juxtaposition during metallographic analysis between the AISI 4140 and the AISI 1040.

The dimensions of the wheels, Figure 5, were obtained using the same proportion 

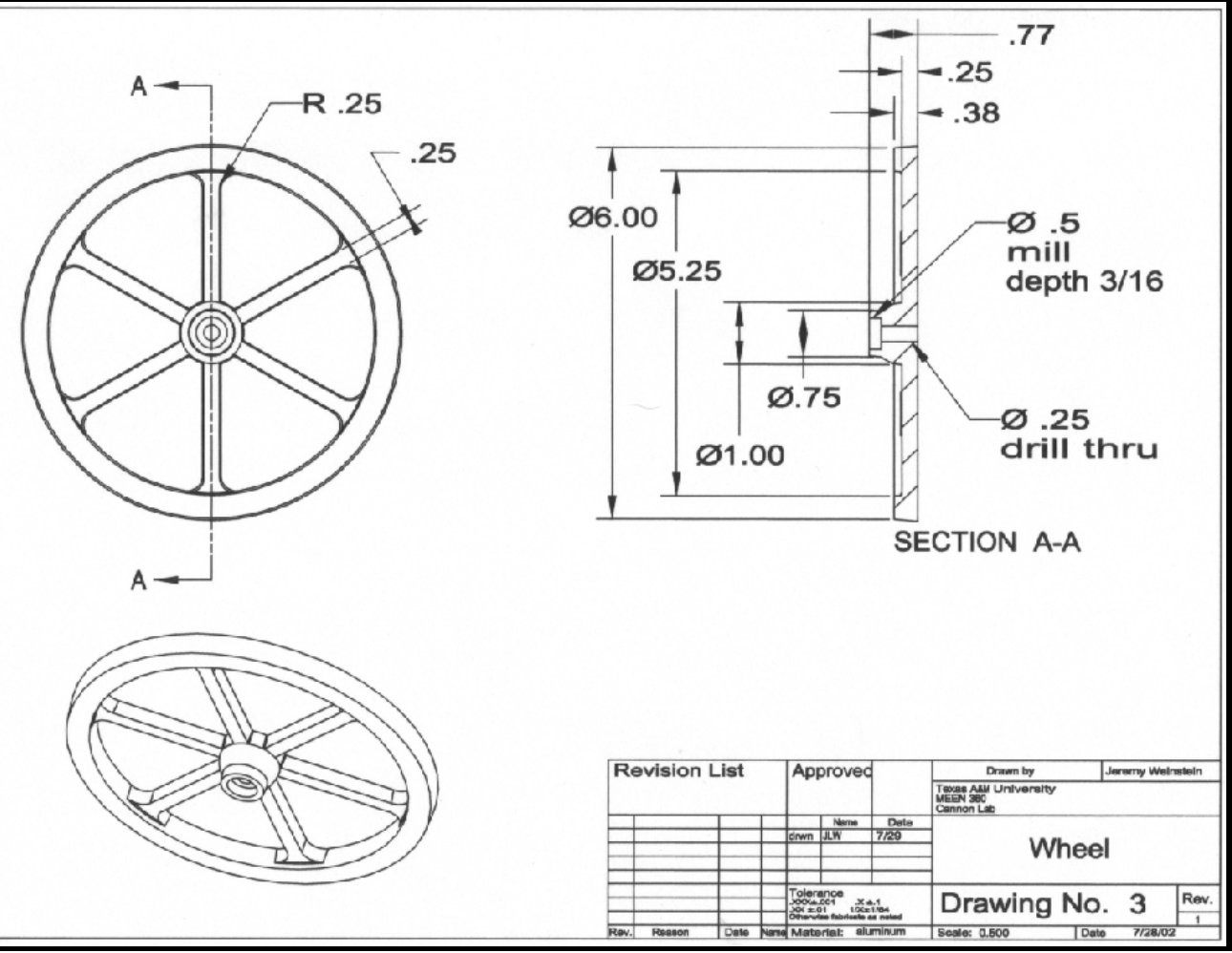

Figure 5. Drawing of the Wheel Used in Cannon Assembly

used to determine the size of the scale cannon. The function of the cannon wheels is to provide transport, means of absorbing recoil, and a pivot point for the aiming of the cannon. The dimensions of the wheel and inspiration for the configuration of the wheel were taken from historical references ${ }^{16}$. The design of the wheel was made to showcase the capabilities of rapid prototyping and rapid tooling technology. The cannon wheels are cast from A356 aluminum using simple coreless cope and drag green sand molds. The parts were then machined on a lathe for concentricity and ease of fitment on the axle.

The trail was drawn based on an estimation made from dimensions given in the same text as that used for the wheels. The trail acts as a third point of support for the cannon. It is used as a lever to move and aim the cannon during firing. The trail is used as a point of connection to the caisson for transport. Last the trail contains the elevation screw and acts as a support for the cheek pieces of the cannon. The trail, as shown in 


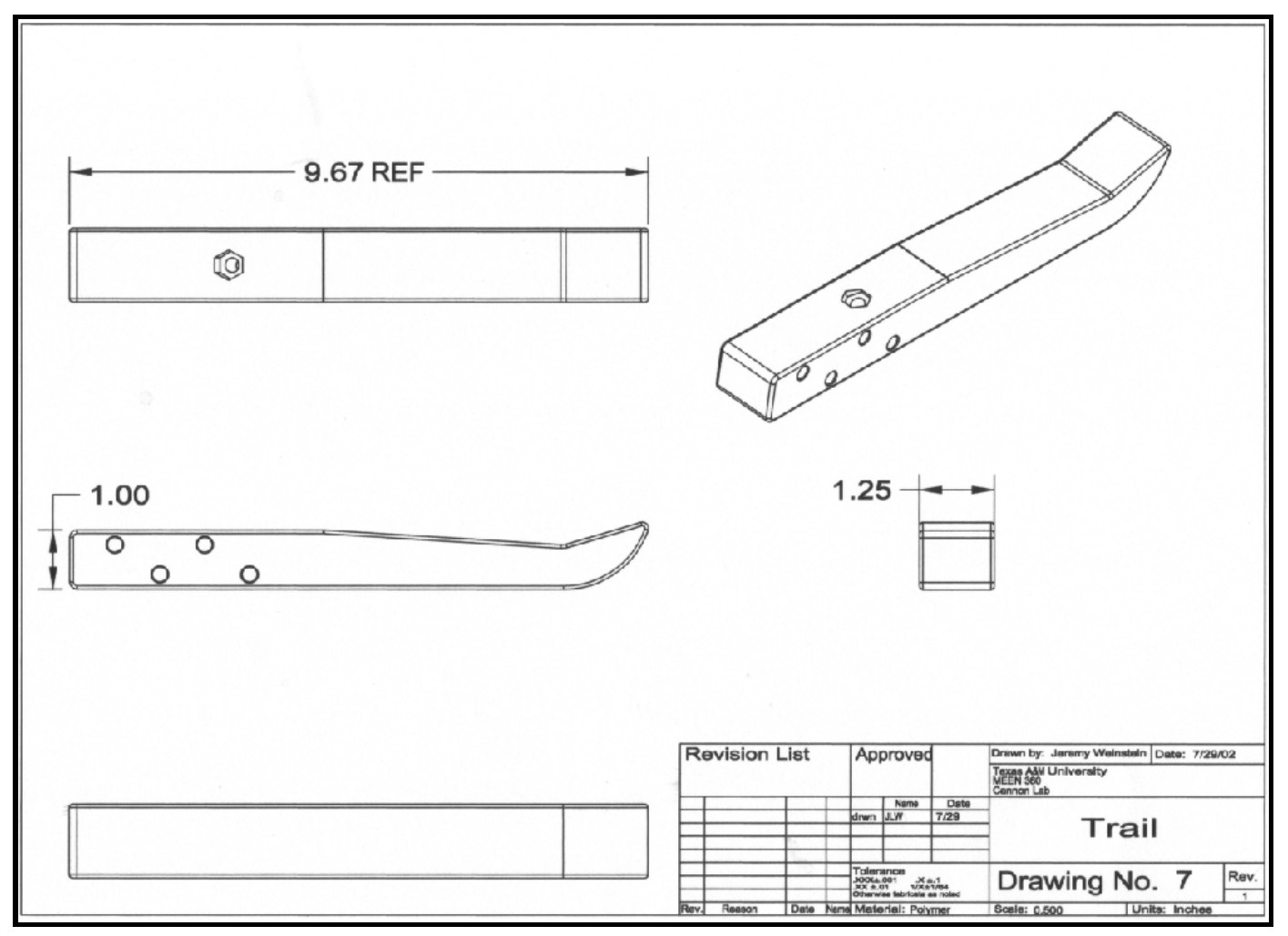

Figure 6. Drawing of the Trail Piece as Used in the Cannon Laboratory

Figure 6, lends itself to fabrication using $\mathrm{CNC}$ machining. The relatively complex geometry can be quickly generated using linear and circular interpolation performed by $\mathrm{CNC}$ machines. Because the trail supports little weight, and historically was fabricated of wood, PVC was used as the material for fabrication. An unusual layered configuration was employed to decrease material cost and minimize set up time during fabrication. All features can be cut using a 0.25 " end mill eliminating the need for tool changes thereby simplifying programming and setup.

The axle was made of brass. The dimensions and configuration were modified from the same drawings as those of the wheel. The axle as used in the laboratory is shown in Figure 7. The function of the axle was to act as a mounting point for the wheels 


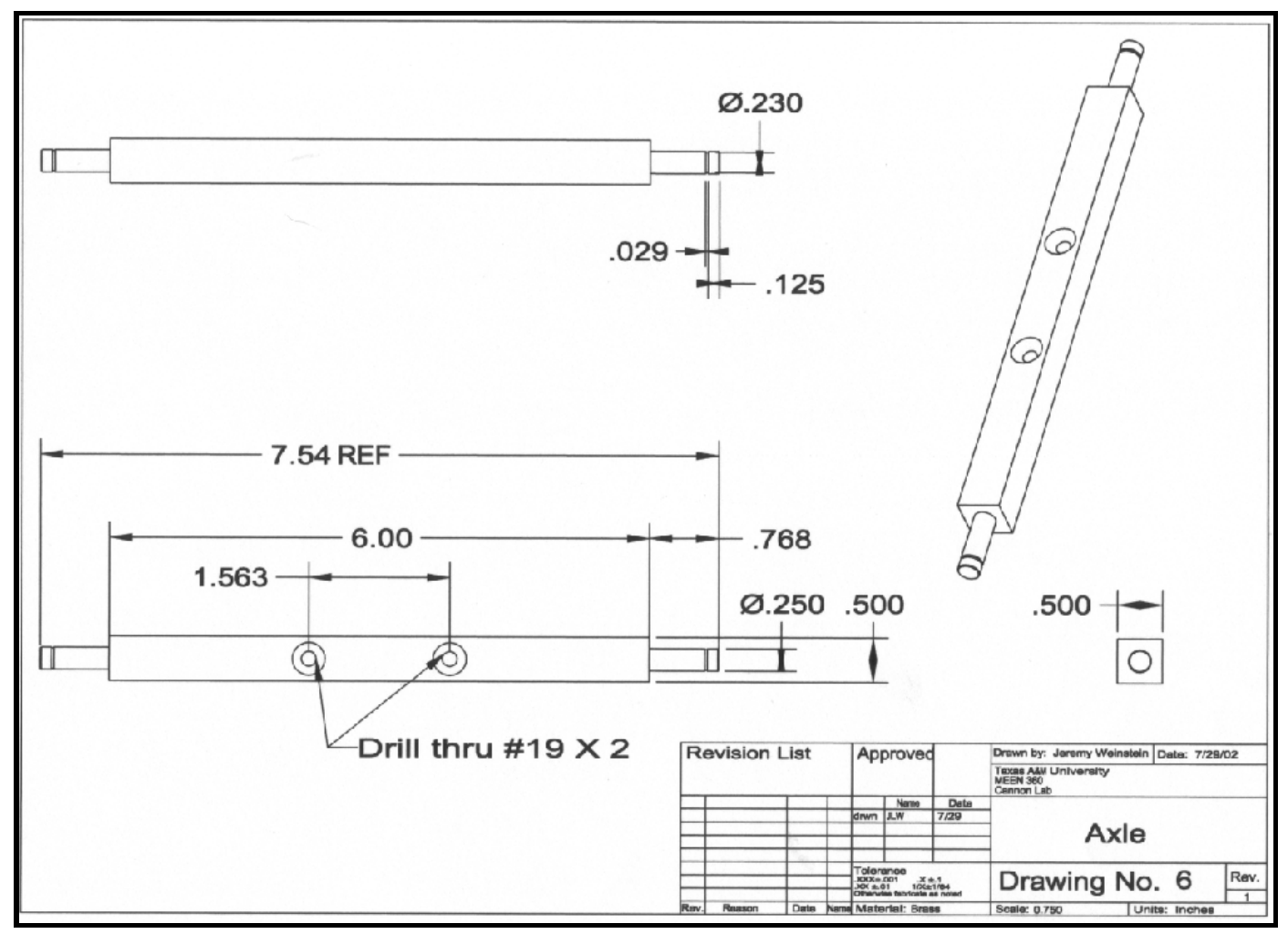

Figure 7. The Axle as Used in the Laboratory

and to connect the wheels to the frame of the cannon. The design was simplified to be quickly machined from 0.5 " bar stock using a lathe and a mill. Brass was selected for variety in materials used, attractive appearance, and the potential for incorporating strainhardening into the laboratory at a later date.

The cheek pieces were estimated and modified from the existing drawings of the cannon. The function of the cheek pieces is to secure the cannon to the carriage, provide a pivot for the elevation of the barrel, and to act as a mounting point for the axle. It can be seen in the Figures 8 and 9 that the design of the cheek pieces of the cannon differ 


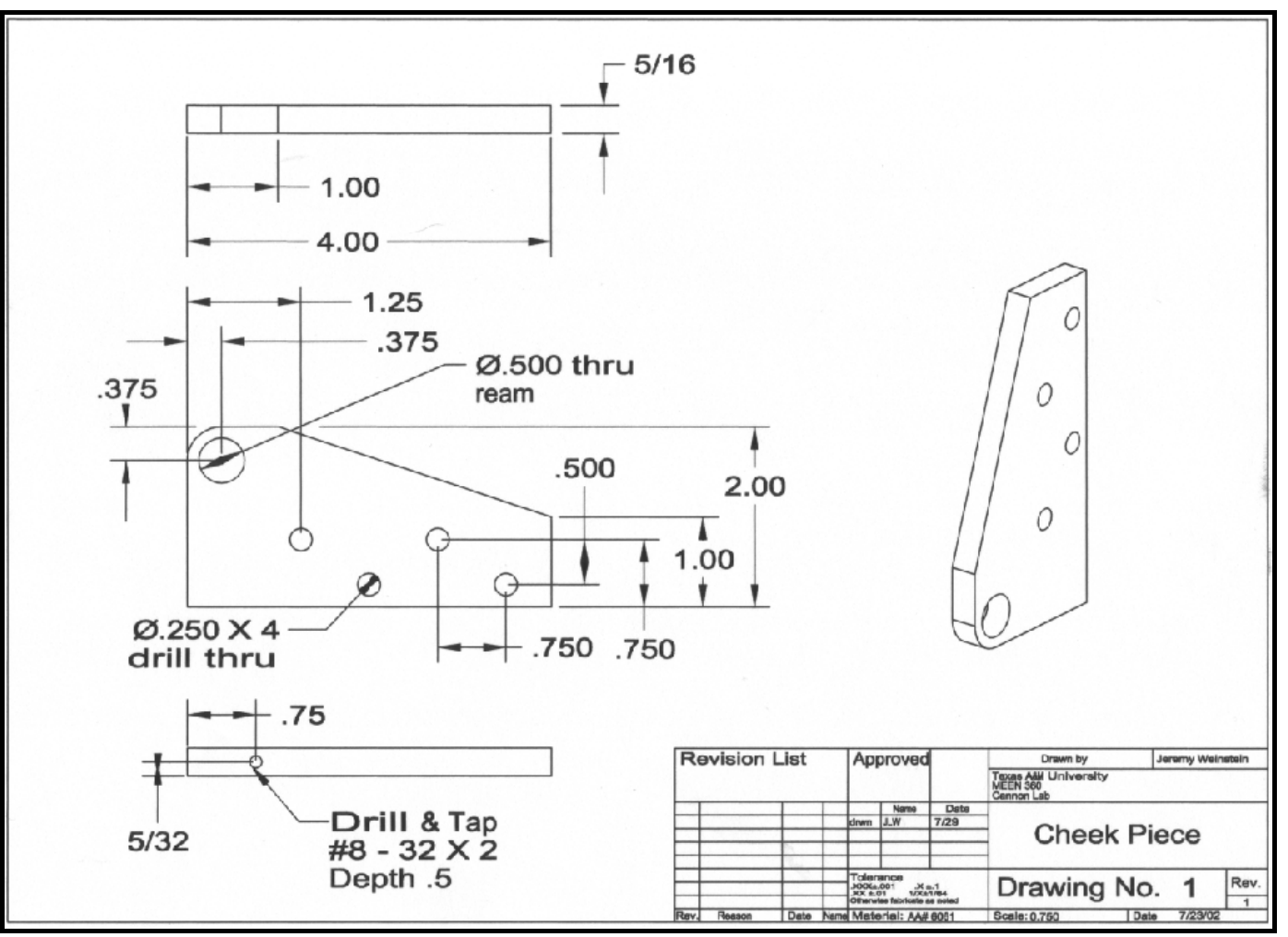

Figure 8. Drawing of the Cheek Pieces as Used in the Laboratory

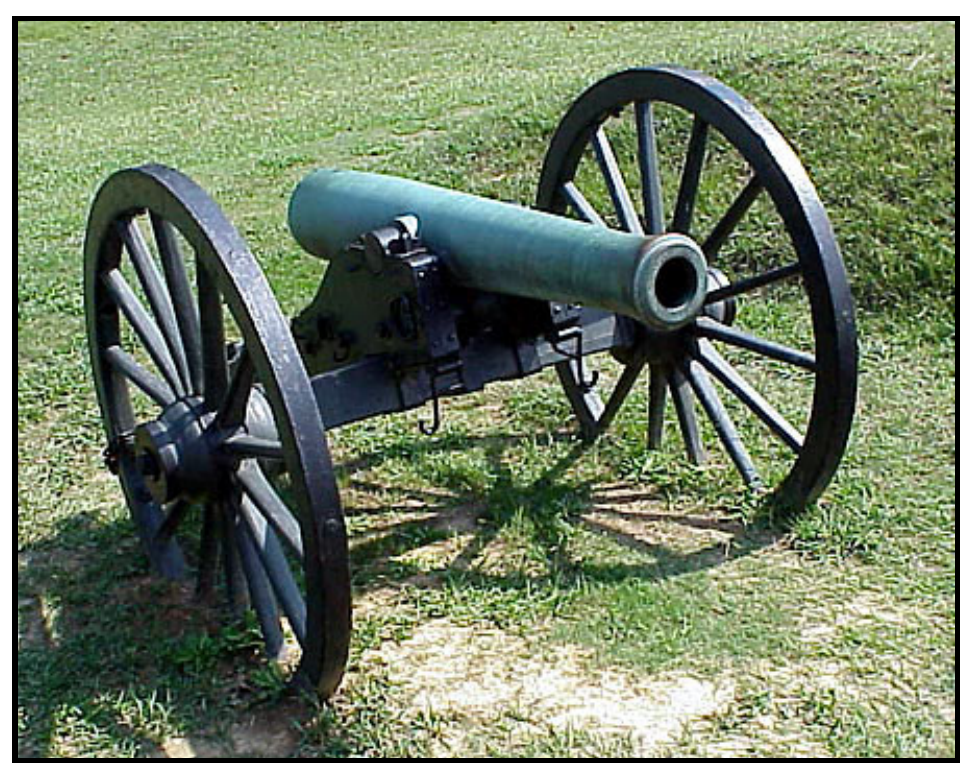

Figure 9. Example Cannon with Original Cheek Configuration

significantly from those of the original model. The project cannon must be much simpler to manufacture and assemble than the conventional model. This means the modification 
of assembly parts to suit this requirement while still satisfying the functional requirements of the original design. The new parts eliminate the need for a bolted strap arrangement to secure the cannon to the carriage. The through bolt design of the axle securing to the cheeks needs only two screws as opposed to four. The only tapped holes on the entire part are in the cheeks. Making the cheek pieces the exact same in appearance and measurement means that they can be machined at the same time using a special jig to speed the laboratory. The material chosen was AA\#6061-T6. The students are required to practice artificial aging of precipitation hardening aluminum alloys. This material has a direct and understandable relation with that in the laboratory. Additionally, the material is inexpensive and easy to machine.

\section{Laboratory Structure}

The MEEN 360 laboratory was synthesized from a combination of the existing MEEN 310 Manufacturing Laboratory and the MEEN 340 Structure and Properties of Materials laboratory. The 310 and the 340 laboratories were conceived with the goal of educating in one topic, either manufacturing systems or materials science, independent of the other subject. The intent of the manufacturing laboratory was to cover the following subjects through a combination of separate laboratory assignments.

- Metrology

- Manual Machining

- Joining

- CNC Machining

- Injection Molding

- Foundry

- Non-destructive Evaluation

The microstructure and materials laboratory covered the following information separate from the manufacturing laboratory.

- Tensile Testing of Metals

- Hardness Testing

- Fatigue Testing

- Three Point Bend Test 
- Impact Testing

- Tensile Testing of Polymers

- Cold Work and Annealing of Brass

- Metallography of Alloys

- Aging of Aluminum Alloys

- Heat Treatment of Steel

When these two laboratories were joined, accommodation was made to allow for the completion of as many subjects as possible from each prior laboratory course. This action resulted in the following structure.

- Metrology

- Injection Molding

- Tensile Test of Plastics

- Fatigue and Impact of Metals

- Welding

- Aging, Hardness, and Heat Treatment of Metals

- Metallography

- Casting

- Machining

- Cold Working and Annealing of Brass

- Rapid Prototyping

This new laboratory maintained the majority of the content of the previous two laboratories, but failed to show the interrelation of manufacturing and materials as they are treated in industry. The choice of a material cannot be made independently of the choice of the process by which the material is to be formed, joined, finished, and otherwise treated $^{18}$. There is an intrinsic relation between materials and manufacturing. This relation should be indicated within the structure of the laboratory. The cannon laboratory format does this by treating the object of the laboratory as the generation of a product composed of a variety of materials each processed by a different means.

The cannon was assembled from the barrel, trunions, cheek pieces, trail, axle and wheels described in the previous section. Each part is manufactured from a material that 
is utilized at some point in the materials testing process. Materials' testing supports the material selection process, and along with standard manufacturing values, indicates the means by which the part should be produced. The arrangement of assignments for the cannon laboratory closely follows this idea.

The cannon laboratory is arranged in the following order:

- Metrology

- Materials Testing

- Heat Treatment

- Injection Molding and Tensile Testing of Polymers

- Manual Machining

- CNC Machining

- Rapid Prototyping and Casting

- Joining

- Metallography

The arrangement of the laboratories was determined by the materials selection, materials treatment, and processing of the cannon. In an ordered manufacturing scheme certain processes must predate succeeding processes for a logical completion of the assembly $^{19}$. The arrangement of the laboratory demonstrated this concept and thereby demonstrated the relation of the assignments within a context of cannon manufacture.

The first laboratory performed by the students was the metrology laboratory. The metrology laboratory was designed to demonstrate the concepts of measurement, reverse engineering, drafting, the significance of tolerance in design, and variation of tolerance within a production group using the various parts of the cannon as measurement fixtures. The laboratory assignment is shown in Figure 10. The students were supplied with a part 
MEEN 360 Cannon Lab

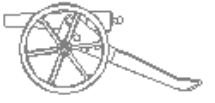

\section{Metrology and Tolerance}

Metrology is the science of measurement. Within the context of this lab we will be working in the area of dimensional measurements. Your group will be supplied with a cannon part. Make measurements of the part sufficient to generate a production drawing of the part. You will be graded according to the supplied drawing rules as well as your group's ability to measure the dimensions accurately. As with all production parts the necessary accuracy of the dimensions varies based on the function of the specified feature. Your grade will correspond to your ability to measure the part within the production tolerances. Accompanying your drawing should be a short letter explaining which features and dimensions require a narrow tolerance and why. Your letter should also explain why you feel the remaining tolerances are less important.

Additionally, your group will be supplied with 5 cannon balls. You must measure the diameter of the balls and you must specify the accuracy of your measuring device and submit calculations of the mean, sample standard deviation, and $95 \%$ confidence interval of the balls.

\section{References}

Kalpakjian, S., and Schmid, S., Manufacturing Processes for Engineering Materials, th $^{\text {th }}$ ed., Prentice Hall, 2002.

Oberg, Jones, Horton, Ryffel, Heald, Hussain, and McCauley, Machinerys Handbook, $26^{\text {th }}$ ed., Industrial Press, 2000.

\section{Figure 10. Arrangement of the Metrology and Tolerance Assignment}

of the cannon, 5 cannon balls, a dial caliper, and a micrometer. They were instructed that they had to make measurements of the given part and reproduce it as an orthographic drawing. Additionally they had to measure the five cannon balls and perform a statistical analysis of their diameters. The laboratory served to introduce the cannon to the students with an engineering focus. The students were required to decide which dimensions of the cannon part were important based on their function. This emphasized the importance of tolerance in engineering design by linking dimensions, with function, and part failure. The students were made to indicate their understanding of this concept in a brief business letter outlining their suppositions.

The second laboratory was the materials testing laboratory. The students used Charpy Impact testing, Tensile Tests, Rockwell Hardness Tests, and Fatigue Tests to 
evaluate the performance of two potential artillery materials, AISI 4140 and brass. The laboratory assignment is in shown in Figure 11. The students moved between four

MEEN 360 Cannon Tat

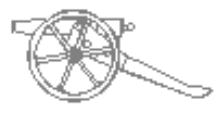

Fatigue, Impact, Tensile Test, and Hardness

Napolean style cannon were traditionally constructed of brass. This was primarily due to the limitations of casting technology at the time as well as material availability. The barrels of modern artillery are constructed of a chromi um-molybdenum alloy very similar to AISI 4140 . Using the following tests: tensile test, fatigue test, charpy impact, and rockwell hardness, you will characterize the physical properties of the two cannon materials. Each student will submit a material purchase specification sheet based on the example given in class. Be sure to designate the specific standard to be used in each material testing process.

\section{References}

Kalpakjian, S., and Schmid, S., Manufacturing Processes for Engineering Materials, $4^{\text {th }}$ ed. . Prentice Hall, 2002.

ASM Handbook, Vol. 8: Mechanical Testing, ASM International, 2000

\section{Figure 11. Details of the Materials Testing Laboratory}

stations. At each station they tested one of the materials and generated performance data. They then compiled this data for use among all the students. The information was then used to generate a material specification sheet. The material testing allowed the students to compare the performance of two materials both of which are considered reasonable for this application, it showed the variability in mechanical properties of materials, and it provided hands on experience in the performance of common industrial tests. The materials specification sheet gave the students an opportunity to perform common industrial tasks and to specify the standards required for testing that must be followed by a vendor who might provide construction materials.

Heat Treatment of metals was the third laboratory. The function of the laboratory was to teach the students potential property improvements that can be achieved through quenching and tempering of steels and precipitation hardening of aluminum. The 
experiment took two laboratory sessions. Initially the students determined the material processing procedures that were required to achieve the properties specified in the assignment shown in Figure 12. The students used available materials texts, ASM metals handbooks, ASTM testing procedures and available phase and TTT diagrams for the given metals. The following week the students performed the experiment. The aluminum was solution treated and aged with a number of samples being tested at different time intervals to determine peak aged and over aged conditions. The steel was austenitized, quenched, hardness tested, tempered, and hardness tested again to achieve an HRC of 35. The students reported on the performance of the experiments in a formal report detailing procedure, setup, results, and conclusions. Outside the goal of simply performing the laboratory and getting hands-on knowledge of materials treatment procedures, it was expected that students would see that certain material characteristics must be achieved prior to manufacture. Additionally, the students imposed order on the microstructure of the barrel through precise techniques. This microstructure could then be used to trace the life cycle of the cannon.

Injection molding and tensile testing was the next laboratory. This laboratory began the manufacturing portion of the laboratory. It would have been best if some part of the cannon assembly were injection molded. The trail piece could have been produced this way. The amount of load on the part is minimal. Unfortunately, the cost of producing a laboratory specific injection mold was prohibitory. Therefore, the best that could be accomplished was to display the performance characteristics of the plastic using a tensile test, and to demonstrate the production of tensile specimens using injection molding. In this laboratory, shown in Figure 13, the students were provided with a thermoplastic material. They had to then determine the correct processing characteristics. 
MEEN 360 Cannon Lab

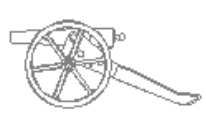

Aging, Hardness, and Heat treatment

The cheek pieces of the cannon will be composed of AA\#6061. The barrel will be machined from AISI 4140 . Both 4140 and 6061 can be significantly strengthened through various methods of heat treatment. 6061 as with many aluminum alloys can be strengthened through a process known as precipitation hardening or aging. 4140 can be significantly strengthened by quenching and tempering.

For 6061 you must demonstrate the methodology required to peak age and overage the material within one class period.

For 4140 you must quench and temper the material to obtain a hardness value of RC 35.

You will be required to submit a formal report of your experiments. The report must follow the requirements for a formal report given in class.

\section{References}

Kalpakjian, S., and Schmid, S., Manufacturing Processes for Engineering Materials, $4^{\text {th }}$ ed., Prentice Hall, 2002, p. $235-245$.

ASM Handbook, Vol. 4: Heat Treating, ASM International, 1991.

Callister, W. D., Materia/s Science and Engineering: An introduction, $5^{\text {th }}$ ed., John Wiley and Sons Inc., 1999.

Figure 12. Requirements for the Aging, Hardness, and Heat Treatment Laboratory 


\section{Injection Molding and Tensile Testing}

Injection Molding is a method of rapidly producing relatively small thin parts from thermoplastic materials. You will use the Boy $15 S$ injection molding machine to produce 5 tensile test specimens from a selected thermoplastic at three different machine speeds. You will then tensile test these specimens to determine their physical properties. Upon completion of the experiment you will generate a business letter, due next week, detailing the process as well as answering the following questions.

What equipment do you have available for injection molding and tensile testing of polymers?

What ASTM standards were followed in the two processes?

What methods of verification were used to inspect the parts and what visual flaws were detected?

What physical properties of the material can be determined in the tensile test?

What are the values of these properties?

How do the evaluated properties compare to published values?

What difficulties were encountered in the experiment and how could these be corrected?

Is Injection molding a viable process for manufacturing any parts of cannon assembly?

Could the polymer you tested be employed in the cannon assembly?

The business letter must follow the format given as a handout in class.

\section{References}

Kalpakjian, S., and Schmid, S., Manufacturing Processes for Engineering

Materials, $4^{\text {th }}$ ed. Prentice Hall, 2002, $568-575,591-605$.

Buckley, C. P., C. B. Bucknall, and N. G. Mccrum, Principies of Poiymer

Engineering, 2nd. Ed., Oxford, 1997.

\section{Figure 13. Requirements for the Injection Molding Tensile Test Laboratory}

They set up the injection molding machine and produced 15 plastic tensile test specimens. The specimens were divided into three groups of five. Each group had a 
slightly different screw speed. The students tested the specimens in a tensile test machine to determine the relative change in mechanical properties between batches.

The construction of the cannon began with the manual machining experiments. The assignment is given in Figure 14. The students used drawings of the barrel and

MEEN 360 Cannon Lab

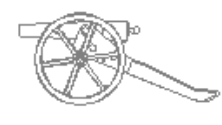

\section{Manual Machining}

Manual machining is the process of shaping a workpiece through material removal where machine operation is left in the hands of a person. The two most common powered machine tools in a shop are the lathe and mill. We will be using the lathe to shape and bore the barrel of the cannon and turn the trunions. We will be using the mill to create the cheek pieces as well as drilling the vent and the brazing reliefs for the trunions. At the end of the two experiments you will be required to submit a business letter detailing the machining processes used as well as answering the following questions.

What tools and work holding devices were required in addition to the lathe and mill to complete the cannon parts?

What methods and instruments were used to verify the quality of the finished cannon parts?

What is meant by the term "indicating the mill"?

The business letter should be submitted one week after the completion of the second machining lab.

\section{References}

Kalpakjian, S., and Schmid, S., Manufacturing Processes for Engineering Materials, $4^{\text {th }}$ ed., Prentice Hall, 2002, $455-481$.

Oberg, Jones, Horton, Ryffel, Heald, Hussain, and McCauley, Machinerys Handbook, 26 $6^{\text {th }}$ ed., Industrial Press, 2000.

\section{Figure 14. The Manual Machining Assignment}

cheek to manufacture the parts on manual machining equipment. The barrel started with the heat treated piece of AISI 4140 steel. The stock was placed in a lathe. The barrel was initially faced to length. Then a shoulder was cut on one end. The end opposite the shoulder was drilled to depth. The barrel was then suspended between the headstock and 
a live center. The barrel was cut to the correct diameter concentric to the bore. The barrel then received the taper characteristic of the Napoleon cannon by using the compound feed. Last, the cascable was shaped from the previously cut shoulder using a filleting tool and a file. The reliefs for the trunions and the touch hole were cut on a mill. The following laboratory, the cheek pieces were machined. Two pieces of 6061-T6 were stacked and secured to a jig. The jig was placed in a vice on a mill. The pieces were initially cut to length. The holes were then drilled. The jig was then replaced in the vice to cut the angle on the cheek pieces. Finally, the parts were removed and placed on another jig for drilling and tapping. The students recorded the details of the assignment and answered a short list of questions in a business letter. The laboratory taught the skills necessary to perform simple machining tasks while simultaneously providing information about the limitations and capabilities of the two most common powered machine tools. The students should have also gained a greater understanding of the meaning of tolerance in design and manufacturing. Ultimately, it was desired that this experience would allow the students to optimize their future designs to minimize the difficulty of manufacture.

The CNC Machining laboratory follows the manual machining laboratory. The assignment for the experiment is given in Figure 15. CNC machining differs from 


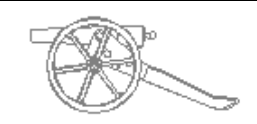

\section{CNC Machining}

CNC stands for Computer Numerical Control. When high precision, high production quantities and or complex geometries are required to be machined, CNC Machining will be selected over manually operated machines. CNC Machines are commonly programmed in a language called G-Code. G-Code is a simple command based programming language, which can be used to select machine speeds as well as direct tool movements within a simple Cartesian frame.

You have been given a drawing of the trail piece of the cannon assembly as well as a reference on the available G-Code functions. After instruction in the methodology behind programming $\mathrm{CNC}$ and use of the various functions, you must generate a program for the Haas $\mathrm{CNC}$ mill which will cut the completed trail from a piece of stock. Your program will then be verified for acceptability within Gibbs CAM (Computer Aided Manufacturing). Once the program is verified you will participate in the production of the trail piece for your cannon.

\section{References}

Kalpakjian, S., and Schmid, S., Manufacturing Processes for Engineering Materials, $4^{\text {th }}$ ed., Prentice Hall, 2002, $808-826$.

Oberg, Jones, Horton, Ryffel, Heald, Hussain, and McCauley, Machinerys Handbook, $26^{\text {th }}$ ed., Industrial Press, 2000.

\section{Figure 15. Requirements for the CNC Machining Laboratory}

manual machining primarily in that control of the machine tool is left to a computer program which moves the tools in a 3D coordinate space. After the students have operated the manual machines they may be better able to understand the operation and movement of the CNC machine. The part to be cut on the CNC mill was the cannon trail. The cannon trail was to be produced from PVC sheet. The construction was a laminate to minimize the tool changes required. The shape of the trail lent itself to production using a $\mathrm{CNC}$ machine. The students were expected to take the initial drawing and generate G-code required to cut the major shape of the trail. The students then inputted a drawing of the part into Gibbs CAM, were they saw the use of Computer Aided Manufacturing programs in generating machine code. Last the students saw the mill operate, cutting out the required parts. Students were graded by their completion of 
the programming assignment. The experiment was expected to show students the advantages and limitations of CNC machining over manual machining. It was hoped that with this experience the students would be better able to recognize the desirability of one machining process over another.

Wheels of the carriage were produced using a novel rapid manufacturing process $^{20}$. The assignment is given in Figure 16. Students were asked to draw either a medallion or a wheel design for the cannon carriage. The drawing was then reproduced in a Z-Corp ${ }^{\mathrm{TM}}$ rapid prototyping machine. The prototype part was then attached to a matchplate. This matchplate was then used in a cope and drag sand mold to produce an aluminum part. Cast parts were then machined for fitment to the cannon carriage. The process represented a unique opportunity for students to experience rapidly evolving technology. Prior to the advent of rapid prototyping, casting patterns took weeks or months to create and required trained craftsmen. This process bypassed many steps once involved in cast part production. It allowed the students to see the fabrication of a complex part from beginning to end in an educational environment. After completing the laboratory the students produced a laboratory report which detailed the specifics of the process. It was hoped that the students would not only learn about the potential of rapid prototyping and casting, but also the advantages offered by the combination of these processes to quickly produce a working part. 
Rapid Prototyping and Casting

Rapid Prototyping is a method of lamellar manufacturing which generates a product with less than optimum physical properties, but with dimensional accuracy that allows for processes such as inspection of fits, concept verification, and in some instances rapid tooling. We will use the Z400 powder-binder machine to generate tooling for a small medallion as well as the wheels of the cannon carriage. The medallion should be no more than 4 " $\times 4^{\prime \prime} \times 1 "$ ", and must be suitable for casting as a coreless pattern in a simple cope and drag mold utilizing green sand. Once the pattern is complete it will be attached to a simple matchplate and you will make casts of your part as well as the wheels of the cannon in the foundry.

A lab report detailing the process will be required the week after casting is completed. The report must include the following information.

Detailed account of the process required to manufacture the part as well as applicable ASTM standards for casting of Aluminum and Rapid Prototyping.

Results in the form of an evaluation of the finished cast and tooling process.

Conclusions as to the viability of the process with recommendations for the improvement of the process.

The report must follow the format given as a handout in class, it will be due the week following casting of the part.

\section{References}

Kalpakjian, S., and Schmid, S., Manufacturing Processes for Engineering Materials, $4^{\text {th }}$ ed. Prentice Hall, 2002. $218-235$.

Oberg, Jones, Horton, Ryffel, Heald, Hussain, and McCauley, Machinerys Handbook, 26 $6^{\text {th }}$ ed. Industrial Press, 2000.

\section{Figure 16. Rapid Prototyping and Casting Assignment}

Joining was the last step in production of the cannon. The trunions needed to be brazed into the reliefs on the side of the cannon. The joining laboratory centered around four processes: GMAW, SMAW, Oxy-Acetylene cutting, and brazing. The students experimented with each of the four stations. At the brazing station the students brazed 
the trunions onto the cannon. The students first experimented with brazing plugs onto a plate. The student who performed the best or had the most experience, then completed the assembly of the barrel. The students then submitted a business letter answering the questions given in Figure 17. The purpose of the laboratory was to give the students the experience of using welding equipment. Welding causes tremendous alterations in the microstructure of metals ${ }^{21}$. At the completion of the laboratory the students should have had a better understanding of how to limit these changes and in what situations welding is appropriate. They should have also understood the significance in selecting brazing as opposed to welding to join the trunions. The trunions have a different metallurgy from the barrel, 1040 as opposed to 4140 . The carbon content was such that the part could not be welded without preheating. Also, welding occurs at a much higher temperature than brazing and would have a deleterious effect on the temper of the barrel.

After the barrel had been brazed the cannon was assembled and tested. This is followed by the destruction of the barrel and the Metallography Laboratory, Figure 18. The Cannon was sectioned into pieces small enough to be potted in a Bakelite mold. Three pieces of the barrel were then selected. The selected parts were potted, polished, and etched. The etched surface was then viewed under a microscope. The students were expected to evaluate the microstructure of the part using textbooks, handbooks, and expert opinion. The students then reported on their findings in a presentation. The presentation related the expected state of the barrel given the previous heat treatment and compared this expected state with the microstructure found in examination. If the microstructure differed from that expected they had to explain the differences based on the lifecycle of the part as they participated in its creation, use, and destruction.

The construction of the new laboratory borrowed its topics from the previous three laboratories, but the focus was changed. Each laboratory contributed to the development and construction of the cannon. The final laboratory was an evaluation of the material processes used and the effects of manufacturing on microstructure. Pending an evaluation of the assessment tools implemented during the course of the semester it is expected that this revised format with project focus will create students with a better understanding of the interrelation of materials and manufacturing and the place of these concepts in design and production. 


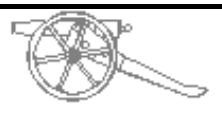

\section{Welding and Brazing}

Welding is the method by which workpieces are joined through melting and solidification often times additional material is added to act as a filler and reinforcement. Brazing is the method by which workpieces maybe joined by melting a filler metal below the melting temperature of the workpiece materials and allowing it to fill a void. You will be employing the processes of SMAW. GMAW, Brazing, and Oxy-Acetylene cutting to join and cut metals. During the lab you will braze the trunions into the body of the cannon. Upon completion of the lab you will write a business letter detailing the processes employed as well as answering the following questions.

What equipment do you have available?

What visual flaws might be apparent in a completed weld or braze?

Are there any professional organizations, which certify welds and welders?

What is HAZ?

What steps are commonly taken to limit its affects?

What is the reasoning behind choosing brazing as opposed to SMAW or GMAW to join the trunions?

What are the potential harmful effects of applying heat to the barrel during the joining process?

Select another manufacturing process and detail why it might be superior to brazing in this application?

The business letter will be due the week following the lab and it should follow the form provided in class.

\section{References}

Kalpakjian, S., and Schmid, S., Manufacturing Processes for Engineering Materials, $4^{\text {th }}$ ed. Prentice Hall, 2002, Sections 12.2, 12.12, 12.16

Oberg, Jones, Horton, Ryffel, Heald, Hussain, and McCauley, Machinerys Handbook, 26 $6^{\text {th }}$ ed. Industrial Press, 2000.

Figure 17. Requirements for the Welding and Brazing Assignment 
MEENT-360 Cannon Lab

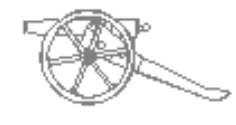

\section{Metallography}

Metallography is the science and methodology of examining the microstructure of a metal. The microstructure of a metal is the physical evidence tracing the processes that the sample has experienced. Metallography can be used in quality control, research, failure analysis and at any other time where a snapshot of the metal's microstructure may prove beneficial or informative. You have produced and tested a cannon. The history of the barrel from the time you received a billet of material is written in the microstructure. Select three sections of the cannon that interest you. Make samples of the selected sections, and examine their microstructure.

You quenched and tempered the steel to achieve a Rockwell Hardness of 35C. The hardness reflects changes in the microstructure from that of the untreated material. Use the knowledge you have gained from your materials courses, pertinent equations, and the available references to predict the microstructure at each stage of the heat-treating process.

Use your knowledge of the manufacturing processes and function of the barrel to explain the variation or similarity of the microstructure of the part to the predicted microstructure.

What other manufacturing processes might be suitable for the production of a cannon? How might the microstructure and properties of these other methods differ from those of the current cannon.

Make an oral presentation of your findings. The presentation should last no more than 30 minutes.

\section{References}

Kalpakjian, S., and Schmid, S., Manufacturing Processes for Engineering Materials, $4^{\text {th }}$ ed. Prentice Hall, 2002, p. $235-245$.

Callister, W. D., Materials Science and Engineering: An introduction, $5^{\text {th }}$ ed., John Wiley and Sons Inc., 1999.

Figure 18. Metallography Assignment for the Cannon Laboratory 


\title{
CHAPTER III
}

\begin{abstract}
ASSESSMENT TOOLS
The proposed function of the revised laboratory was to increase students' depth of learning in the field of manufacturing and materials with particular emphasis on the topic of design. The revised laboratory differs from the previous laboratory in the switch from unrelated assignments in the field of materials and manufacturing to a project configured to show the relation between these two subjects and their place in design. The new project was novel and interesting, but unwarranted change was neither essential nor advisable. The format change required justification. Justification comes from weighing the advantages and disadvantages of the new laboratory relative to the previous one. To make this calculation an experimental format was required to generate data which would distinguish between the effects of the new laboratory relative to the previous one. For this purpose, a quasi-experimental two by two factorial design was employed. . Data in this case came in the form of results obtained from assessment tools. It was proposed that evaluation of the success of this laboratory be based on student performance using five measurement tools. These five tools included three surveys of students' perceptions' and two open-ended, qualitative, essay measuring students' knowledge of course content, and scored by rubrics.
\end{abstract}

\section{Surveys}

The function of the surveys was to assess student opinion of the course as well as student opinion of their progress in the course. The surveys were given at three different points in the semester. The students were surveyed immediately after the introduction to the course. The students were again surveyed after four weeks. Last, the students were surveyed immediately after the laboratory final. As the students progressed within in the development of the laboratory data was taken to be later evaluated as a measurement of the success of the laboratory.

The first survey was given to the two cannon sections the first week of class and to one noncannon section in the third week of class. The survey had a number of goals:

- Establish the educational intent for the laboratory.

- Assess initial concerns about revised format. 
- Determine interest in the laboratory.

- Determine interest in the project.

- Establish a basis for future correlation.

- Obtain written responses that might point to unconsidered subjects.

The complete form of the survey is given in Appendix A. Every subject to be covered in the laboratory was also addressed in the survey. Each subject had a list of questions. The questions were determined based on the expected educational goals for each subject. The students ranked their level of comfort in each subject on a scale of 1 to 5 with 1 being very well prepared and 5 being very poorly prepared. The survey also had a section were the students were asked to rank there interest in the laboratory course and their interest in the cannon project. The same one to five scale was used with 1 being very interested and 5 being not interested. There were also a series of yes or no questions asking the students to speculate on the value of the course. The questions follow:

- Do you feel the project can be effectively integrated in the course format?

- Do you anticipate that the project will result in more effort on your part?

- Will it help you as an engineer to manufacture and test the cannon?

- Do you foresee potential problems with this new laboratory?

The students had an opportunity to answer these questions with a yes or no response. In the last portion of the survey, the students were asked to express their opinion of the new course in a written response.

Five weeks into the semester the students in the cannon section were given a second survey. At this point in the semester the students had completed experiments in metrology, materials testing, and heat treatment. The function of the survey was to determine the students' level of interest in the laboratory after having experienced half of the subject matter. The survey is given in Appendix C. Each of the three subjects was addressed through three similar questions. The first question was:

- Could you apply the techniques used in this laboratory to a potential engineering career? How?

- The intent of this question was to get the students to consider the broad spectrum application of the particular laboratory.

The second question was: 
- Could you see a benefit in having a project incorporated as part of this laboratory? Why?

- The students are expected to render their opinion of the value of the cannon project in aiding learning. The final question in each section was.

- Do you see a means of improving upon this laboratory? How?

This gives the students an opportunity to relate problems with the new format or the overall structure of the laboratory.

The third survey followed the same format as the first survey. This survey was given to the two cannon groups and the same noncannon group on the last day of laboratory class. The second survey had similar but separate goals to the first student survey:

- There was a need to assess the perceived advancement in laboratory subjects.

- This survey must also act as a tool for correlation.

- Assess the final opinion of the laboratory.

- Assess any change in project interest.

- Allow for free response regarding project success.

All the subjects covered during the course of the semester were presented on the survey. The students' sense of mastery in each subject was addressed by the same questions as presented in the initial survey. The content of the final survey can be seen in Appendix C. The students rated their level of understanding in each subject on the same 1 to 5 scale.

The final survey asked the same questions with regard to interest in the cannon project and interest in the laboratory itself. The yes or no questions differed in content from the earlier survey. The intent of these questions was to determine the students' final opinion of the new laboratory and its value.

- Do you feel the project was effectively integrated in the course format?

- Do you feel that the project resulted in more effort on your part?

- Will it help you as an engineer to have manufactured and tested the cannon?

- Do you feel the experience provided by this laboratory is of sufficient value that the format should be continued? 
The last question requested a written response covering the students' impression of the laboratory. This response can be compared to the previous written response to see if there has been a change of opinion and it can also act as a point of insight for future improvements in the laboratory.

\section{Essays}

The surveys generated a picture of students' opinion of their learning. To obtain an objective comparison of the students' learning in the project laboratory as opposed to the assignment based laboratory a written test was required. During the course of the semester two open-ended qualitative essays were given to assess the depth of student learning. The essays took place during the lecture portion of the class when all students enrolled in the MEEN 360 course were present. The quizzes took place during the midpoint of the semester and the end of the semester. The essays were graded using a rubric style key and verified by independent sources.

\section{First Essay Development}

The first essay took place at the mid point of the semester. The focus was on material that the students had previously covered in laboratory and in the lecture portion of the class. The intent of the quiz was to determine the ability with which the students were able to relate design criteria with material properties. The quiz began with a statement of the problem, Figure 19. The problem statement lists a number of functional

\footnotetext{
Problem Statement:

You have been given the task of selecting a material for a petrochemical pipeline that will be installed in Alaska. The pipeline will operate at temperature extremes of $-40^{\circ} \mathrm{F}$ to well above $212^{\circ} \mathrm{F}$. The pipeline will also be subject to pressures from atmospheric to 2000 psi. These pressures and temperatures will fluctuate throughout installation and operation.
}

\section{Figure 19. Problem Statement from the First Essay Assessment}

requirements for a pipeline in Alaska. The intent was establish a limited and accessible set of functional requirements, which all the students in the class could visualize and make decisions based upon.

The first question, Figure 20, required the students to list a number of mechanical 
1. Given the preceding information, list the different mechanical properties of materials that must be taken into account for such an application. Explain what each property you listed quantifies.

\section{Figure 20. First Question from the First Essay Assessment}

properties, which could be used to make a selection of specific materials or a group of materials to be used in the application. The question also requires the students define the properties listed. At this point in the semester all students had completed a review of the various mechanical properties of materials as well as having experienced a variety of test methods in the laboratory. The genesis of the question and its place in assessing students' ability to design can be found in common design methodologies. One of the first requirements after proposing a need statement is to determine the functions required of the design to meet this need. These functions are met by satisfying a variety of design criteria. Design criteria are often met through selection of a material that is capable of performing the needed functions $\mathrm{s}^{22}$.

The next question, Figure 21, asked the students to list the required tests needed

2. You have listed a number of mechanical properties of materials. List the corresponding test, which is used to determine each particular property.

\section{Figure 21. Second Question from the First Essay Assessment}

to generate the mechanical property information. Mechanical properties of materials even within a specification vary within a prescribed range ${ }^{23}$. In the course of specifying a particular material for use in a given application it is necessary to locate a vendor. This vendor must supply material that fulfills the design needs of the engineer. To guarantee the performance of the material a performance specification is issued to the vendor. The specification requires that the tests to be used to obtain property information be listed.

The third question, Figure 22, asked the students to select the two most important 
3. Given your list of properties select two properties, which you feel would be most important for material selection in this application and explain why you selected them.

\section{Figure 22. Third Question from the First Essay Assessment}

material properties for design in this application. Design is often attributed to design for failure prevention. Failure prevent can revolve around a comparison of performance requirements relative to material specification. This question sought to determine if students could delineate two obvious design parameters that might be used for material selection in this application.

The fourth question, Figure 23, requests that the students present a logical

4. How would you use these properties to determine the suitability of a particular material or class of materials?

\section{Figure 23. Fourth Question from the First Essay Assessment}

methodology of material selection. Over and above simply determining the required value of particular properties, students must be able to apply this information in a logical methodology to select the best material for a given application.

Materials can be broken into three classes: Polymers, Ceramics, and Metals. These materials each possess class specific characteristics ${ }^{24}$. Students should have knowledge of these characteristics and the ability to weigh them relative to one another to make the proper selection. Question 5 shown in Figure 24 attempted to determine the students' ability to perform in this capacity.

5. Materials are commonly broken into three groups: metals, polymers, and ceramics. Using your background in materials, select a particular group of materials to fulfill this application. Explain your reasoning by addressing how your particular class of material is superior in this application to the other two classes.

Figure 24. Fifth Question from the First Essay Assessment 
Knowledge of material properties and applications is ultimately worthless unless a resource is available to select from a list of materials. Question 6, Figure 25, required that the students relate a variety of resources that they have been presented with in class and in laboratory.

6. What sources of information would you address to finally select a specific material for this application?

\section{Figure 25. Sixth Question from the First Essay Assessment}

The first question made a distinction between mechanical properties and other material properties. The phrasing of the problem statement presents criteria that demanded a variety of material property types, but the focus of the laboratory is on test and analysis of mechanical properties. It is expected that the students should understand the difference. Design is also often dependent upon other properties ${ }^{25}$. This last question, Figure 26, allowed the students explore other design criteria and to present a design solution based on these additional criteria.

7. Are there any potential material properties that you feel are called for in this application, but were not clearly indicated by the problem statement? Why are these properties important?

Figure 26. Seventh Question from the First Essay Assessment 


\section{Second Essay Development}

The second open-ended qualitative essay was given at the end of the semester. The first essay only required students to show the ability to select the correct material for a given application. The second essay required performing the same activities as the first with the additional requirement that they select a variety of manufacturing techniques dependent on production volume.

The quiz was initiated with the following problem statement, Figure 27. It was expected that all the students would have familiarity with wheels in some form. Knowledge of the function of the object is important in development of the functional requirements. The functional requirements in turn demand certain material properties. These properties can then be used to select materials and manufacturing processes.

\footnotetext{
Background:

Automobile wheels have been built from a variety of materials through the years, but all wheels seem to serve the same functional requirements.
}

\section{Figure 27. Background Information for the Second Essay Assessment}

The students' were initially asked to define the functional requirements of a wheel as well as the related material properties, Figure 28. Functional needs determine

1. List what you believe are the functional requirements of an automotive wheel. For each function list the material property that applies

\section{Figure 28. First Question Second Essay Assessment}

design constraints which in turn determine design parameters. Design parameters are often a measure of material properties. The first step in the selection of a material is breaking down the performance capabilities of that material. This question requires that the students explore the behavior of a wheel in service and make design decisions, which will lead to the selection of the correct material. 
In the generation of a product one of the questions that must be answered is material selection. The students were provided with a list of materials, Table 1 that had been used for automotive wheels. Next they were given a series of related questions, Figure 29. They were asked to identify the most suitable material for use as a wheel.

\begin{tabular}{|c|c|c|c|c|c|c|c|c|c|}
\hline & & $\begin{array}{l}\text { Young's } \\
\text { Modulus }\end{array}$ & $\begin{array}{l}\text { Yied } \\
\text { Strength }\end{array}$ & $\begin{array}{l}\text { Ultimate } \\
\text { Strength }\end{array}$ & $\%$ Elongation & $\begin{array}{l}\text { Endurance } \\
\text { Limit }\end{array}$ & $\begin{array}{l}\text { Fracture } \\
\text { Toughness }\end{array}$ & Density & Price \\
\hline Material & & $10^{\wedge} 6 \mathrm{psi}$ & ksi & ksi & & ksi & ksi.in^1/2 & $\mathrm{lb} / \mathrm{in}^{\wedge} 3$ & USD/lb \\
\hline & & & & & & & & & \\
\hline 6061-T6 & Aluminum & 9.427 & 27.99 & 34.95 & 5 & 13.05 & 30.03 & 0.0965 & 0.4963 \\
\hline A356-T6 & Aluminum & 10.2 & 22.05 & 32.05 & 2 & 8.702 & 16.38 & 0.0965 & 0.8074 \\
\hline Hickory & wood & 0.2611 & 10.47 & 20.56 & 2.02 & 6.628 & 8.372 & 0.0332 & 1.324 \\
\hline Carbon fib & re and epoxy composite & 6.42 & 65.22 & 65.22 & 0.84 & 35.87 & 5.57 & 0.06 & 25.65 \\
\hline Cast Iron & & 12.76 & 26.83 & 40.61 & 3.00 & 18.85 & 32.76 & 0.27 & 0.30 \\
\hline ZC71A-T6 & Magnesium & 6.24 & 44.96 & 48.59 & 4.00 & 25.38 & 14.56 & 0.07 & 1.85 \\
\hline 1020 & Steel & 25.38 & 52.94 & 72.52 & 43.00 & 38.29 & 61.88 & 0.29 & 0.30 \\
\hline
\end{tabular}

\section{Table 1. List of Materials Available for Selection in Question 2}

2. The given list is representative of a number of materials that have been chosen for use as wheel materials through the preceding century. Select one material you might use for an automobile wheel. How does the material you chose meet the functional requirements of a wheel. Beyond just the listed functional requirements, what other properties make your selection superior. Explain the importance of these properties.

\section{Figure 29. Second Question Second Essay Assessment}

After identifying the material they were asked to relate how the selected material met the functional requirements. Last, materials even within the same functional, group may possess properties that may make them more suitable for a particular application. The students were asked to use their personal knowledge of materials to elaborate on this facet of material selection.

The students were asked to provide a negative example of proper materials selection, Figure 30. They were asked to select a material from the list that was not

3. Pick a material from the list and explain why it is not suitable for use as an automobile wheel.

Figure 30. Third Question Second Essay Assessment 
suited use as a wheel material. This required that the students establish an ordered methodology by which the materials would be judged relative to one another for selection.

Integrated within product development and design is the selection of the applicable manufacturing processes. Selection of the correct manufacturing process is heavily dependent upon production volume. Often times the process selected to produce one part will not be the same process required to produce one million parts ${ }^{19}$. Figure 31

4. I need to manufacturer eight wheels. What manufacturing process is suitable for this task? Explain your reasoning for choosing this process. Is your selected material suitable for this process? Explain why your material is suitable or why it is not.

\section{Figure 31. Fourth Question Second Essay Assessment}

shows question 4. Questions 5 and 6 were the same as questions 4 excepting the production quantity, 1000 units in question 5 and 1000000 units in question 6. Additionally the students were required to address the applicability of the process to the selected material. Materials are often suitable for only a few types of manufacturing processes. The students should have been able to exhibit this knowledge in response to the question.

The last question, Figure 32, requires the students to select an alternate material

7. Select an alternate material either from the list or from your experience and develop a situation where this alternate material might be more suitable than the material you selected in $\# 2$.

\section{Figure 32. Seventh Question Second Essay Assessment}

and develop a situation where this new material might be suitable. Although a wheel may perform the same function in all applications, other constraints may place limits on the materials that are applicable to the situation. The students were expected to 
understand this concept and to be able see the variability in material requirements based on application.

\section{Rubrics}

The open-ended qualitative essay is potentially a valuable tool for determining the students' level of knowledge of a subject, but the validity of the tool is determined by the repeatability of the scoring from grader to grader. Rubrics are tools used to establish an ordered grading format. A well formulated test with a well formulated rubric should generate consistent results from grader to grader. Each survey had a corresponding rubric formulated to act as a scoring tool.

\section{Rubric 1}

For each question an analytic rubric was generated. The full text of Rubric 1 is given in the Appendix E. The questions were broken down into a series parts based on their expressed goal. Each part had value of 1 to 4 . The rubric was configured such that the grader would read the question. Read the student response. Make a determination of student performance and mark it accordingly. The scores could then be tallied and analyzed to form a basis for determining relative student performance.

The analysis of the first question of the essay given at mid semester relied on comparing students' performance relative to accepted design sources. The question falls within the knowledge and comprehension function of Bloom's taxonomy ${ }^{26}$. The first question and succeeding analytic rubric is given in Figure 33. The accepted mechanical

\begin{tabular}{|c|c|c|c|c|c|}
\hline \multicolumn{6}{|c|}{$\begin{array}{l}\text { Question 1: } \\
\text { Given the preceding information, list the different mechanical properties of materials that } \\
\text { must be taken into account for such an application. Explain what each property you listed } \\
\text { quantifies. } \\
\text { Analysis: }\end{array}$} \\
\hline Criteria & $\begin{array}{c}\text { Beginning } \\
1 \\
\end{array}$ & $\begin{array}{c}\text { Developing } \\
2 \\
\end{array}$ & \begin{tabular}{|c|} 
Accomplished \\
3 \\
\end{tabular} & \begin{tabular}{|c|} 
Exemplary \\
4 \\
\end{tabular} & Score \\
\hline $\begin{array}{l}\text { List mechanical } \\
\text { properties that are } \\
\text { required in the design } \\
\text { of the pipeline. }\end{array}$ & $\begin{array}{l}\text { Important mechanical } \\
\text { properties are } \\
\text { neglected and the } \\
\text { majority of properties } \\
\text { listed occupy other } \\
\text { categories. }\end{array}$ & $\begin{array}{l}\text { At least one of: yield } \\
\text { strength and fracture } \\
\text { toughness must be } \\
\text { listed with additional } \\
\text { properties. }\end{array}$ & $\begin{array}{l}\text { At least four important } \\
\text { mechanical properties } \\
\text { should be listed with } \\
\text { two of: yield strength, } \\
\text { fracture toughness, or } \\
\text { fatigue strength. }\end{array}$ & $\begin{array}{l}\text { Five important mechanical } \\
\text { properties should be } \\
\text { listed:yield strength, fracture } \\
\text { toughness, ultimate tensile } \\
\text { strength, fatigue strength, } \\
\text { creep resistance, or DBTT. }\end{array}$ & \\
\hline $\begin{array}{l}\text { Explain what each } \\
\text { property you listed } \\
\text { quantifies. }\end{array}$ & $\begin{array}{l}\text { Properties are } \\
\text { incorrectly defined, or } \\
\text { undefined }\end{array}$ & $\begin{array}{l}\text { Properties are defined } \\
\text { poorly }\end{array}$ & $\begin{array}{l}\text { Properties are defined } \\
\text { correctly without } \\
\text { reference to proper } \\
\text { design criteria. }\end{array}$ & $\begin{array}{l}\text { Each property is defined } \\
\text { correctly with relation to proper } \\
\text { design criteria. }\end{array}$ & \\
\hline
\end{tabular}

Figure 33. Analytic Assessment Tool for Essay 1 Question 1 
properties available for reference are take from commonly accepted resources ${ }^{24}$. This list was then pared down to a list of fundamental mechanical properties based on the design question. A pipe operating at pressure can be assumed to be a pressure vessel. Pressure vessels are designed to meet safety requirements. Small pressure vessels are designed to yield before they fail and large pressure vessels are designed to crack and vent before they fail ${ }^{18}$. These two criteria indicate that yield and fracture toughness are two important mechanical properties. The vessel is also subjected to fluctuating temperature and pressure loads. This would indicate that fatigue strength is important ${ }^{27}$. Last, due to the extremes of temperature and pressure, DBTT, Ultimate Strength, and Creep Resistance maybe a factor ${ }^{24}$. This information was used to establish a measure by which to evaluate student performance on the question. If a student related a number of the properties including fracture toughness and yield strength as well as defining these properties from a design context, they received the highest marks. If the students failed to correctly identify the difference between mechanical and other properties and poorly defined the properties they received the lowest marks on this question.

The second question falls under the category of knowledge ${ }^{26}$. Students are scored according to there ability to match materials tests with the listed materials property, Figure 34. The primary concern was that the students knew specific test names and could apply them when required. Poor performance was indicated by a lack of listed tests or the incorrect tests.

\begin{tabular}{|c|c|c|c|c|c|}
\hline \multicolumn{6}{|c|}{$\begin{array}{l}\text { Question 2: } \\
\text { You have listed a number of mechanical properties of materials. List the } \\
\text { corresponding test, which is used to determine each particular property. } \\
\text { Analysis: }\end{array}$} \\
\hline Criteria & $\begin{array}{c}\text { Beginning } \\
1\end{array}$ & \begin{tabular}{|c|} 
Developing \\
2 \\
\end{tabular} & \begin{tabular}{|c|} 
Accomplished \\
3 \\
\end{tabular} & $\begin{array}{c}\text { Exemplary } \\
4\end{array}$ & Score \\
\hline $\begin{array}{l}\text { List the tests used to } \\
\text { determine the } \\
\text { mechanical } \\
\text { properties. }\end{array}$ & $\begin{array}{l}\text { Fails to correctly list } \\
\text { even common tests. }\end{array}$ & $\begin{array}{l}\text { Only a portion of the } \\
\text { tests are correctly } \\
\text { listed and named. }\end{array}$ & $\begin{array}{l}\text { All tests are listed but } \\
\text { some are named with } \\
\text { the incorrect } \\
\text { terminology. }\end{array}$ & $\begin{array}{l}\text { All tests are correctly named } \\
\text { and matched to the } \\
\text { corresponding properties, with } \\
\text { descriptions of the tests } \\
\text { outside of course content }\end{array}$ & \\
\hline
\end{tabular}

Figure 34. Analytic Assessment Tool for Essay 1 Question 2

The students were then asked to select the two most important properties, Figure 35. This falls under the heading of Application and Evaluation ${ }^{26}$. The students were 


\begin{tabular}{|c|c|c|c|c|c|}
\hline \multicolumn{6}{|c|}{$\begin{array}{l}\text { Question 3: } \\
\text { Given your list of properties select two properties, which you feel would be most } \\
\text { important for material selection in this application and explain why you selected them. } \\
\text { Analysis: }\end{array}$} \\
\hline Criteria & \begin{tabular}{|c|} 
Beginning \\
1 \\
\end{tabular} & \begin{tabular}{|c|} 
Developing \\
2 \\
\end{tabular} & \begin{tabular}{|c|} 
Accomplished \\
3 \\
\end{tabular} & $\begin{array}{c}\text { Exemplary } \\
4 \\
\end{array}$ & Score \\
\hline $\begin{array}{l}\text { Select two properties } \\
\text { which you feel would } \\
\text { be most important }\end{array}$ & $\begin{array}{l}\text { selected no } \\
\text { mechanical properties } \\
\text { which can be used for } \\
\text { failsafe design based } \\
\text { on the given criteria. }\end{array}$ & $\begin{array}{l}\text { Selected properties } \\
\text { which can be used for } \\
\text { failsafe design based } \\
\text { on the given criteria. }\end{array}$ & \begin{tabular}{|l|} 
Selected at least one \\
yield strength, fracture \\
toughness, or fatigue \\
strength and one \\
other, both of which \\
could be used for \\
failure analysis.
\end{tabular} & $\begin{array}{l}\text { Selected two of yield strength, } \\
\text { fracture toughness, and fatigue } \\
\text { strength }\end{array}$ & \\
\hline $\begin{array}{l}\text { Explain what each } \\
\text { property you listed } \\
\text { quantifies. }\end{array}$ & $\begin{array}{l}\text { Fails to relate selected } \\
\text { properties to design } \\
\text { methodologies. }\end{array}$ & $\begin{array}{l}\text { Outlines potentially } \\
\text { useful design } \\
\text { methodology, but not } \\
\text { the best. }\end{array}$ & $\begin{array}{l}\text { Uses a design criteria } \\
\text { comparison in at least } \\
\text { one case and some } \\
\text { other acceptable } \\
\text { explanation in the } \\
\text { second. }\end{array}$ & $\begin{array}{l}\text { Correctly outlines the } \\
\text { methodology by which the two } \\
\text { selected parameter could be } \\
\text { used for design based on } \\
\text { given criteria. }\end{array}$ & \\
\hline
\end{tabular}

Figure 35. Analytic Assessment Tool for Essay 1 Question 3

expected to determine the most important properties given the design situation. In this situation yield, fracture toughness, and fatigue would be the most important ${ }^{18,25}$. The students then had to exhibit the methodology by which these material properties could be used in design. It was determined that a suitable response would be based on a design for failure model. The students had to establish the criteria by which the listed properties could be applied to this model ${ }^{25}$. Deviation from this concept resulted in a lower score.

The students then had to use the previously selected properties as a basis for developing a suitable method of selection, Figure 36. This is an application of skills in

\begin{tabular}{|c|c|c|c|c|c|}
\hline \multicolumn{6}{|c|}{$\begin{array}{l}\text { Question 4: } \\
\text { How would you use these properties to determine the suitability of a particular } \\
\text { material or class of materials. } \\
\text { Analysis: }\end{array}$} \\
\hline Criteria & $\begin{array}{c}\text { Beginning } \\
1\end{array}$ & \begin{tabular}{|c|} 
Developing \\
2
\end{tabular} & $\begin{array}{c}\text { Accomplished } \\
3\end{array}$ & $\begin{array}{c}\text { Exemplary } \\
4\end{array}$ & Score \\
\hline $\begin{array}{l}\text { propose methodology } \\
\text { for selecting the } \\
\text { correct group of } \\
\text { materials given } \\
\text { previous properties. }\end{array}$ & $\begin{array}{l}\text { Fails to establish a } \\
\text { clear easy to follow } \\
\text { method by which the } \\
\text { properties of one set } \\
\text { of materials can be } \\
\text { weighed against the } \\
\text { next. }\end{array}$ & $\begin{array}{l}\text { Proposes limited and } \\
\text { poorly defined process } \\
\text { without methodology } \\
\text { of comparison to } \\
\text { determine selection. }\end{array}$ & $\begin{array}{l}\text { Proposes a logical } \\
\text { process of selection } \\
\text { without methodology } \\
\text { of comparison. }\end{array}$ & $\begin{array}{l}\text { Establishes a clearly defined, } \\
\text { functional, method of } \\
\text { comparison by which materials } \\
\text { maybe evaluated. }\end{array}$ & \\
\hline
\end{tabular}

Figure 36. Analytic Assessment Tool for Essay 1 Question 4

class. It was expected that the students could relate that a material or group of materials had to meet certain property minimums to be available for selection. Suitability would 
then be determined through comparison until the correct material is recognized ${ }^{18}$. Students with a less clearly stated process or a process that focused less on comparison received lower scores.

The students then had to judge the best group of materials from three groups of engineering materials. It was expected that the students would relate basic properties of the groups of materials, Figure 37 . Weigh the suitability of the material group to the

\begin{tabular}{|c|c|c|c|c|c|}
\hline \multicolumn{6}{|c|}{$\begin{array}{l}\text { Question 4: } \\
\text { How would you use these properties to determine the suitability of a particular } \\
\text { material or class of materials. } \\
\text { Analysis: }\end{array}$} \\
\hline Criteria & $\begin{array}{c}\text { Beginning } \\
1\end{array}$ & \begin{tabular}{|c|} 
Developing \\
2 \\
\end{tabular} & $\begin{array}{c}\text { Accomplished } \\
3 \\
\end{array}$ & \begin{tabular}{|c|} 
Exemplary \\
4 \\
\end{tabular} & Score \\
\hline $\begin{array}{l}\text { propose methodology } \\
\text { for selecting the } \\
\text { correct group of } \\
\text { materials given } \\
\text { previous properties. }\end{array}$ & $\begin{array}{l}\text { Fails to establish a } \\
\text { clear easy to follow } \\
\text { method by which the } \\
\text { properties of one set } \\
\text { of materials can be } \\
\text { weighed against the } \\
\text { next. }\end{array}$ & $\begin{array}{l}\text { Proposes limited and } \\
\text { poorly defined process } \\
\text { without methodology } \\
\text { of comparison to } \\
\text { determine selection. }\end{array}$ & $\begin{array}{l}\text { Proposes a logical } \\
\text { process of selection } \\
\text { without methodology } \\
\text { of comparison. }\end{array}$ & $\begin{array}{l}\text { Establishes a clearly defined, } \\
\text { functional, method of } \\
\text { comparison by which materials } \\
\text { maybe evaluated. }\end{array}$ & \\
\hline
\end{tabular}

\section{Figure 37. Analytic Assessment Tool for Essay 1 Question 5}

application and to the other material groups and make a selection ${ }^{24}$. Students who correctly related general property characteristics to the three groups and clearly evidenced a tactic for selection of the correct group were awarded the highest scores.

The students were then asked to show there knowledge of available material resources, Figure 38. The ability to apply the processes of material selection to the best

\begin{tabular}{|c|c|c|c|c|c|}
\hline \multicolumn{6}{|c|}{$\begin{array}{l}\text { Question 6: } \\
\text { What sources of information would you address to finally select a specific material for } \\
\text { this application. } \\
\text { Analysis: }\end{array}$} \\
\hline Criteria & \begin{tabular}{|c} 
Beginning \\
1 \\
\end{tabular} & \begin{tabular}{|c|} 
Developing \\
2 \\
\end{tabular} & $\begin{array}{c}\text { Accomplished } \\
3 \\
\end{array}$ & $\begin{array}{c}\text { Exemplary } \\
4 \\
\end{array}$ & Score \\
\hline $\begin{array}{l}\text { List available material } \\
\text { information sources. }\end{array}$ & $\begin{array}{l}\text { Fails to list any } \\
\text { sources. }\end{array}$ & $\begin{array}{l}\text { Lists only non- } \\
\text { professional non- } \\
\text { specific sources such } \\
\text { as textbooks and the } \\
\text { internet. }\end{array}$ & $\begin{array}{l}\text { Lists at least one } \\
\text { specific and or a } \\
\text { variety of non-specific } \\
\text { resources. }\end{array}$ & $\begin{array}{l}\text { Lists } 3 \text { specific: Standards } \\
\text { organizations, Software, } \\
\text { textbooks, internet, } \\
\text { experienced professionals, and } \\
\text { manufacturers. }\end{array}$ & \\
\hline
\end{tabular}

Figure 38. Analytic Assessment Tool for Essay 1 Question 6

of their capability is predicated on the availability of material information. Students were scored on their ability to list a variety of specific resources available to engineers. Many of these resources were addressed in class, some in the laboratory, and some in 
personal experiences of the students. Answers such as; an expert in the field, Cambridge Engineering Selector, ASM Handbooks, Vendors, etc.; were considered best. Answers that were more general in nature decreased the score. The poorest scorers were given to respondents with no answers.

The final question required the students to apply their knowledge of material properties beyond mechanical. Students were graded on their ability to relate specific properties of materials that could be used for material selection, Figure 39. The problem

\begin{tabular}{|c|c|c|c|c|c|}
\hline \multicolumn{6}{|c|}{$\begin{array}{l}\text { Question 7: } \\
\text { Are there any potential material properties that you feel are called for in this application, } \\
\text { but were not clearly indicated by the problem statement. Why are these properties important? } \\
\text { Analysis: }\end{array}$} \\
\hline Criteria & $\begin{array}{c}\text { Beginning } \\
1\end{array}$ & \begin{tabular}{|c|} 
Developing \\
2
\end{tabular} & \begin{tabular}{|c|} 
Accomplished \\
3
\end{tabular} & $\begin{array}{c}\text { Exemplary } \\
4\end{array}$ & Score \\
\hline \begin{tabular}{|l|} 
List important non- \\
mechanical properties \\
\\
\end{tabular} & $\begin{array}{l}\text { Lists no additional } \\
\text { properties or lists } \\
\text { properties that should } \\
\text { have been addressed } \\
\text { in the previous } \\
\text { sections. }\end{array}$ & $\begin{array}{l}\text { Lists a variety of } \\
\text { properties specific and } \\
\text { unspecific, but not } \\
\text { germane to the } \\
\text { question. }\end{array}$ & $\begin{array}{l}\text { Lists important but } \\
\text { non-specific properties } \\
\text { ex. Corrosion, Cost } \\
\text { etc. }\end{array}$ & $\begin{array}{l}\text { Lists a variety of specific } \\
\text { important non-mechanical } \\
\text { properties ex. Material Cost, } \\
\text { Atmospheric Corrosion } \\
\text { Resistance, Coefficient of } \\
\text { Thermal Expansion, etc. }\end{array}$ & \\
\hline $\begin{array}{l}\text { Importance of } \\
\text { properties? }\end{array}$ & $\begin{array}{l}\text { No explanation is } \\
\text { provided or the } \\
\text { explanation provided } \\
\text { is scientifically } \\
\text { implausible }\end{array}$ & $\begin{array}{l}\text { Provides poorly } \\
\text { defined analysis with } \\
\text { wrong or no design } \\
\text { criteria. }\end{array}$ & $\begin{array}{l}\text { Explains alternate } \\
\text { design methodology } \\
\text { without reference to } \\
\text { specific criteria. }\end{array}$ & $\begin{array}{l}\text { Clear explanation of the } \\
\text { importance of the property as } \\
\text { related to potential design } \\
\text { criteria }\end{array}$ & \\
\hline
\end{tabular}

Figure 39. Analytic Assessment Tool for Essay 1 Question 7

statement establishes an operating environment that requires attention to such properties as material cost, manufacturability, and environmental corrosion ${ }^{25}$. A good response would contain references to these properties and others. Poor response would list properties of a general nature, mechanical properties, or no properties at all. The question additionally requires the students to recount a means by which these new properties might be utilized in design. The process should be similar to that expected in question 3.

\section{Rubric 2}

The second rubric broadened the emphasis of the assessment tool from material selection to material selection and manufacturing. The quiz was given at the end of the semester in the week prior to the course final. The rubric was developed using principles of product development and design. 
The first question asked students to detail the functional requirements of an automotive wheel. The main function of a wheel is to transmit force from the engine and brakes to the tire and to transmit force from the tire to the suspension and chassis. Additionally there are a number of secondary roles including supporting the tire and cosmetic appearance in some instances ${ }^{28}$. Students were graded by there ability to recognize these functions, Figure 40. The best students would recognize the importance

\begin{tabular}{|c|c|c|c|c|c|}
\hline \multicolumn{6}{|c|}{$\begin{array}{l}\text { Question 1: } \\
\text { List what you believe are the functional requirements of an automotive wheel. } \\
\text { For each function list the material property that applies. }\end{array}$} \\
\hline Criteria & $\begin{array}{c}\text { Beginning } \\
1\end{array}$ & \begin{tabular}{|c} 
Developing \\
2 \\
\end{tabular} & $\begin{array}{c}\text { Accomplished } \\
3 \\
\end{array}$ & $\begin{array}{c}\text { Exemplary } \\
4 \\
\end{array}$ & Score \\
\hline $\begin{array}{l}\text { List what you believe } \\
\text { are the functional } \\
\text { requirements of an } \\
\text { automotive wheel. }\end{array}$ & $\begin{array}{l}\text { No functions or wrong } \\
\text { functions }\end{array}$ & \begin{tabular}{|l} 
Functional \\
requirements listed \\
are general and non- \\
specific in nature.
\end{tabular} & $\begin{array}{l}\text { Lists a number of specific } \\
\text { functional requirements } \\
\text { without one being: } \\
\text { transmit load. }\end{array}$ & $\begin{array}{l}\text { Lists a number of specific } \\
\text { functional requirements } \\
\text { one of which must be: } \\
\text { transmit load. }\end{array}$ & \\
\hline $\begin{array}{l}\text { For each function list } \\
\text { the material property } \\
\text { that applies. }\end{array}$ & $\begin{array}{l}\text { No properties listed or } \\
\text { the properties listed } \\
\text { are wrong. }\end{array}$ & $\begin{array}{l}\text { Poor matching and } \\
\text { naming of properties. }\end{array}$ & $\begin{array}{l}\text { Correct properties are } \\
\text { matched to each } \\
\text { function. }\end{array}$ & $\begin{array}{l}\text { Correct properties are } \\
\text { matched to each function, } \\
\text { preferable more than one. }\end{array}$ & \\
\hline
\end{tabular}

\section{Figure 40. Analytic Assessment Tool Question 1 Essay 2}

of load transmission as well as some ancillary functions. The poorest students would list no functions or the wrong functions. The question also required knowledge of important material properties for use in this instance. Students should have been able to provide multiple correct properties for each function.

The second question required the students to select a material, indicate the method by which it met the functional requirements, and state any additional special characteristics. The best students should have indicated a material and compared its properties as they met the functional needs of a wheel relative to the other materials listed, Figure 41. Additionally, all the properties listed in the provided table were 


\begin{tabular}{|c|c|c|c|c|c|}
\hline \multicolumn{6}{|c|}{$\begin{array}{l}\text { Question 2: } \\
\text { The given list is representative of a number of materials that have been chosen for use } \\
\text { as wheel materials through the preceding century. Select one material you might use for } \\
\text { an automobile wheel. How does the material you chose meet the functional requirements } \\
\text { of a wheel. Beyond just the listed functional requirements, what other properties make } \\
\text { your selection superior. Explain the importance of these properties. } \\
\text { Analysis: }\end{array}$} \\
\hline Criteria & \begin{tabular}{|c|} 
Beginning \\
1
\end{tabular} & \begin{tabular}{|c|} 
Developing \\
2 \\
\end{tabular} & \begin{tabular}{|c|} 
Accomplished \\
3 \\
\end{tabular} & $\begin{array}{c}\text { Exemplary } \\
4 \\
\end{array}$ & Score \\
\hline $\begin{array}{l}\text { Select one material } \\
\text { you might use for an } \\
\text { automobile wheel. }\end{array}$ & no material selected & & & material selected & \\
\hline $\begin{array}{l}\text { How does the } \\
\text { material you chose } \\
\text { meet the functional } \\
\text { requirements of a } \\
\text { wheel. }\end{array}$ & $\begin{array}{l}\text { None or incorrect } \\
\text { relation of properties } \\
\text { to functions. }\end{array}$ & $\begin{array}{l}\text { Poorly relates material } \\
\text { properties to } \\
\text { functional } \\
\text { requirements. }\end{array}$ & $\begin{array}{l}\text { Makes general reference } \\
\text { to satisfaction of } \\
\text { functions. }\end{array}$ & $\begin{array}{l}\text { Names specific properties } \\
\text { as related to listed } \\
\text { functions. }\end{array}$ & \\
\hline $\begin{array}{l}\text { Other properties that } \\
\text { make the selection } \\
\text { superior. }\end{array}$ & $\begin{array}{l}\text { No properties or the } \\
\text { properties referenced } \\
\text { are incorrect. }\end{array}$ & \begin{tabular}{|l|} 
Poor correlation \\
between selected \\
properties and \\
application. \\
\end{tabular} & $\begin{array}{l}\text { General reference to } \\
\text { properties. }\end{array}$ & $\begin{array}{l}\text { Names specific properties } \\
\text { of the material that make it } \\
\text { superior. }\end{array}$ & \\
\hline $\begin{array}{l}\text { Explain the } \\
\text { importance of these } \\
\text { properties. }\end{array}$ & $\begin{array}{l}\text { The importance of the } \\
\text { property is not } \\
\text { explained or the } \\
\text { explanation is wrong. }\end{array}$ & \begin{tabular}{|l|}
$\begin{array}{l}\text { Selected some } \\
\text { appropriate but not the } \\
\text { best methodology. }\end{array}$ \\
\end{tabular} & $\begin{array}{l}\text { Makes limited use of } \\
\text { proper design criteria. }\end{array}$ & $\begin{array}{l}\text { Explains the importance of } \\
\text { the property by relating it to } \\
\text { specific design criteria. }\end{array}$ & \\
\hline
\end{tabular}

\section{Figure 41. Analytic Assessment Tool Question 2 Essay 2}

mechanical excepting cost and density. This allows students to evidence their knowledge of additional material properties for these materials. The best performing students would have indicated additional information such as formability and corrosion resistance. The students then had to pick a material which was not suitable. The list provided contained materials, all of which had been used as automotive wheels in the past. The best answer should have related the selected material properties to the functional requirements listed in the answer to the first question, Figure 42. The students

\begin{tabular}{|c|c|c|c|c|c|}
\hline \multicolumn{6}{|c|}{$\begin{array}{l}\text { Question 3: } \\
\text { Pick a material from the list and explain why it is not suitable for use as an automotive wheel. } \\
\text { Analysis: }\end{array}$} \\
\hline Criteria & $\begin{array}{c}\text { Beginning } \\
1\end{array}$ & \begin{tabular}{|c} 
Developing \\
2
\end{tabular} & $\begin{array}{c}\text { Accomplished } \\
3\end{array}$ & $\begin{array}{c}\text { Exemplary } \\
4\end{array}$ & Score \\
\hline $\begin{array}{l}\text { Pick a material from } \\
\text { the list. }\end{array}$ & $\begin{array}{l}\text { No Material is } \\
\text { Selected. }\end{array}$ & & & Material Selected. & \\
\hline $\begin{array}{l}\text { Explain why it is not } \\
\text { suitable for use as an } \\
\text { automotive wheel }\end{array}$ & $\begin{array}{l}\text { No explanation is } \\
\text { made or the } \\
\text { explanation presented } \\
\text { is wrong. }\end{array}$ & $\begin{array}{l}\text { Makes general } \\
\text { commentary, without } \\
\text { comparison, and } \\
\text { displays poor } \\
\text { reasoning. }\end{array}$ & $\begin{array}{l}\text { Selection is good and } \\
\text { proper reasoning is } \\
\text { evident, but properties } \\
\text { are not related well to } \\
\text { proper design criteria. }\end{array}$ & $\begin{array}{l}\text { Names specific properties } \\
\text { related to functional needs } \\
\text { which display how the } \\
\text { material will not work. }\end{array}$ & \\
\hline
\end{tabular}

Figure 42. Analytic Assessment Tool Question 3 Essay 2 
should have also properly demonstrated an understanding of the utilization of properties in design. Poor answer improperly related the listed properties to design criteria or failed to list any means of applying the given material properties in design.

The next question began the manufacturing portion of the exam. The students selected materials suitable for use as an automotive wheel. Now they were asked to select a production method based on manufacturing volume. The students were first asked to select a process, Figure 43. Their response was graded on their ability to list a

\begin{tabular}{|c|c|c|c|c|c|}
\hline \multicolumn{6}{|c|}{$\begin{array}{l}\text { Question 4: } \\
\text { I need to manufacturer eight wheels. What manufacturing process is suitable for this task. } \\
\text { Explain your reasoning for choosing this process. Is your selected material suitable for this } \\
\text { process. Explain why your material is suitable or why it is not. } \\
\text { Analysis: }\end{array}$} \\
\hline Criteria & \begin{tabular}{|c|} 
Beginning \\
1
\end{tabular} & \begin{tabular}{|c|} 
Developing \\
2 \\
\end{tabular} & $\begin{array}{c}\text { Accomplished } \\
3\end{array}$ & $\begin{array}{c}\text { Exemplary } \\
4\end{array}$ & Score \\
\hline $\begin{array}{l}\text { What manufacturing } \\
\text { process is suitable for } \\
\text { this task? }\end{array}$ & $\begin{array}{l}\text { No process is selected } \\
\text { of the wrong process } \\
\text { is selected. }\end{array}$ & $\begin{array}{l}\text { Poorly describes the } \\
\text { applicable process. }\end{array}$ & $\begin{array}{l}\text { Names the process in } \\
\text { general terms ex. } \\
\text { Casting. }\end{array}$ & $\begin{array}{l}\text { Names the process in } \\
\text { specific terms ex. Sand } \\
\text { Casting. }\end{array}$ & \\
\hline $\begin{array}{l}\text { Explain your } \\
\text { reasoning for } \\
\text { choosing this process. }\end{array}$ & $\begin{array}{l}\text { The explanation is non } \\
\text { existent or blatantly } \\
\text { incorrect. }\end{array}$ & $\begin{array}{l}\text { The process } \\
\text { description is limited } \\
\text { and fails to completely } \\
\text { answer the question. }\end{array}$ & $\begin{array}{l}\text { Indicates general details } \\
\text { of the process which lend } \\
\text { itself to manufacture. }\end{array}$ & $\begin{array}{l}\text { Indicates specific details of } \\
\text { the process which lend } \\
\text { itself to manufacture. }\end{array}$ & \\
\hline $\begin{array}{l}\text { Is your selected } \\
\text { material suitable for } \\
\text { this process. }\end{array}$ & $\begin{array}{l}\text { incorrectly identifies } \\
\text { the suitability of the } \\
\text { selected material. }\end{array}$ & & & $\begin{array}{l}\text { correctly identifies the } \\
\text { suitability of the selected } \\
\text { material. }\end{array}$ & \\
\hline $\begin{array}{l}\text { Explain why your } \\
\text { material is suitable or } \\
\text { why it is not. }\end{array}$ & $\begin{array}{l}\text { no explanation given } \\
\text { or the explanation } \\
\text { given is wrong. }\end{array}$ & $\begin{array}{l}\text { limited and or poor } \\
\text { explanation. }\end{array}$ & $\begin{array}{l}\text { Makes suitable } \\
\text { explanation which lacks } \\
\text { detail. }\end{array}$ & $\begin{array}{l}\text { Indicates specific material } \\
\text { properties or } \\
\text { characteristics which } \\
\text { demonstrate suitability. }\end{array}$ & \\
\hline
\end{tabular}

Figure 43. Analytic Assessment Tool Questions 4, 5, 6 Essay 2

correct process using a specific name. One example is casting. There are many types of casting. The best student responses used specific terminology: sand casting, centrifugal casting, and investment casting. After naming the process students should have related the reasoning for their process selection by indicating details of the process which lend it to use for this application and production volume. The final part of the question required the students to tell if the previously selected material was suitable for use in the chosen manufacturing process. The purpose of this question was to determine if the students understood the suitability and inherent limitation of some materials when it comes to production. One example is casting of 6061 aluminum will typically have a poorer result than A356 due to the difference in silicon content. The students should then be able to substantiate their response by discussing the nature of the material. 
The last question asked the students to select an alternate material and develop a design situation for which this material would be more suitable. Wheels have basic functional requirement, but this list of functions is added to when specific applications are approached. A race car will typically need a lighter stronger wheel. A compact car expecting high production volume and a low price might require a steel wheel. Students were expected to indicate these additional functional needs, Figure 44, and relate how properties individual to the selected material would better satisfy this new application.

\begin{tabular}{|c|c|c|c|c|c|}
\hline \multicolumn{6}{|c|}{$\begin{array}{l}\text { Question 7: } \\
\text { Select an alternate material either from the list or from your experience and develop } \\
\text { a situation where this alternate material might be more suitable than the material you } \\
\text { selected in } \# 2 \text {. } \\
\text { Analysis: }\end{array}$} \\
\hline Criteria & $\begin{array}{c}\text { Beginning } \\
1\end{array}$ & \begin{tabular}{|c} 
Developing \\
2 \\
\end{tabular} & $\begin{array}{c}\text { Accomplished } \\
3\end{array}$ & $\begin{array}{c}\text { Exemplary } \\
4\end{array}$ & Score \\
\hline $\begin{array}{l}\text { Select an alternate } \\
\text { material either from } \\
\text { the list or from your } \\
\text { experience. }\end{array}$ & $\begin{array}{l}\text { No Material is } \\
\text { Selected. }\end{array}$ & & & Material Selected. & \\
\hline $\begin{array}{l}\text { Develop a situation } \\
\text { where this alternate } \\
\text { material might be } \\
\text { more suitable than the } \\
\text { material you selected } \\
\text { in \#2. }\end{array}$ & $\begin{array}{l}\text { Fails to indicate a } \\
\text { design situation or } \\
\text { incorrectly justifies the } \\
\text { use of the material. }\end{array}$ & $\begin{array}{l}\text { Establishes a special } \\
\text { design situation and } \\
\text { selects general } \\
\text { material properties } \\
\text { which indicate } \\
\text { suitability. }\end{array}$ & $\begin{array}{l}\text { Establishes a special } \\
\text { design situation, } \\
\text { develops separate } \\
\text { situation specific } \\
\text { functions, and selects } \\
\text { general material } \\
\text { properties which indicate } \\
\text { suitability. }\end{array}$ & $\begin{array}{l}\text { Establishes a special } \\
\text { design situation, develops } \\
\text { separate situation specific } \\
\text { functions, and selects } \\
\text { specific material properties } \\
\text { which indicate suitability. }\end{array}$ & \\
\hline
\end{tabular}

Figure 44. Analytic Assessment Tool Question 7 Essay 2 


\section{CHAPTER IV}

\section{RESULTS AND DISCUSSION}

\section{First Survey}

At the beginning of the semester during the first laboratory the students in Sections 502 and 504 were told that they would take part in a new laboratory format. The students were supplied with course material including schedule and grading structure. The students were then shown a video demonstrating the operation of the cannon. After the Initial introduction the students were supplied with a survey to record their opinion of the laboratory and their feelings on their current knowledge in the subjects to be covered during the semester. The full results of the survey can be seen in Appendix F. Table 2 lists the average results for the two groups participating in the Cannon laboratory format.

\begin{tabular}{|c|c|c|c|c|c|c|c|c|c|c|}
\hline & $\begin{array}{c}\text { metrology } \\
\text { and } \\
\text { tolerance }\end{array}$ & $\begin{array}{c}\text { materials } \\
\text { testing }\end{array}$ & $\begin{array}{c}\text { heat } \\
\text { treatment }\end{array}$ & $\begin{array}{c}\text { manual } \\
\text { machining }\end{array}$ & $\begin{array}{c}\text { cnc } \\
\text { machining }\end{array}$ & casting & welding & $\begin{array}{l}\text { injection } \\
\text { molding }\end{array}$ & $\begin{array}{c}\text { rapid } \\
\text { prototyping }\end{array}$ & metallography \\
\hline \multirow{7}{*}{ 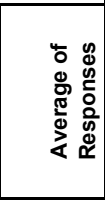 } & 3.31 & 3.31 & 3.31 & 3.59 & 4.21 & 3.61 & 2.97 & 3.97 & 3.93 & \begin{tabular}{|l|}
4.00 \\
\end{tabular} \\
\hline & 3.14 & 2.34 & 3.41 & 3.72 & 4.21 & 3.90 & 3.24 & 4.14 & 3.93 & 4.03 \\
\hline & 3.03 & 3.07 & 3.59 & 3.39 & 3.93 & 3.62 & 2.68 & 3.83 & 3.55 & 3.86 \\
\hline & 2.83 & 3.14 & 3.28 & 3.66 & 4.21 & 3.86 & 3.31 & 4.10 & 4.07 & 4.07 \\
\hline & 3.62 & & 3.55 & 3.48 & 4.10 & 3.72 & 3.07 & 4.03 & 3.62 & 3.93 \\
\hline & & & 3.70 & 3.62 & 4.24 & 3.83 & 3.31 & 4.17 & 3.90 & \\
\hline & & & & & & & & & 3.38 & \\
\hline Subject & & & & & & & & & & \\
\hline Average & 3.19 & 2.97 & 3.47 & 3.58 & 4.15 & 3.76 & 3.10 & 4.04 & 3.83 & 3.98 \\
\hline
\end{tabular}

Table 2. Average Results of Students from the Cannon Laboratory: Initial Survey

The columns under the listed subjects are the average responses to the questions given in the survey. The subject average represents the average of all responses for each subject. The scores range was from 1 to 5 with 1 being "very well prepared" and 5 being "very poorly prepared". Commiserate with the students lack of experience in the listed subject are scores which average from 3.00, indicating "prepared", to as low as low as 4.00 , indicating "poorly prepared". It is interesting to note that the students felt most comfortable with their knowledge of materials testing methodology. All the students in the MEEN 360 had previously participated in the ENGR 213 course where they were exposed to a variety of materials test methods. 
The students in the laboratory were also questioned as to their interest and enthusiasm in the project being incorporated in the laboratory. Table 3 gives a summary of the students' initial responses to their interest in the laboratory. In question 11 a score

\begin{tabular}{|c|c|c|c|c|c|c|c|}
\hline 11. The project & 1 & 2 & 3 & 4 & 5 & \multicolumn{2}{|c|}{5 \# of resp. avg. } \\
\hline a). Rate your overall interest in the lab course & 14 & 11 & 3 & 0 & 1 & 29 & 1.724138 \\
\hline b). Rate your interest in the cannon project & 24 & 2 & 1 & 0 & 1 & 28 & 1.285714 \\
\hline \multicolumn{3}{|l|}{ For the following questions answer yes or no } & yes & no & & & \\
\hline \multirow{2}{*}{\multicolumn{3}{|c|}{$\begin{array}{l}\text { 12. Do you feel the project can be effectively integrated in the course } \\
\text { 13. Do you anticipate that the project will result in more effort on your }\end{array}$}} & 28 & 1 & 1 & & \\
\hline & & & 21 & 7 & 7 & & \\
\hline \multicolumn{3}{|c|}{ 14. Will it help you as an engineer to manufacture and test the cannon? } & 28 & 0 & 0 & & \\
\hline
\end{tabular}

\section{Table 3. Initial Measure of the Students' Interest in the Project Laboratory}

of one indicates "very interested" and a score of 5 indicates "not very interested". The students appear to be somewhat split in their interest in the course with $51 \%$ indicating less than "very interested". This is in sharp contrast to the second question asking about their interest in the project. In part b. of question $11,85 \%$ of students responding to the question registered as "very interested". In the succeeding question the students were asked about their opinion regarding integration of the new project within the course, anticipation of effort, and potential benefit. The majority of students responded yes to each question.

The final part of the survey asked the students to respond freely with their opinions regarding the laboratory. The typed responses of the students can be viewed in appendix F. The overwhelming majority of the responses were positive nature with no truly dissenting remarks concerning the laboratory. Two excerpted comments follow:

- It's about time we had a laboratory like this. All previous laboratories have been in the format where each week is a new experience. Encompassing all the experiments of this course into one ultimate goal and larger experiment should be beneficial.

- The idea sounds very interesting. Not only will we learn a lot, but it should be very enjoyable. To have something to show for your work at the end of the semester will give us a feeling of accomplishment.

It was suggested in the early part of the semester that the students in as many laboratories as possible also participate in the survey. The students in section 506 participated in the survey as well. These students had already experienced three 
laboratories and therefore had in class experience in some of the subjects. Their responses are recorded in Table 4. It should be noted that that the scores are for the

\begin{tabular}{|c|c|c|c|c|c|c|c|c|c|c|}
\hline & $\begin{array}{c}\text { metrology } \\
\text { and } \\
\text { tolerance }\end{array}$ & $\begin{array}{c}\text { materials } \\
\text { testing }\end{array}$ & $\begin{array}{c}\text { heat } \\
\text { treatment }\end{array}$ & $\begin{array}{c}\text { manual } \\
\text { machining }\end{array}$ & $\begin{array}{c}\text { cnc } \\
\text { machining }\end{array}$ & casting & welding & $\begin{array}{l}\text { injection } \\
\text { molding }\end{array}$ & $\begin{array}{c}\text { rapid } \\
\text { prototyping }\end{array}$ & metallography \\
\hline \multirow{7}{*}{ 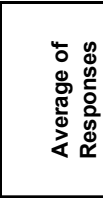 } & 3.73 & 2.40 & 2.53 & & 3.67 & 4.07 & 3.73 & 2.93 & 3.60 & $\begin{array}{r}4.27 \\
\end{array}$ \\
\hline & 2.87 & 2.00 & 2.47 & & 3.87 & 4.00 & 3.67 & 3.40 & 3.60 & 4.40 \\
\hline & 3.47 & 2.40 & 3.29 & & 3.40 & 3.67 & 3.47 & 3.07 & 3.67 & 4.33 \\
\hline & 2.93 & 2.40 & 3.33 & & 4.07 & 4.20 & 3.80 & 3.40 & 3.87 & 4.33 \\
\hline & 3.86 & & 3.07 & & 3.93 & 4.13 & 3.67 & 3.27 & 3.73 & 4.33 \\
\hline & & & 3.47 & & 4.07 & 4.27 & 3.80 & 3.27 & 3.80 & \\
\hline & & & & & & & & & 3.07 & \\
\hline Subject & & & & & & & & & & \\
\hline Average & 3.37 & 2.30 & 3.03 & & 3.83 & 4.06 & 3.69 & 3.22 & 3.62 & 4.33 \\
\hline
\end{tabular}

\section{Table 4. Initial Survey Results Non-Cannon Section}

most part still comparable in magnitude to scores in the previous section, despite the fact that some groups had completed laboratories in materials testing, injection molding, machining, and rapid prototyping. Students in the standard format were to have no training in Manual Machining. What should be of particular interest is that the students in this section had already performed a measurement and drawing laboratory yet their average scores are actually slightly lower than the experimental group. This survey did not contain the additional questions regarding the laboratory project, but there was a section where the students were allowed a free response regarding their feelings about the laboratory. Only two students responded and their responses were not to the comparison of the two labs.

\section{Second Survey}

The second survey was given just after the completion of the materials testing and processing experiments. The survey was only given to the experimental group. The survey followed a short answer format. Three similar questions were asked about each of the three subjects already covered in the semester. The purpose of the survey was to allow student to express their opinion about the current success of the laboratory and to allow the students the opportunity to express any desire for change in the performance of the laboratory. The student responses to the survey questions are given in Appendix F. The responses generally maintained the positive opinion expressed in the previous survey regarding the laboratory. Some students did not recognize the value of the course 
towards their career as engineers, but others did. Responses requesting change were directed towards the laboratory assignments and not the project itself. It is difficult to quantify written responses of this nature in a manner consistent enough to make conclusions regarding the success of a course, but reported student opinions can be used as a resource for meeting student needs if this course is continued.

\section{Final Survey}

The final survey was given to sections 502, 504, and 506 immediately following the laboratory final. The students took the same survey as that given at the beginning of the semester with slight modification to allow for completion of the course. Table 5 is the same format as Table 1 using the scores taken from the final survey for sections 502 and 504. It can be seen that the students felt they improved on average 1 to 2 points in

\begin{tabular}{|c|c|c|c|c|c|c|c|c|c|c|}
\hline & $\begin{array}{c}\text { metrology } \\
\text { and } \\
\text { tolerance }\end{array}$ & $\begin{array}{c}\text { materials } \\
\text { testing }\end{array}$ & $\begin{array}{c}\text { heat } \\
\text { treatment }\end{array}$ & $\begin{array}{c}\text { manual } \\
\text { machining }\end{array}$ & $\begin{array}{c}\text { cnc } \\
\text { machining }\end{array}$ & casting & welding & $\begin{array}{l}\text { injection } \\
\text { molding }\end{array}$ & $\begin{array}{c}\text { rapid } \\
\text { prototyping }\end{array}$ & metallography \\
\hline \multirow{7}{*}{ 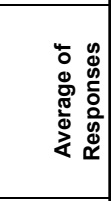 } & 1.87 & 1.63 & 1.83 & 1.93 & 2.33 & 1.66 & 1.86 & 2.24 & 1.83 & 1.63 \\
\hline & 1.90 & 1.50 & 1.83 & 1.93 & 2.03 & 1.70 & 1.93 & 2.31 & 1.87 & 2.17 \\
\hline & 1.83 & 1.60 & 1.93 & 1.47 & 1.87 & 1.63 & 1.80 & 2.07 & 1.53 & 2.00 \\
\hline & 2.07 & 1.80 & 2.40 & 2.23 & 2.40 & 1.90 & 2.13 & 2.28 & 2.13 & 2.00 \\
\hline & 2.13 & & 2.03 & 1.83 & 2.03 & 1.87 & 1.83 & 2.07 & 1.76 & 1.80 \\
\hline & & & 2.07 & 2.13 & 2.47 & 1.90 & 2.10 & 2.24 & 2.07 & \\
\hline & & & & & & & & & 1.53 & \\
\hline & & & & & & & & & & \\
\hline $\begin{array}{l}\text { Subject } \\
\text { Average }\end{array}$ & 1.96 & 1.63 & 2.01 & 1.92 & 2.19 & 1.78 & 1.94 & 2.20 & 1.83 & 1.92 \\
\hline
\end{tabular}

Table 5. Average Results of Students from the Cannon Laboratory: Final Survey

preparedness from "prepared and poorly prepared" to "well prepared" in all categories. The significance of this as a metric for evaluating the course is questionable. It simply shows that the students felt that they learned the course content. In this way it does serve as a testament to the students' confidence in the value of the course. The scores for the control group are given in Table 6. The difference between the average scores for the control group and the experimental group are negligible excepting the relatively higher score in metrology and tolerance. The questions were focused towards goals in the cannon laboratory. Many of the questions in metrology and tolerance were not addressed in the normal noncannon laboratory. 


\begin{tabular}{|c|c|c|c|c|c|c|c|c|c|c|}
\hline & $\begin{array}{c}\text { metrology } \\
\text { and } \\
\text { tolerance }\end{array}$ & $\begin{array}{c}\text { materials } \\
\text { testing }\end{array}$ & $\begin{array}{c}\text { heat } \\
\text { treatment }\end{array}$ & $\begin{array}{c}\text { manual } \\
\text { machining }\end{array}$ & $\begin{array}{c}\text { cnc } \\
\text { machining }\end{array}$ & casting & welding & $\begin{array}{l}\text { injection } \\
\text { molding }\end{array}$ & $\begin{array}{c}\text { rapid } \\
\text { prototyping }\end{array}$ & metallography \\
\hline \multirow{7}{*}{ 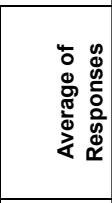 } & 2.53 & 1.65 & 2.18 & & 2.41 & 1.59 & 2.12 & 2.24 & 2.06 & 2.00 \\
\hline & 2.53 & 1.59 & 2.29 & & 2.35 & 1.76 & 2.18 & 2.41 & 2.18 & 2.29 \\
\hline & 2.35 & 1.88 & 2.41 & & 2.29 & 1.82 & 1.88 & 2.12 & 2.06 & 2.29 \\
\hline & 2.59 & 1.94 & 2.59 & & 3.00 & 2.06 & 2.35 & 2.59 & 2.53 & 2.35 \\
\hline & 2.94 & & 2.29 & & 2.47 & 1.94 & 1.88 & 2.24 & 2.06 & 2.18 \\
\hline & & & 2.47 & & 2.59 & 1.94 & 2.18 & 2.59 & 2.35 & \\
\hline & & & & & & & & & 1.88 & \\
\hline & & & & & & & & & & \\
\hline $\begin{array}{l}\text { Subject } \\
\text { Average }\end{array}$ & 2.59 & 1.76 & 2.37 & & 2.52 & 1.85 & 2.10 & 2.36 & 2.16 & 2.22 \\
\hline
\end{tabular}

Table 6. Average Results of Students from the Non-Cannon Laboratory: Final Survey

The next part of the survey for the cannon laboratory focused on their ending evaluation of the worth of the cannon project. Table 7 shows the students final opinion

\begin{tabular}{|c|c|c|c|c|c|c|}
\hline \multicolumn{5}{|c|}{ On a scale of 1 to 5 with $1=$ very interested and $5=$ not very interested } & \multirow{2}{*}{ \# of resp. } & \multirow[t]{2}{*}{ avg. } \\
\hline 11. The project & 1 & 2 & 3 & \begin{tabular}{l|l}
4 & 5 \\
\end{tabular} & & \\
\hline a). Rate your overall interest in the lab course & 14 & 11 & 4 & $0 \mid 0$ & 29 & 1.66 \\
\hline b). Rate your interest in the cannon project & 19 & 8 & 3 & \begin{tabular}{l|l}
0 & 0 \\
\end{tabular} & 30 & 1.47 \\
\hline For the following questions answer yes or no & & & yes & no & & \\
\hline $\begin{array}{l}\text { 12. Do you feel the project was effectively integrated in the } \\
\text { course format? }\end{array}$ & & & 29 & 1 & & \\
\hline $\begin{array}{l}\text { 13. Do you feel that the project resulted in more effort on } y \\
\text { part? }\end{array}$ & your & & 20 & 11 & & \\
\hline $\begin{array}{l}\text { 14. Will it help you as an engineer to have manufactured a } \\
\text { tested the cannon? }\end{array}$ & & & 28 & 2 & & \\
\hline $\begin{array}{l}\text { 15. Do you feel that the experience provided by this lab is } \\
\text { sufficient value that the format should be continued }\end{array}$ & & & 30 & 0 & & \\
\hline
\end{tabular}

\section{Table 7. Final Measure of the Students' Interest in the Project Laboratory}

of the revised format. Interest in the project and the laboratory overall seemed to remain consistent throughout the semester. Opinion as to the place of the project in the laboratory, question 12, effort involved, question 13, and professional benefit, question 14 , remained the same. What should be noted is that the students unanimously requested that the laboratory be continued.

The final portion of the survey that was included for all three sections 502, 504, and 506 was the open written response. The complete written results of this survey are contained in Appendix F. Student comments on the format of the laboratory in 502 and 504 were uniformly positive. Two excerpted comments are listed below: 
- I'm glad I was a part of it because I feel like we got to actually see how all these processes are applied and do something with them. Forming a product is of more value than just seeing every process done separately.

- This was the only laboratory where I feel like I have learned a lot. No one liked the fact we had to do an extra formal report. Also, I think we should make 2 cannon barrels, one to cut up and one to keep.

The comments made by students in the 506 section were also positive in nature. One student comment is listed below.

- The laboratory was very educational in a sense that there was a lot of hands on activity which helped my personal learning process (ability). Doing a lot experiments increased my awareness of the manufacturing of materials.

\section{Peer Review}

Alan Wolfenden supervised the development of the MEEN 360 course used prior to the testing of the project based cannon laboratory. His comments as an independent evaluator of the new laboratory are given below.

- Identify the focal point for all of the laboratory experiments. The experiments concerned with the production of the focal point should include: metrology, machine drawing, injection molding, cold working, annealing, tensile testing, fatigue testing, impact testing, rapid prototyping, ageing, heat treatment, metallography, casting, machining, and welding

- Staff should include people experienced with materials testing methods, metallography and the following manufacturing processes: machining, welding, rapid prototyping, injection molding, casting, and heat treatment.

- Arranging the logistics for 100 students to do 15 experiments safely is not easy.

- The construction of an engineering object follows a certain flow path. Therefore, in a semester with a focal point, the sequence of the various experiments is rigid. In contrast, for a semester without a focal point, there is a lot of flexibility in the sequence of the experiments. An example of the consequence of rigid scheduling this semester is the metallographic experiment for four teams of students (16 people) within one three-hour session. We can accommodate four students easily within our metallographic facility, but 16 students represent overcrowding. 
- Serious consideration needs to be given to the maintenance of the equipment used in the experiments. Sometimes we rely on one critical item of equipment to function properly for 100 students. An example of a problem area is the furnace for the casting experiment. The furnace in Thompson Hall is antique and we have no spare parts for it. We have alternative furnaces in the ENPH building. Of course, the furnace needs to be in the casting shop.

- There is a high level of enthusiasm among the students doing the Cannon Project. For most of the students, this Project represents their only practical opportunity to manufacture an item at TAMU.

The majority of Dr. Wolfenden's comments revolve around the difficulties involved with executing a hands-on laboratory at Texas A\&M University. Dr. Wolfenden also notes a specific difficulty of a project based laboratory. These laboratories have an inherent order that can only be manipulated in a limited fashion without disturbing the development and manufacturing process. Dr. Wolfenden's final comment is a direct evaluation of the laboratory. As an independent observer he recognized the students' enthusiasm for the laboratory and the singular opportunity the students had to generate a product.

\section{Essays}

The function of the essays was to assess student performance on core subjects related to the laboratory with the concept that this assessment would be based on common design problems. The first issue in validating student performance is to establish that the students functioning in the experimental group were comparable in background with the students in the control group. Students signed up for the laboratory sections without prior knowledge that there would be a variation in the course syllabus. Prior to analysis of the essay scores the key pre-treatment variables were examined for both groups to determine if they were normally distributed, and similarly distributed in both experimental and control groups Overall comparability of the groups was verified by comparing ethnicity, gender, verbal and total SAT, performance in a previous materials course, and CBK GPA. The first objective of the comparisons was to ascertain if experimental group students' demographic or pre-treatment preparedness alone could account for any differences which might have been observed following the treatment. 
The data for this comparison is given in Appendix G. The analysis of this data is shown in Table 8. The given table shows the distribution of mean scores is extremely similar excepting the variation in the Common Body of Knowledge (CBK) GPA. An evaluation of the significance of the scores employing the computer program Statistical Package for Social Sciences (SPSS) reveals that the background of the students varies with respect to their CBK GPA. The students in the cannon group had a significantly lower CBK GPA when compared to the students in control group.

\begin{tabular}{|c|c|c|c|c|c|}
\hline Category & Groups & Sample & Mean & Std. Dev. & Sig. \\
\hline \multirow{2}{*}{ Sat Verbal } & Exp. Grp. & 19 & 609.47 & 61.867 & \multirow{2}{*}{0.400} \\
\cline { 2 - 5 } & Control Grp. & 54 & 610.37 & 78.114 & \\
\hline \multirow{2}{*}{ Sat Total } & Exp. Grp. & 19 & 1238.95 & 96.718 & \multirow{2}{*}{0.138} \\
\cline { 2 - 5 } & Control Grp. & 54 & 1278.52 & 132.329 & \\
\hline \multirow{2}{*}{ CBK GPA } & Exp. Grp. & 23 & 3.01 & 0.300 & \multirow{2}{*}{0.000} \\
\cline { 2 - 5 } & Control Grp. & 54 & 3.22 & 0.532 & \\
\hline
\end{tabular}

Table 8. Statistical Analysis of Students' Background

The student essays were scored using a rubric. The validity of this instrument was verified through the use of multiple scorers. First all the grades from both essays were evaluated by one individual. During the initial scoring students names were covered and each document was assigned a number to serve as a tracking label. After the initial grading the group of documents was passed to a second evaluator Dr. Richard Griffin. Who selected a random sample of essays and scored them using the rubric. These scores were then compared to the previous scores and reported in Table 9. On whole the majority of scores differed by less than a point. The greatest difference can be noted on question 5 and question 7. Here the grades given by Dr. Griffin were significantly but consistently lower than that of the previous scorer. 


\begin{tabular}{|c|c|c|c|c|c|c|c|}
\hline & \multicolumn{7}{|c|}{ Difference } \\
\cline { 2 - 8 } & Questions & & & & & \\
\hline & & & & & & & \\
student & $\mathbf{1}$ & $\mathbf{2}$ & $\mathbf{3}$ & $\mathbf{4}^{*}$ & $\mathbf{5}$ & $\mathbf{6}$ & $\mathbf{7}$ \\
\hline $\mathbf{1}$ & -1 & 0 & 0.5 & 0 & -1.5 & -1 & 0 \\
\hline $\mathbf{2}$ & -0.5 & -2 & -0.5 & -1 & -1 & & -1 \\
\hline $\mathbf{3}$ & -0.5 & 0 & & 0 & -1 & 0 & -1.5 \\
\hline $\mathbf{4}$ & & -1 & 1 & -1 & -1 & 0 & 0.5 \\
\hline $\mathbf{5}$ & & -1 & 0 & 1 & -0.5 & 0 & 1 \\
\hline $\mathbf{6}$ & & 0 & 0.5 & -1 & 0 & -2 & -1 \\
\hline $\mathbf{7}$ & 1 & 0 & 0.5 & 0 & -2 & -1 & -0.5 \\
\hline $\mathbf{8}$ & -0.5 & 1 & 1 & 0 & -0.5 & 0 & -0.5 \\
\hline $\mathbf{9}$ & & 0 & 0.5 & -1 & 0 & 0 & -1 \\
\hline $\mathbf{1 0}$ & 2 & 0 & 0 & 1 & -1.5 & & 1 \\
\hline $\mathbf{1 1}$ & & -1 & -0.5 & 0 & -1.5 & & -1 \\
\hline $\mathbf{1 2}$ & & 0 & -1.5 & -2 & 0 & -1 & 0.5 \\
\hline $\mathbf{1 3}$ & & -1 & 0.5 & 0 & -1.5 & 0 & 1.5 \\
\hline $\mathbf{1 4}$ & & -1 & 1 & 0 & 0 & 0 & \\
\hline $\mathbf{1 5}$ & -0.5 & 1 & 1 & -1 & -2 & & -1 \\
\hline $\mathbf{1 6}$ & -0.5 & -1 & 1.5 & -1 & 0.5 & 0 & 0 \\
\hline $\mathbf{1 7}$ & 1.5 & 0 & 1 & -1 & -0.5 & 1 & -1 \\
\hline $\mathbf{1 8}$ & & 1 & 2 & -1 & -1.5 & 0 & 0.5 \\
\hline $\mathbf{1 9}$ & -0.5 & -1 & 1 & 0 & -1 & & -2 \\
\hline $\mathbf{2 0}$ & 0 & 1 & -1.5 & -1 & -1 & 0 & 0 \\
\hline
\end{tabular}

Table 9. Analysis of Score Reliability

After the scores had been verified they could then be compared in an SPSS, T-test for any significant differences in performances between the two groups. Table 10 shows

\begin{tabular}{|c|c|c|c|c|c|}
\hline Category & Groups & Sample & Mean & Std. Dev. & Sig. \\
\hline \multirow{2}{*}{ Lab Final } & Exp. Grp. & 27 & 62.06 & 14.630 & \multirow{2}{*}{0.256} \\
\cline { 2 - 5 } & Control Grp. & 64 & 63.78 & 12.600 & \\
\hline \multirow{2}{*}{ Course Final } & Exp. Grp. & 28 & 70.72 & 8.016 & \multirow{2}{*}{0.686} \\
\cline { 2 - 6 } & Control Grp. & 68 & 72.10 & 7.967 & \\
\hline \multirow{2}{*}{ Final Grade } & Exp. Grp. & 28 & 76.69 & 6.047 & \multirow{2}{*}{0.550} \\
\cline { 2 - 6 } & Control Grp. & 68 & 78.33 & 5.807 & \\
\hline \multirow{2}{*}{ Func. ID S1 } & Exp. Grp. & 27 & 11.44 & 1.683 & \multirow{2}{*}{0.053} \\
\cline { 2 - 5 } & Control Grp. & 64 & 10.52 & 2.281 & \\
\hline \multirow{2}{*}{ Mat. ID S1 } & Exp. Grp. & 27 & 9.30 & 2.158 & \multirow{2}{*}{0.591} \\
\cline { 2 - 5 } & Control Grp. & 64 & 8.73 & 2.037 & \\
\hline \multirow{2}{*}{ Func. ID S2 } & Exp. Grp. & 27 & 5.11 & 1.188 & \multirow{2}{*}{0.521} \\
\cline { 2 - 5 } & Control Grp. & 57 & 4.75 & 1.327 & \\
\hline \multirow{2}{*}{ Mat. ID S2 } & Exp. Grp. & 28 & 9.76 & 0.821 & \multirow{2}{*}{0.185} \\
\cline { 2 - 5 } & Control Grp. & 58 & 9.68 & 1.066 & \\
\hline \multirow{2}{*}{ Man. Sel. S2 } & Exp. Grp. & 28 & 8.37 & 1.663 & \multirow{2}{*}{0.966} \\
\cline { 2 - 5 } & Control Grp. & 58 & 8.00 & 1.655 & \\
\hline
\end{tabular}

Table 10. Evaluation of the Significance of Differences in the Course Metrics 
an analysis of the scoring data for the students who took the mid-semester essay. Many of the questions for the mid-semester and end of semester survey had more than one part. Each of these parts was averaged together to produce a single score for each question. These questions were then put into categories. These categories were material selection, functional identification, and manufacturing process selection. The scores of the questions applying to these separate categories were each summed and given a variable name. Taking the opportunity afforded by the use of SPSS, the scores for both the laboratory final exam, course final exam, and the overall course grade were also analyzed. The scores were then analyzed in SPSS. It was found that there was no statistically significant difference in the performance of the two tested groups on any of the metrics used during the semester. This suggests, given the difference in the CBK GPA of the two groups, that the students in the experimental group performed at a higher level than expected. 


\section{CHAPTER V}

\section{CONCLUSIONS AND RECOMMENDATIONS}

The stated objective of the study was to provide a stimulating project to the MEEN 360 Materials and Manufacturing Laboratory, which would in turn foster depth of learning in the form of a superior understanding of design. Throughout the semester the students performed materials processing methods and manufactured the parts required for the production of the cannon. Each section was broken into four groups. Each group produced a cannon. The final eight cannons are shown in Figure 45. The fact that this is

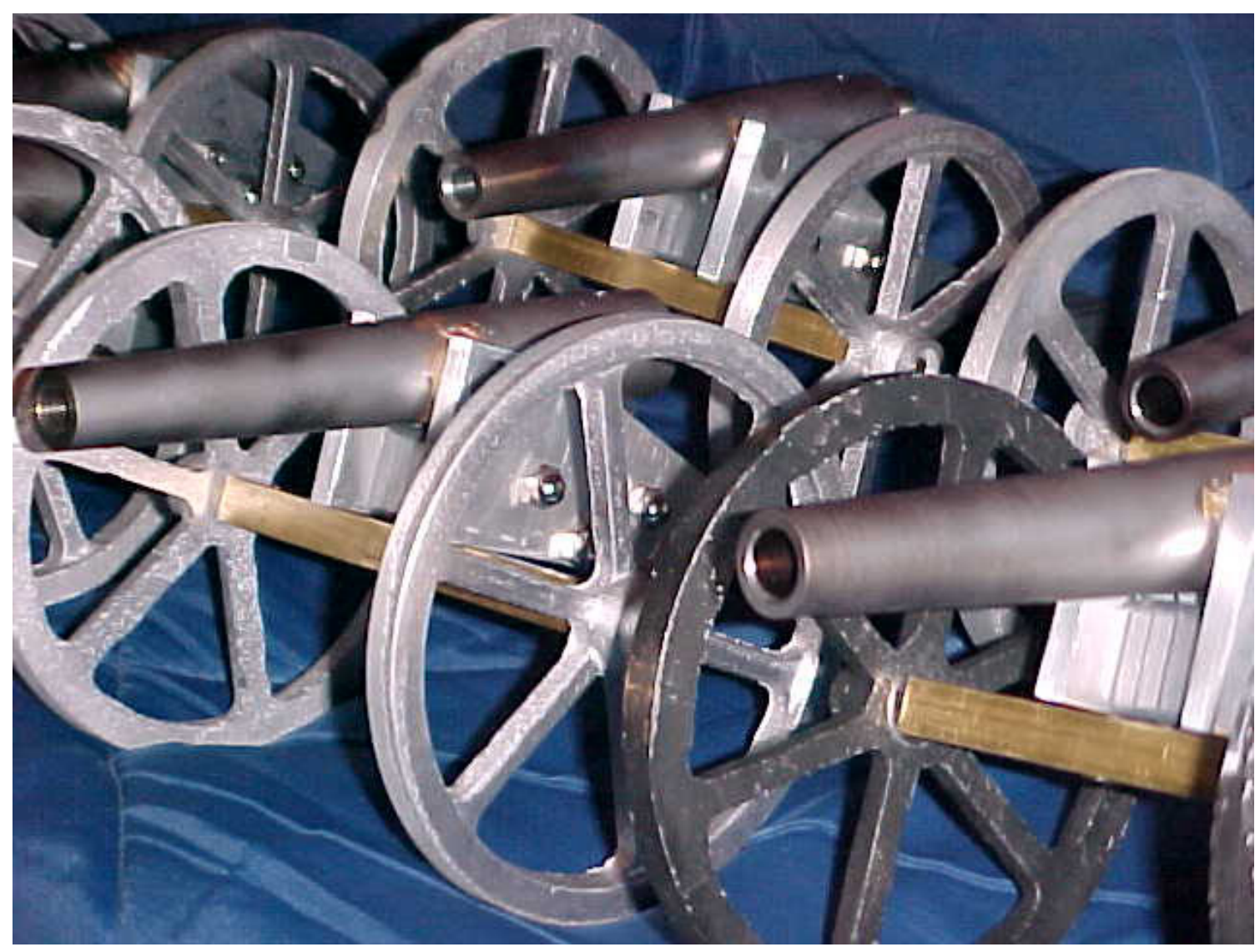

Figure 45. Students' Completed Cannon Assemblies

the only course in the mechanical engineering curriculum where students actually manufacture a product should in part make this course a success. ABET criteria requires that mechanical engineering graduates have the ability to demonstrate proficiency in the 
area of design and realization of mechanical systems ${ }^{4}$. If this is the only point in the majority of the students' career that they have an opportunity to realize an actual mechanical system then the completion of the project can be considered a positive outcome.

The students responded favorably to the course in the surveys offered during the semester. Students in cannon laboratory felt that they learned subjects at an equal level to the students operating in the traditional format. When the results of the opinion portion of the survey are analyzed it should be noted that the students in the cannon laboratory began with a very positive opinion of the laboratory and ended the semester with a positive opinion of the laboratory. All the surveys had free response sections. In all the free response sections the majority of the students revealed a high level enthusiasm for the laboratory. This enthusiasm could be noted in the beginning of the laboratory and throughout the semester, and was independently confirmed by Dr. Alan Wolfenden, the developer of the previous laboratory format. The students' higher level of enthusiasm for the class can be interpreted as an increased interest in the subject matter. The only difference between the two courses was the introduction of the project. The project required no additional student or instructor time. If a slight change in focus of the class towards an entertaining project results in only an increase in positive student attitude as well as satisfaction of accreditation criteria then this format should be considered for continued development as well as implementation in other laboratories.

There were a number of opportunities for the students in the experimental group to be compared to the students in control group. The proposed metric was two openended qualitative essays to determine any relative improvement in the design skills of students in the cannon laboratory. Since neither random selection of students, nor random assignment of students to experimental and control groups was possible, explorations of pre-treatment group similarities and differences were very important to the interpretation of project results. After establishing the general comparability of the experimental and control student groups on variables including gender and ethnic groups, pre-college entrance examination scores, and grades received in the pre-requisite materials science course several, analysis of the essay scores revealed no significant improvement in the experimental group over the control group on the essays, in the 
laboratory final, course final, or course grade, and the analysis also revealed that the experimental group students' skill levels were not weaker relative to the control group. What the analysis showed is that the students in the experimental group raised their overall performance in the class relative to their previous grades as evidenced in the CBK GPA comparison between the two groups. Although it cannot be concluded from the available data that the students in the project laboratory became better designers due to the intervention, the results obtained within the parameters of this quasi experimental design strongly suggest that the students in the class performed better than they would have otherwise due to the intervention provided by the change in laboratory format.

From the available data it is recognized that there is no conclusive objective measure that states that the cannon laboratory is a better design pedagogy than the assignment based laboratory. However the laboratory appears to have improved the student performance in the overall laboratory. Additionally, student and peer observation recognize that the laboratory has a variety intangible merits that make it desirable to be continued. When these observations are coupled with the satisfaction of ABET criteria, an argument substantiating the continuance of the laboratory is formed. It is recommended that this laboratory or variants of its focus continue to be developed at A\&M. 


\section{REFERENCES}

1. Griffin, R. B., and T. S. Creasy, "The Development of a Combined Materials/Manufacturing Processes Course at Texas A\&M University," ASEE Conf. Albuquerque, NM, June 2001.

2. Wankat, P., and F. Oreovicz, "What Is Good Teaching," ASEE Prism, Sept. 1998, pp. 16-18.

3. Silverman, S. L., and M. E. Casazza, Learning and Development: Making Connections to Enhance Teaching, Jossey-Bass Publishers, San Francisco, CA, 2000.

4. "Criteria for Accrediting Engineering Programs: Effective for Evaluations During the 2002-2003 Accreditation Cycle," Engineering Accreditation Commission, Accreditation Board for Engineering and Technology, Inc., Baltimore, MD, November 2001, http:/ /www.abet.org/images/Criteria/200203EACCriteria.pdf.

5. Wood, K. L., D. Jensen, and J. Bezdek, K. N. Otto, "Reverse Engineering and Redesign: Courses to Incrementally and Systematically Teach Design," Journal of Engineering Education, vol. 90, no. 3, 2001, pp. 363 - 374.

6. Simon, H. A., "What We Know About Learning," Journal of Engineering Education, vol. 87. no. 4, Oct. 1998, pp. 343 - 347.

7. Dally, J. W., and G. M. Zhang, "A Freshman Engineering Design Course," Journal of Engineering Education, vol. 82, no. 2, 1993, pp. 83 - 90.

8. Tsang, E., “Applying James Stice's Strategy to Teach Design to Sophomore Mechanical Engineering Undergraduates," Journal of Engineering Education, vol. 89, no. 2, 2000, pp. $231-236$.

9. Demetry, C. and J. E. Groccia, "A Comparative Assessment of Students' Experience in Two Instructional Formats of an Introductory Materials Science Course," Journal of Engineering Education, vol. 86, no. 3, 1997, pp. 203 - 210.

10. Moskal, B. M., "Scoring Rubrics: What, When and How?," Practical Assessment, Research \& Evaluation, vol. 7, no. 3, 2000. Available: http://ericae.net/pare/getvn.asp?v=7\&n=3

11. Svinicki, M. D., "Practical Implications of Cognitive Theories," College Teaching: From Theory to Practice, vol. 45. pp. 75 - 80, Jossey-Bass Publishers, San Francisco, CA, 1991.

12. Meade, J., "Change Is in the Wind," ASEE Prism, May 1993, pp. 20 - 24. 
13. Norris, J., Artillery: A History, Sutton, Phoenix Mill, UK, 2000.

14. Timoshenko, S.P., History of Strength of Materials, with a Brief Account of the History of Theory of Elasticity and Theory of Structures. McGraw-Hill, New York, 1953.

15. Ripley, W., Artillery and Ammunition of the Civil War, Van Nostrand Reinhold Co., New York, 1970.

16. Hazlett, J.C., E. Olmstead, M. H. Parks, Field Artillery Weapons of the Civil War, University of Delaware Press., Cranbury, NJ, 1983.

17. Doig, A., Military Metallurgy, IOM Co., London, 1998

18. Ashby, M.F., Material Selection in Design, Butterworth-Heineman, Oxford, 1997.

19. Kalpakjian, S., and S. R. Schmid, Manufacturing Engineering and Technology, Prentice Hall, Upper Saddle River, NJ, 2001.

20. Griffin, Richard B., T. S. Creasy, and J. L. Weinstein, "Laboratory Activity Using Rapid Prototyping and Casting," ASEE Conf., Montreal, Canada, June 2002.

21. Callister, W.D., Materials Science and Engineering, John Wiley and Sons Inc., New York, 2000.

22. Dieter, George E., Engineering Design: A Materials and Processing Approach, McGraw-Hill, New York, 2000.

23. Cambridge Engineering Selector, V4.0, Granata Design Limited, Cambridge, UK, 2002.

24. ASM Handbook, Vol. 20: Materials Selection and Design, ASM International, New York, pp. 243-250, 1997.

25. Woods, G. E., and R. B. Baguley, CASTI Guidebook to ASME B31.3, Casti Publishing Inc., Edmonton, Alberta, Canada, 2000.

26. Bloom, B. S., Taxonomy of Educational Objectives, Longmans, New York, 1956.

27. Shigley, J. E., and C. R. Mischke, Mechanical Engineering Design, McGrawHill, Inc., New York, 1989. 
28. Garrett, T.K., K. Newton, and W. Steeds, The Motor Vehicle, 13 th ed. SAE Int. Warrendale, PA. pp. 1109 - 1143. 2001. 
APPENDICES 
APPENDIX A

DRAWINGS OF THE CANNON ASSEMBLY AND PARTS 


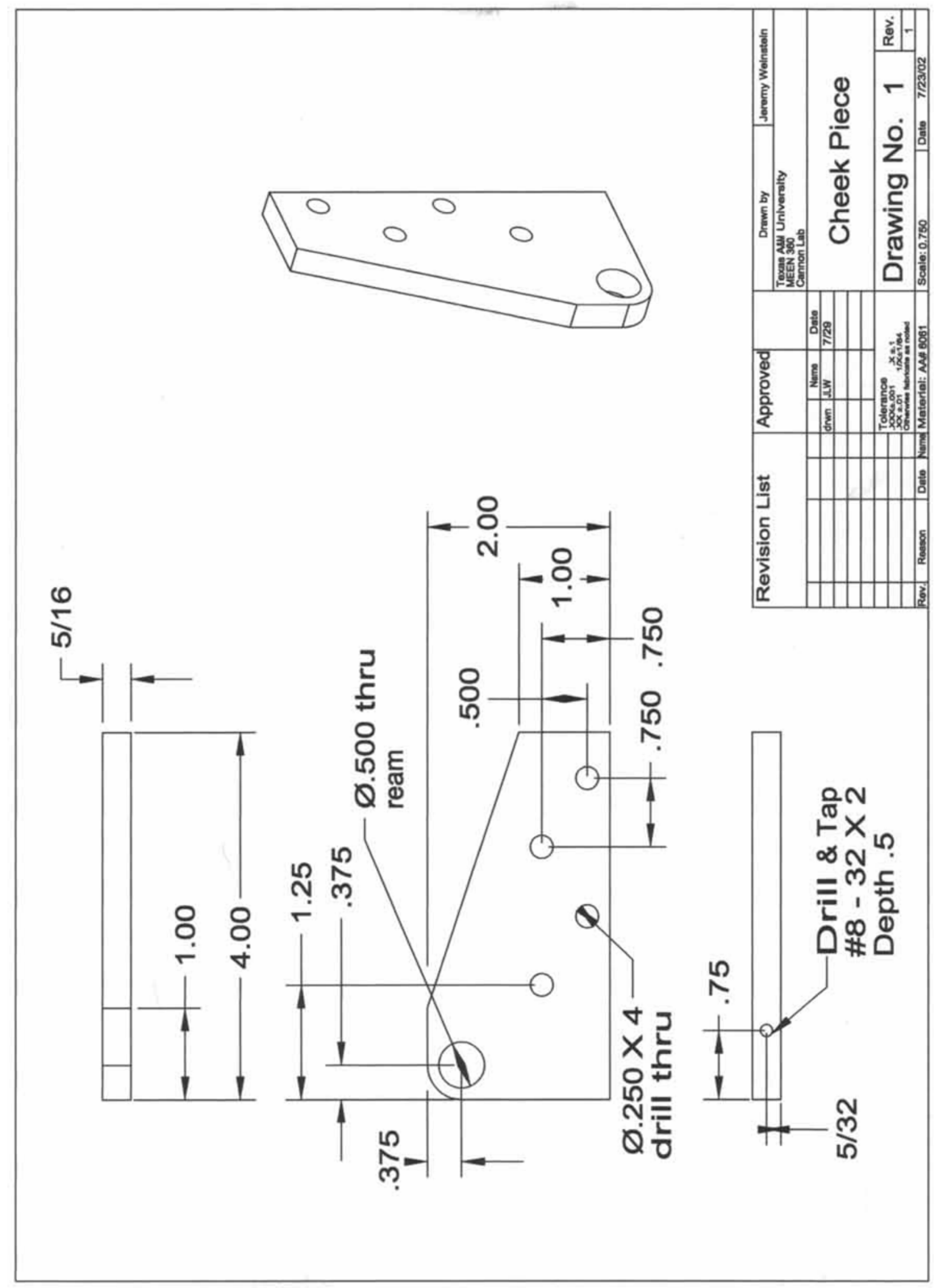




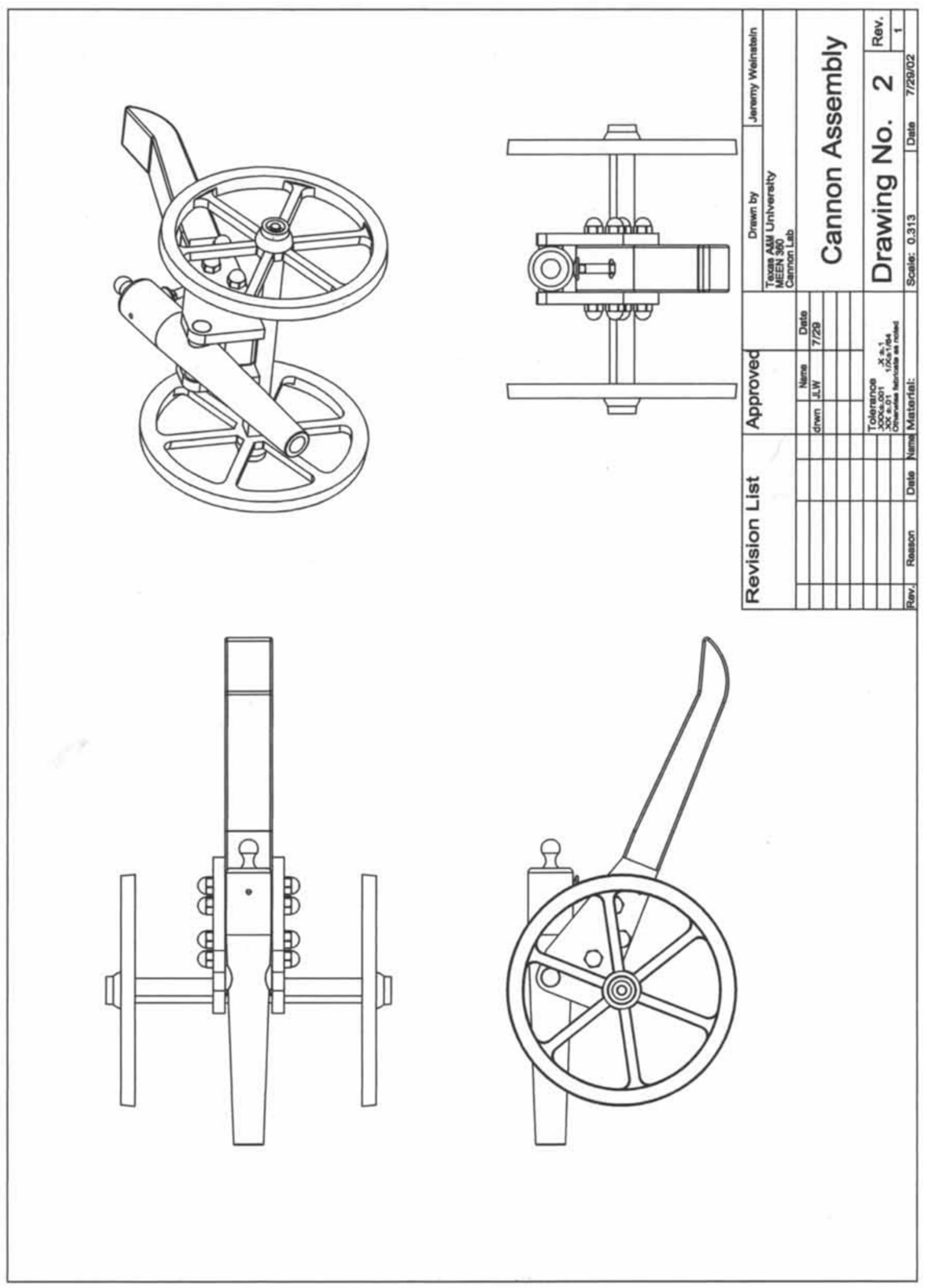




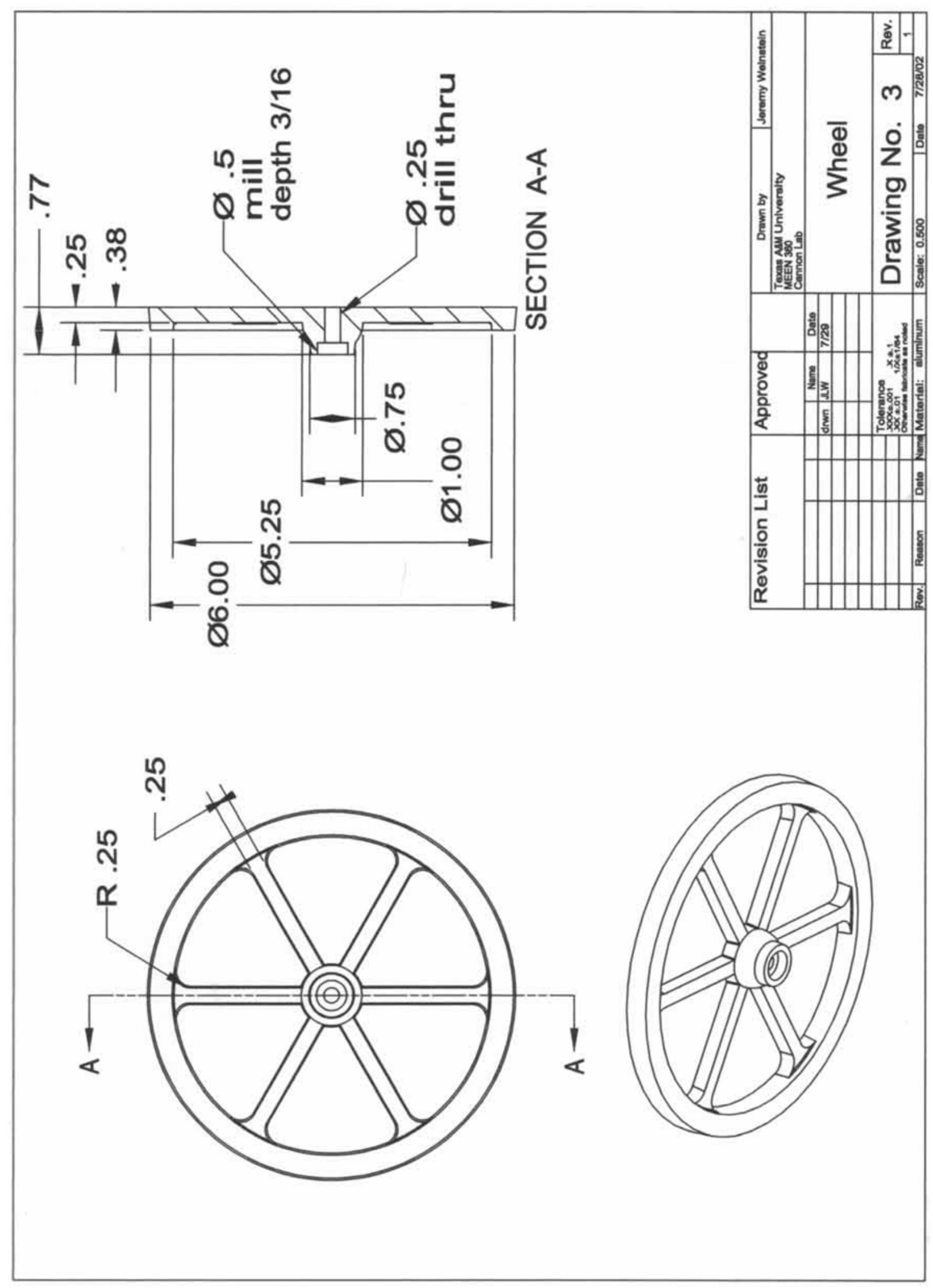




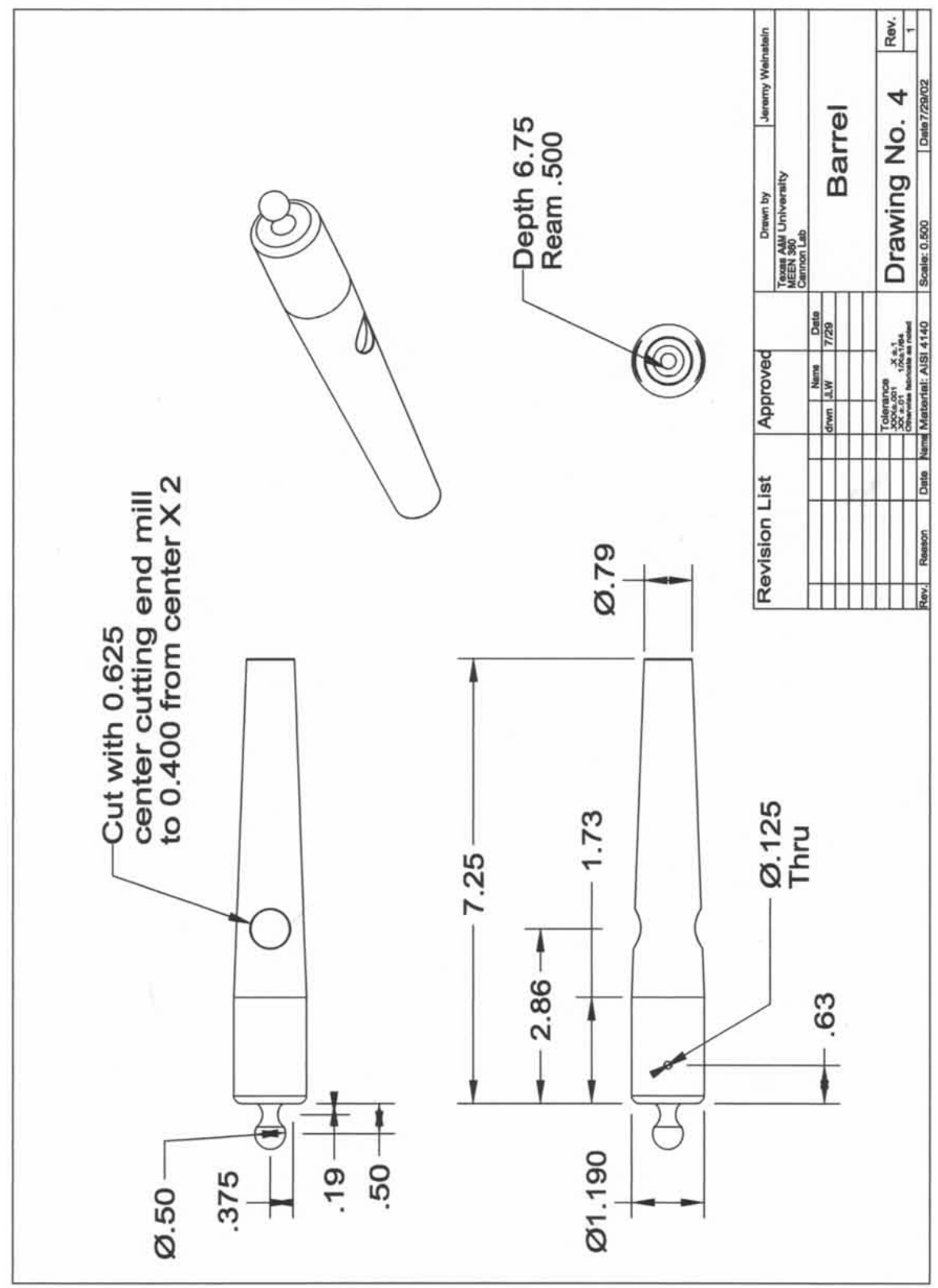




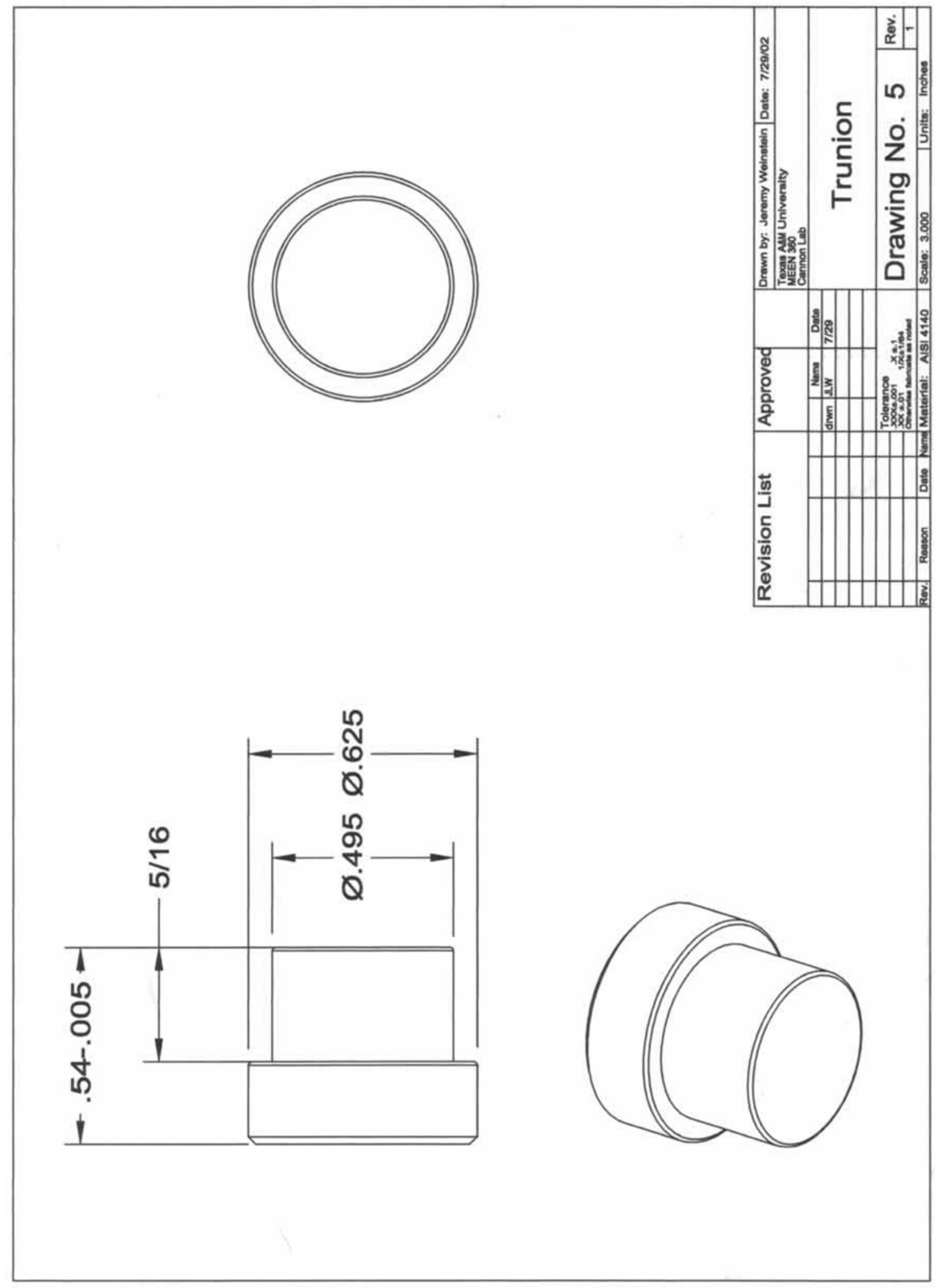




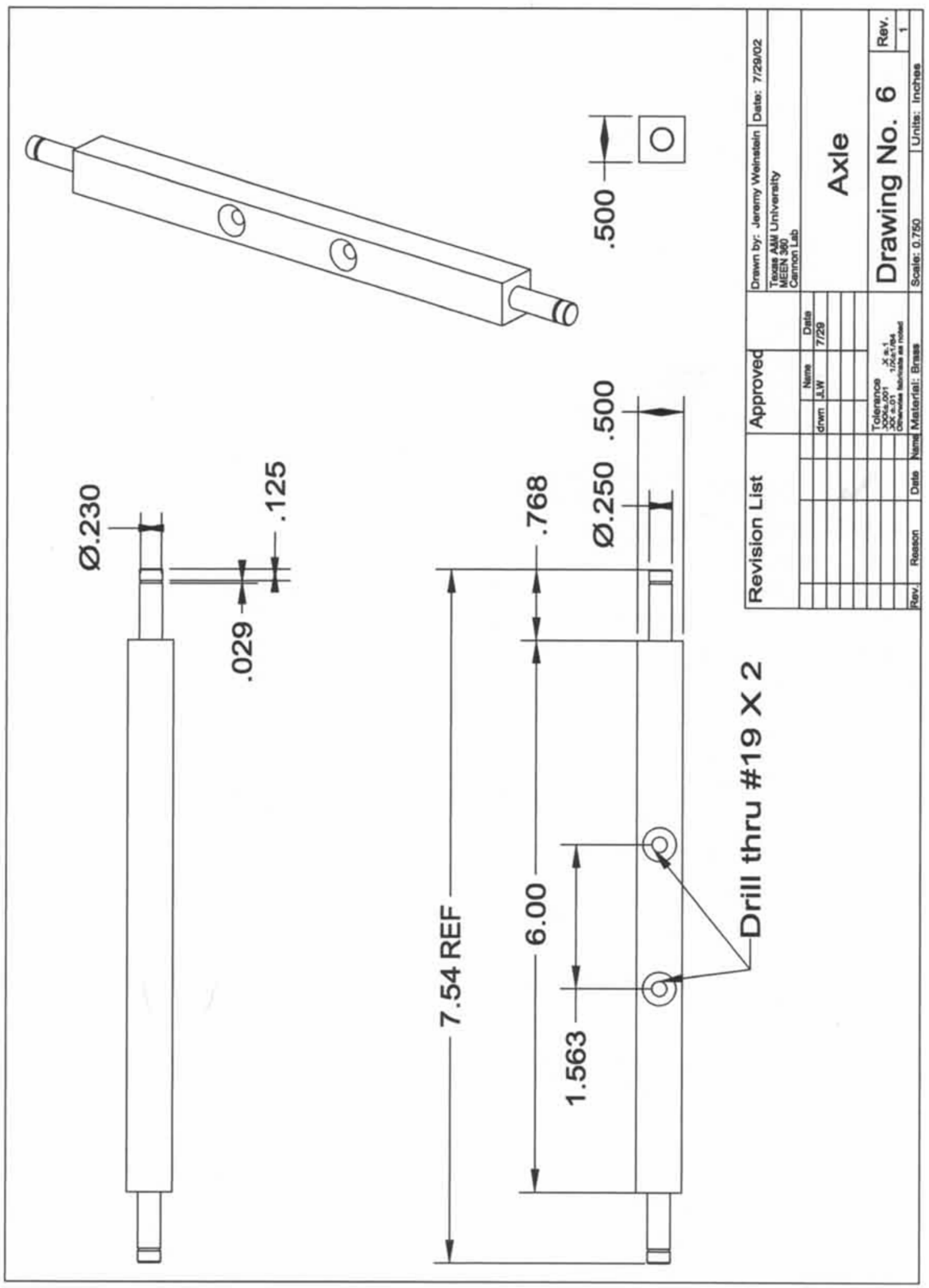




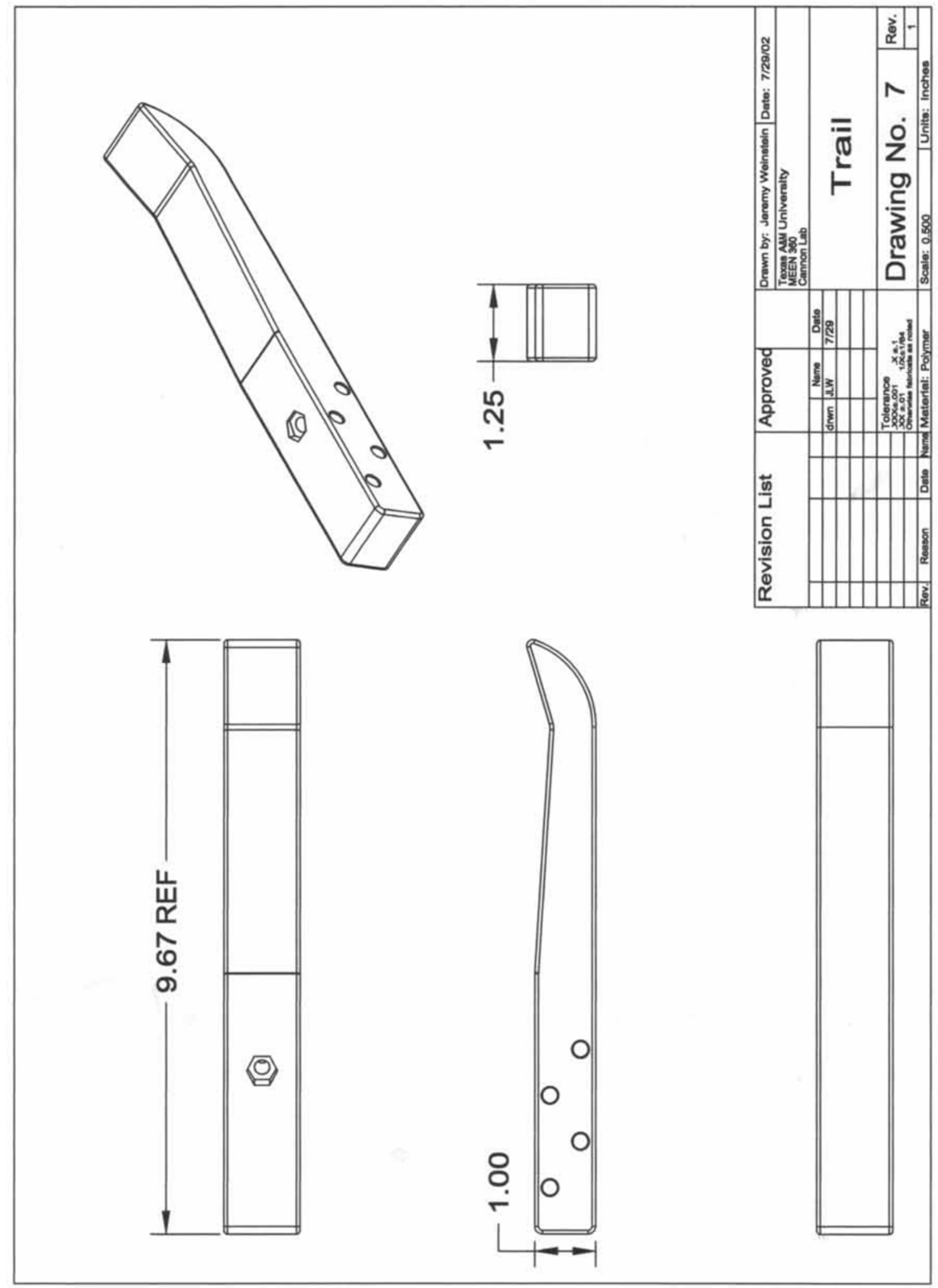


APPENDIX B

COURSE ASSIGNMENTS AND SCHEDULE 
FALL 2002

\section{Schedule for the Laboratory Experiments}

\section{Team}

\begin{tabular}{|c|c|c|c|c|}
\hline $\begin{array}{c}\text { week } \\
\text { starting }\end{array}$ & 1 & 2 & 3 & 4 \\
\hline 2-Sep-02 & $\begin{array}{c}\text { Intro. \& } \\
\text { measurement }\end{array}$ & $\begin{array}{c}\text { Intro. \& } \\
\text { measurement }\end{array}$ & $\begin{array}{c}\text { Intro. \& } \\
\text { measurement }\end{array}$ & $\begin{array}{c}\text { Intro. \& } \\
\text { measurement }\end{array}$ \\
\hline 9-Sep-02 & $\begin{array}{c}\text { Fatigue, Impact, } \\
\text { Tensile Test, \& } \\
\text { Hardness } \\
\end{array}$ & $\begin{array}{c}\text { Fatigue, Impact, } \\
\text { Tensile Test, \& } \\
\text { Hardness }\end{array}$ & $\begin{array}{c}\text { Fatigue, Impact, } \\
\text { Tensile Test, \& } \\
\text { Hardness }\end{array}$ & $\begin{array}{c}\text { Fatigue, Impact, } \\
\text { Tensile Test, \& } \\
\text { Hardness } \\
\end{array}$ \\
\hline 16-Sep-02 & $\begin{array}{c}\text { Material Selection } \\
\text { \& Planning } \\
\end{array}$ & \begin{tabular}{|c|} 
Material Selection \\
\& Planning \\
\end{tabular} & $\begin{array}{c}\text { Material Selection } \\
\text { \& Planning } \\
\end{array}$ & \begin{tabular}{|c|} 
Material Selection \\
$\&$ Planning \\
\end{tabular} \\
\hline 23-Sep-02 & $\begin{array}{l}\text { Aging, Hardness, } \\
\text { \& Heat Treatment }\end{array}$ & $\begin{array}{l}\text { Aging, Hardness, } \\
\text { \& Heat Treatment }\end{array}$ & $\begin{array}{l}\text { Aging, Hardness, } \\
\text { \& Heat Treatment }\end{array}$ & $\begin{array}{l}\text { Aging, Hardness, } \\
\text { \& Heat Treatment }\end{array}$ \\
\hline 30-Sep-02 & $\begin{array}{c}\text { Injection Molding } \\
\text { \& Tensile Test } \\
\end{array}$ & Manual Lathe & Rapid Prototyping & Rapid Prototyping \\
\hline 7-Oct-02 & Manual Mill & $\begin{array}{l}\text { Injection Molding } \\
\& \text { Tensile Test } \\
\end{array}$ & Casting & Casting \\
\hline 14-Oct-02 & Manual Lathe & Manual Mill & $\begin{array}{l}\text { Injection Molding } \\
\& \text { Tensile Test }\end{array}$ & Manual Lathe \\
\hline 21-Oct-02 & CNC Machining & CNC Machining & Manual Mill & $\begin{array}{c}\text { Injection Molding } \\
\text { \& Tensile Test } \\
\end{array}$ \\
\hline 28-Oct-02 & Rapid Prototyping & Rapid Prototyping & Manual Lathe & Manual Mill \\
\hline 4-Nov-02 & Casting & Casting & CNC Machining & CNC Machining \\
\hline 11-Nov-02 & Welding & Welding & Welding & Welding \\
\hline 18-Nov-02 & Metallography & Metallography & Metallography & Metallography \\
\hline 25-Nov-02 & Thanksgiving & Thanksgiving & Thanksgiving & Thanksgiving \\
\hline 2-Dec-02 & $\begin{array}{c}\text { Final Presentation } \\
\text { \& Examination }\end{array}$ & $\begin{array}{c}\text { Final Presentation } \\
\text { \& Examination }\end{array}$ & $\begin{array}{c}\text { Final Presentation } \\
\text { \& Examination }\end{array}$ & $\begin{array}{c}\text { Final Presentation } \\
\text { \& Examination }\end{array}$ \\
\hline
\end{tabular}




\section{Methodology of Assessment}

Introduction and Measurement................... Drawing-Business Letter-Calculations

Fatigue, Impact, and Tensile Test..................Quiz-Material Specification Sheet

Material Selection and Planning............................................... Quiz

Aging, Hardness and Heat Treatment.............................Laboratory Report

Manual Machining............................................... Quiz-Business Letter

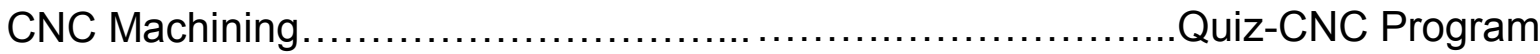

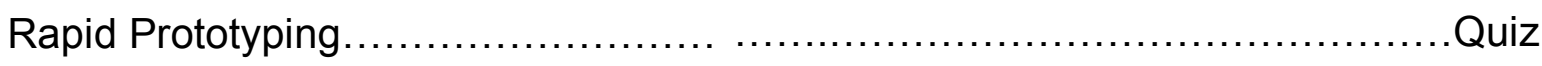

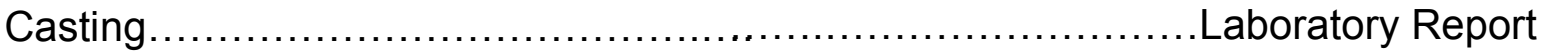

Injection Molding and Tensile Test.............................Quiz-Business Letter

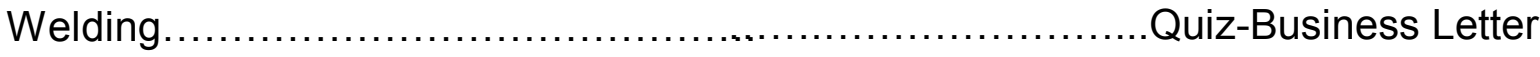

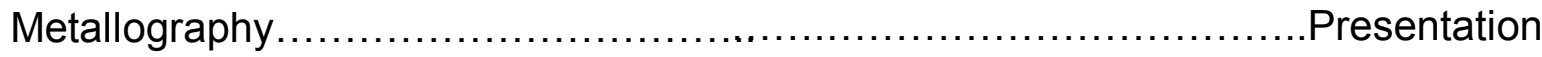

Course Content .......................................................... Examination

\section{Assignment weight}

Quizzes $\quad 10 \%$

Business Letters $\quad 25 \%$

Laboratory Reports $25 \%$

Presentation $\quad 15 \%$

Final Examination $\quad 25 \%$ 


\section{Safety Requirements for Laboratory Experiments}

Safety is of crucial importance in industry. Many of you have heard of the Occupational Safety and Health Administration (OSHA) but there are other world wide standards organizations that are also interested in safety such as the International Standards Organization(ISO) and others. We are also critically interested in your safety. In many of the labs we will be working with processes that could maim or kill you, as such it is important that you wear the proper clothing to lab. You must bring safety glasses to every Lab. You must wear closed toed shoes to every lab, no sandals. Additionally you will be required to have the following equipment for each of the listed labs.

Manual Machining - Long pants, closed toed shoes, and short sleeve shirts. No rings or bracelets.

Casting - Long cotton pants, closed toed leather shoes, and long sleeve cotton shirts

Welding-Long cotton pants, closed toed leather shoes, and long sleeve cotton shirts. You should wear no jewelry, watches, or large metal belt buckles. We will be dealing with extremely high electrical power outputs, which may arc.

Failure to wear the appropriate clothing will be counted as an unexcused absence. 


\section{Technical Report Format}

Write your report for a technically informed reader. Be concerned with organization, completeness, spelling, grammar, and neatness.

I. TITLE PAGE

a. Include:

i. A descriptive title of the laboratory report

ii. $3-5$ key words placed near the bottom of the page

iii. Course and section number

iv. Author's name

v. Date of the laboratory experiment and date turned in

II. ABSTRACT

a. This is a "mini" version of the report and should be 100-200 words in length. Imagine that your boss only has time to read the Abstract.

b. Include:

i. Principle objectives and scope of the investigation

ii. Description of materials tested

iii. Key experimental methods employed

iv. Summary of results

v. Principle conclusions

III. TABLE OF CONTENTS

a. Include major sections of report and page numbers.

IV. INTRODUCTION

a. Establish general interest in the subject, that is, why is the general topic of interest to the reader? This section puts the subject in context for the reader and includes relevant background (literature review).

b. Establish specific interest and justification for conducting this investigation leading to a statement of the specific objective(s). It is in this portion of the introduction that the specific aspect of the subject or the specific problem is identified so that the reader is informed of exactly what is to be accomplished, solved, proved, answered, etc. Present the theoretical basis for the experiment or investigation and equations used with a clear indication of which variables were measured and which are calculated. If the equation is not a common one (e.g., ideal gas equation of state) and not derived, cite a reference from which it was obtained.

c. Describe how the data will be reduced to results information.

d. Describe the general concept of how the investigation was conducted to satisfy the objective, answer the questions, or solve the problems. 
e. Introduce the report itself. That is, tell the reader how the report is organized and what to expect.

V. MATERIALS AND METHODS

a. Give a clear description of the test specimens and materials under study. Include shape, dimensions, chemical composition and thermalmechanical processing.

b. Present a diagram of the test set-up illustrating the general relationships among the various components of the system and the locations at which the measurements were taken.

c. Instrumentation (measurement systems) that was used should be described and related to the measurement locations on the diagram (with a statement of the uncertainty associated with each measurement system). Mention the appropriate ASTM standard, and the manufacturer of the machine(s) and model number(s).

d. Anything unusual about the instruments or set-up should be explained.

e. Discuss the general conceptual approach (general methodology) of the procedure (not step by step process).

f. Might note any special precautions or novel approaches taken to avoid errors, obtain better results or to expedite work.

g. Define properties you determined; describe any data reductions or analysis program you used; discuss calculations.

h. Explain your uncertainty analysis stating what the uncertainty of the dependant variable is, for example, $( \pm 5 \%$ for power). Put details of the uncertainty analysis in the appendix.

VI. RESULTS

a. Present data in tabular form. Each column of data MUST have its error limits.

b. Introduce the results; that is, tell what is being presented. State how the results are presented and refer to the various plots, tables, etc. Do not just include plots, charts, etc., without any explanation.

c. Include the results in terms of plots, charts, and tables. Be sure to have a figure or table number for each plot or table presented.

d. All figures, tables, etc., must have a descriptive title stating what the figure actually shows or is about. For example: "EPA Fuel Economy as a Function of Curb Weight for 1990 Automobiles in Various Price Ranges" rather than Fuel Economy vs. Weight. Look in books and reports to get an idea of how to do figure titles. 
VII. DISCUSSION

a. Interpret and explain results

i. Interpret the results for the reader; that is, tell the reader how to read or look at the results. Tell what your method of presentation illustrates or demonstrates and why the results were presented this way.

ii. Explain any discrepancies, scatter of data, anomalies, etc. Explain why the results turned out as they did, and if they were expected or unexpected and explain why. COMPARE YOUR RESULTS TO THOSE FOUND IN THE LITERATURE.

b. Point out the most important results

i. Even if the results as presented seem obvious to you, you want to be sure your reader notices the most important features and trends, etc.

ii. State what you think the results show, prove, demonstrate, or illustrate.

iii. It is in this section that you are "setting up" your conclusions. In fact, there may be conclusions in the discussion that will be restated in itemized form in the Conclusions section.

VIII. CONCLUSIONS

a. Summarize your findings and conclusions; that is, itemize the most important things that you found out, measured, and observed.

Anything that could be preceded by "It was found that" or "It was discovered that" is a finding, not a conclusion. This itemized list will give you a chance to think about what you discovered and aid you in identifying what you wish to conclude from the results of the experiment. Remember conclusions are generalizations based on results of a specific investigation.

IX. BIBLIOGRAPY

a. Cite the references used. All citations must be referenced in your report. Use the correct format for all citations: author's or editor's names, title, journal name or publisher, vol. number, pages, date.

XII. APPENDICES

a. You may put special calculations, error analysis, etc. into appendices. The appendices should all be given a title and listed in the Table of Contents. The details of the uncertainty analysis appear in the appendix. 


\section{Guide to Business Letters}

Business letters represent a quick way of getting factual information from one party to another. English is the dominant language of science and business, the letters must be written impeccably and be suitable for sending to educated readers anywhere in the world.

The success of many industrial companies is governed in part by the quality of the written information coming from the companies. In this course, a high standard of writing for business letters is expected.

This lab centers around the construction and development of a miniature cannon, as such you need to develop a corporate name for your miniature arsenal and address all correspondence as if you are communicating with a customer who is interested in purchasing one of your cannons.

Your letter should include the following:

1. Letterhead and logo of the arsenal

2. Customer's name and address

3. Date.

4. Tell the customer what tests or manufacturing processes you performed.

5. Tell the customer what equipment you used (manufacturer's name and model number).

6. List any results in an enclosed table.

7. If questions are asked regarding the process answer them in the letter.

8. Close the letter with a polite sentence.

9. Print and sign your name; list your job title.

Business letters usually consist of 1-2 pages of text, followed by one or several pages of enclosures (data tables, graphs, etc). 


\section{Metrology and Tolerance}

Metrology is the science of measurement. Within the context of this lab we will be working in the area of dimensional measurements. Your group will be supplied with a cannon part. Make measurements of the part sufficient to generate a production drawing of the part. You will be graded according to the supplied drawing rules as well as your group's ability to measure the dimensions accurately. As with all production parts the necessary accuracy of the dimensions varies based on the function of the specified feature. Your grade will correspond to your ability to measure the part within the production tolerances.

Accompanying your drawing should be a short letter explaining which features and dimensions require a narrow tolerance and why. Your letter should also explain why you feel the remaining tolerances are less important.

Additionally, your group will be supplied with 5 cannon balls. You must measure the diameter of the balls and you must specify the accuracy of your measuring device and submit calculations of the mean, sample standard deviation, and $95 \%$ confidence interval of the balls.

\section{References}

Kalpakjian, S., and Schmid, S., Manufacturing Processes for Engineering Materials, $4^{\text {th }}$ ed., Prentice Hall, 2002.

Oberg, Jones, Horton, Ryffel, Heald, Hussain, and McCauley, Machinerys Handbook, $26^{\text {th }}$ ed., Industrial Press, 2000. 


\section{Guidelines for Manufacturing Drawings}

\section{Orthographic Projection:}

Orthographic projection is the system of drawing views of an object by projecting them perpendicularly onto projection planes, as shown in Figure 1.

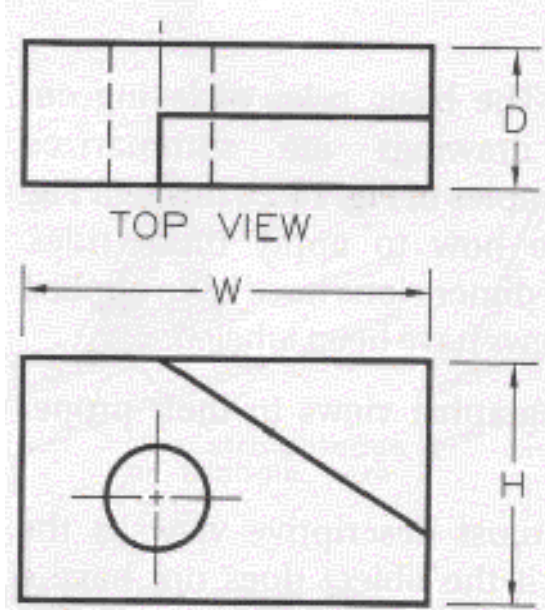

FRONT VIEW

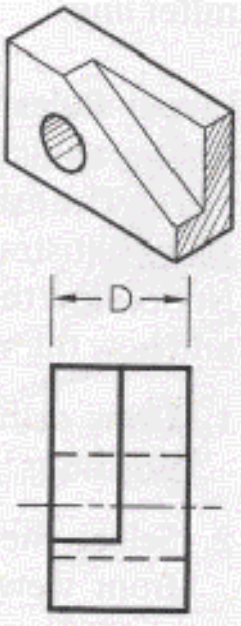

R SIDE $\vee$

Figure 1: Orthographic Projection

The most descriptive view is usually selected as the front view.

Dimensions should be shown between the corresponding views to which they apply.

The layout should be selected which conceals the fewest features.

\section{Rules for dimensioning:}

The first row of dimensions should be placed a minimum of 3 times the letter height from the part.

Dimension the most descriptive views

Dimension from visible lines

Give an overall dimension and omit one of the chain dimensions. 
When one chain dimension is not omitted, mark one dimension as a reference dimension.

Organize and align dimensions for ease of reading.

Do not repeat dimensions.

Dimension lines should not cross any other lines unless necessary.

Extension lines may cross other lines.

Do not place dimensions within views unless necessary.

Place angular dimensions outside the angle.

Dimension rounded corners to the theoretical intersection.

Dimension cylinders in their rectangular views with diameters.

Stagger dimension numerals to prevent crowding.

Hole sizes are best given as diameters with leaders in circular views.

Dimension rounds and fillets with radii.

\section{Rules specific to this lab:}

Do not use baseline dimensioning.

Title blocks should contain the following information: Title, Date, Names of group members, Scale, Section number, Dimension type, Tolerance if requested in class.

Notes should be used in the drawing to clarify any information not clearly obtainable from the drawing itself. 


\section{Fatigue, Impact, Tensile Test, and Hardness}

Napolean style cannon were traditionally constructed of brass. This was primarily due to the limitations of casting technology at the time as well as material availability. The barrels of modern artillery are constructed of a chromiummolybdenum alloy very similar to AISI 4140. Using the following tests: tensile test, fatigue test, charpy impact, and rockwell hardness, you will characterize the physical properties of the three cannon materials. Each student will submit a material purchase specification sheet based on the example given in class. Be sure to designate the specific standard to be used in each material testing process.

\section{References}

Kalpakjian, S., and Schmid, S., Manufacturing Processes for Engineering Materials, $4^{\text {th }}$ ed., Prentice Hall, 2002.

ASM Handbook, Vol. 8: Mechanical Testing, ASM International, 2000. 


\section{Aging, Hardness, and Heat treatment}

The cheek pieces of the cannon will be composed of AA\#-6061. The barrel will be machined from AISI 4140 . Both 4140 and 6061 can be significantly strengthened through various methods of heat treatment. 6061 as with many aluminum alloys can be strengthened through a process known as precipitation hardening or aging. 4140 can be significantly strengthened by quenching and tempering.

For 6061 you must demonstrate the methodology required to peak age and overage the material within one class period.

For 4140 you must quench and temper the material to obtain a hardness value of RC 35.

You will be required to submit a formal report of your experiments. The report must follow the requirements for a formal report given in class.

\section{References}

Kalpakjian, S., and Schmid, S., Manufacturing Processes for Engineering Materials, $4^{\text {th }}$ ed., Prentice Hall, 2002, p. $235-245$.

ASM Handbook, Vol. 4: Heat Treating, ASM International, 1991.

Callister, W. D., Materials Science and Engineering: An introduction, $5^{\text {th }}$ ed., John Wiley and Sons Inc., 1999. 


\section{Injection Molding and Tensile Testing}

Injection Molding is a method of rapidly producing relativ12ely small thin parts from thermoplastic materials. You will use the Boy $15 \mathrm{~S}$ injection molding machine to produce 5 tensile test specimens from a selected thermoplastic at three different machine speeds. You will then tensile test these specimens to determine their physical properties. Upon completion of the experiment you will generate a business letter, due next week, detailing the process as well as answering the following questions.

What equipment do you have available for injection molding and tensile testing of polymers?

What ASTM standards were followed in the two processes?

What methods of verification were used to inspect the parts and what visual flaws were detected?

What physical properties of the material can be determined in the tensile test?

What are the values of these properties?

How do the evaluated properties compare to published values?

What difficulties were encountered in the experiment and how could these be corrected?

Is Injection molding a viable process for manufacturing any parts of cannon assembly?

Could the polymer you tested be employed in the cannon assembly?

The business letter must follow the format given as a handout in class.

\section{References}

Kalpakjian, S., and Schmid, S., Manufacturing Processes for Engineering Materials, $4^{\text {th }}$ ed., Prentice Hall, 2002, $568-575,591-605$.

Buckley, C. P., C. B. Bucknall, and N. G. McCrum, Principles of Polymer Engineering, $2^{\text {nd }}$. Ed., Oxford, 1997. 


\section{Manual Machining}

Manual machining is the process of shaping a workpiece through material removal where machine operation is left in the hands of a person. The two most common powered machine tools in a shop are the lathe and mill. We will be using the lathe to shape and bore the barrel of the cannon and turn the trunions. We will be using the mill to create the cheek pieces as well as drilling the vent and the brazing reliefs for the trunions. At the end of the two experiments you will be required to submit a business letter detailing the machining processes used as well as answering the following questions.

What tools and work holding devices were required in addition to the lathe and mill to complete the cannon parts?

What methods and instruments were used to verify the quality of the finished cannon parts?

What is meant by the term "indicating the mill"?

The business letter should be submitted one week after the completion of the second machining lab.

\section{References}

Kalpakjian, S., and Schmid, S., Manufacturing Processes for Engineering Materials, $4^{\text {th }}$ ed., Prentice Hall, 2002, 455 - 481.

Oberg, Jones, Horton, Ryffel, Heald, Hussain, and McCauley, Machinerys Handbook, $26^{\text {th }}$ ed., Industrial Press, 2000. 


\section{CNC Machining}

CNC stands for Computer Numerical Control. When high precision, high production quantities and or complex geometries are required to be machined, CNC Machining will be selected over manually operated machines. CNC Machines are commonly programmed in a language called G-Code. G-Code is a simple command based programming language, which can be used to select machine speeds as well as direct tool movements within a simple Cartesian frame.

You have been given a drawing of the trail piece of the cannon assembly as well as a reference on the available G-Code functions. After instruction in the methodology behind programming $\mathrm{CNC}$ and use of the various functions, you must generate a program for the Haas $\mathrm{CNC}$ mill which will cut the completed trail from a piece of stock. Your program will then be verified for acceptability within Gibbs CAM(Computer Aided Manufacturing). Once the program is verified you will participate in the production of the trail piece for your cannon.

\section{References}

Kalpakjian, S., and Schmid, S., Manufacturing Processes for Engineering Materials, $4^{\text {th }}$ ed., Prentice Hall, 2002, $808-826$.

Oberg, Jones, Horton, Ryffel, Heald, Hussain, and McCauley, Machinerys Handbook, $26^{\text {th }}$ ed., Industrial Press, 2000. 


\section{Rapid Prototyping and Casting}

Rapid Prototyping is a method of lamellar manufacturing which generates a product with less than optimum physical properties, but with dimensional accuracy that allows for processes such as inspection of fits, concept verification, and in some instances rapid tooling. We will use the $Z 400$ powder-binder machine to generate tooling for a small medallion as well as the wheels of the cannon carriage. The medallion should be no more than 4" X 4" X 1", and must be suitable for casting as a coreless pattern in a simple cope and drag mold utilizing green sand. Once the pattern is complete it will be attached to a simple matchplate and you will make casts of your part as well as the wheels of the cannon in the foundry.

A lab report detailing the process will be required the week after casting is completed. The report must include the following information.

Detailed account of the process required to manufacture the part as well as applicable ASTM standards for casting of Aluminum and Rapid Prototyping.

Results in the form of an evaluation of the finished cast and tooling process.

Conclusions as to the viability of the process with recommendations for the improvement of the process.

The report must follow the format given as a handout in class, it will be due the week following casting of the part.

\section{References}

Kalpakjian, S., and Schmid, S., Manufacturing Processes for Engineering Materials, $4^{\text {th }}$ ed., Prentice Hall, 2002. $218-235$.

Oberg, Jones, Horton, Ryffel, Heald, Hussain, and McCauley, Machinerys Handbook, $26^{\text {th }}$ ed., Industrial Press, 2000. 


\section{Welding and Brazing}

Welding is the method by which workpieces are joined through melting and solidification often times additional material is added to act as a filler and reinforcement. Brazing is the method by which workpieces maybe joined by melting a filler metal below the melting temperature of the workpiece materials and allowing it to fill a void. You will be employing the processes of SMAW, GMAW, Brazing, and Oxy-Acetylene cutting to join and cut metals. During the lab you will braze the trunions into the body of the cannon. Upon completion of the lab you will write a business letter detailing the processes employed as well as answering the following questions.

What equipment do you have available?

What visual flaws might be apparent in a completed weld or braze?

Are there any professional organizations, which certify welds and welders?

What is HAZ?

What steps are commonly taken to limit its affects?

What is the reasoning behind choosing brazing as opposed to SMAW or GMAW to join the trunions?

What are the potential harmful effects of applying heat to the barrel during the joining process?

Select another manufacturing process and detail why it might be superior to brazing in this application?

The business letter will be due the week following the lab and it should follow the form provided in class.

\section{References}

Kalpakjian, S., and Schmid, S., Manufacturing Processes for Engineering Materials, $4^{\text {th }}$ ed., Prentice Hall, 2002, Sections 12.2, 12.12, 12.16

Oberg, Jones, Horton, Ryffel, Heald, Hussain, and McCauley, Machinerys 


\section{Metallography}

Metallography is the science and methodology of examining the microstructure of a metal. The microstructure of a metal is the physical evidence tracing the processes that the sample has experienced. Metallography can be used in quality control, research, failure analysis and at any other time where a snapshot of the metal's microstructure may prove beneficial or informative. You have produced and tested a cannon. The history of the barrel from the time you received a billet of material is written in the microstructure. Select three sections of the cannon that interest you. Make samples of the selected sections, and examine their microstructure.

You quenched and tempered the steel to achieve a Rockwell Hardness of 35C. The hardness reflects changes in the microstructure from that of the untreated material. Use the knowledge you have gained from your materials courses, pertinent equations, and the available references to predict the microstructure at each stage of the heat-treating process.

Use your knowledge of the manufacturing processes and function of the barrel to explain the variation or similarity of the microstructure of the part to the predicted microstructure.

What other manufacturing processes might be suitable for the production of a cannon? How might the microstructure and properties of these other methods differ from those of the current cannon.

Make an oral presentation of your findings. The presentation should last no more than 30 minutes.

\section{References}

Kalpakjian, S., and Schmid, S., Manufacturing Processes for Engineering Materials, $4^{\text {th }}$ ed., Prentice Hall, 2002, p. $235-245$.

Callister, W. D., Materials Science and Engineering: An introduction, $5^{\text {th }}$ ed., John Wiley and Sons Inc., 1999. 
APPENDIX C

\section{CANNON AND NON-CANNON SURVEYS}




\section{Cannon Lab Initial Survey}

Rate your level of understanding, preparedness, and ability to converse on the subject of Manual Machining.

On a scale of 1 to 5 with $1=$ very well prepared and $\mathbf{5}=$ very poorly prepared

4. Manual Machining

a). Can you detail the steps involved in the process of manual machining?

b). Can you weigh the capabilities and limitations in the process of manual machining?

c). Can you recognize the necessity of this process in the manufacture of a particular product?

d). Can you communicate effectively in the terminology of this process?

e). Do you understand the placement of this process in the evolution of a product design?

f). Can you communicate the specifics of this process to a co-worker?

Rate your level of understanding, preparedness, and ability to converse on the subject of CNC Machining.

On a scale of 1 to 5 with $1=$ very well prepared and $5=$ very poorly prepared \begin{tabular}{|l|r|r|r|r|r|}
\hline 5. CNC Machining & 1 & 2 & 3 & 4 & 5 \\
\hline
\end{tabular} a). Can you detail the steps involved in the process of CNC machining?

b). Can you weigh the capabilities and limitations in the process of CNC machining?

c). Can you recognize the necessity of this process in the manufacture of a particular product?

d). Can you communicate effectively in the terminology of this process?

e). Do you understand the placement of this process in the evolution of a product design?

f). Can you communicate the specifics of this process to a co-worker?

Rate your level of understanding, preparedness, and ability to converse on the subject of Casting.

On a scale of 1 to 5 with $1=$ very well prepared and $5=$ very poorly prepared

\begin{tabular}{|l|l|l|l|l|l|}
\hline 6. Casting & $\mathbf{1}$ & $\mathbf{2}$ & $\mathbf{3}$ & $\mathbf{4}$ & $\mathbf{5}$ \\
\hline a). Can you detail the steps involved in the process of casting? & & & & & \\
\hline $\begin{array}{l}\text { b). Can you weigh the capabilities and limitations in the process of } \\
\text { casting? }\end{array}$ & & & & \\
\hline $\begin{array}{l}\text { c). Can you recognize the necessity of this process in the manufacture } \\
\text { of a particular product? }\end{array}$ & & & & \\
\hline $\begin{array}{l}\text { d). Can you communicate effectively in the terminology of this } \\
\text { process? }\end{array}$ & & & & & \\
\hline $\begin{array}{l}\text { e). Do you understand the placement of this process in the evolution of } \\
\text { a product design? }\end{array}$ & & & & \\
\hline \begin{tabular}{l} 
f). Can you communicate the specifics of this process to a co-worker? \\
\hline
\end{tabular} & & & & \\
\hline
\end{tabular}


Rate your level of understanding, preparedness, and ability to converse on the subject of Manual Machining.

On a scale of 1 to 5 with $1=$ very well prepared and $5=$ very poorly prepared

4. Manual Machining

a). Can you detail the steps involved in the process of manual machining?

b). Can you weigh the capabilities and limitations in the process of manual machining?

c). Can you recognize the necessity of this process in the manufacture of a particular product?

d). Can you communicate effectively in the terminology of this process?

e). Do you understand the placement of this process in the evolution of a product design?

f). Can you communicate the specifics of this process to a co-worker?

Rate your level of understanding, preparedness, and ability to converse on the subject of CNC Machining.

On a scale of 1 to 5 with $1=$ very well prepared and $\mathbf{5}=$ very poorly prepared

\begin{tabular}{|l|r|r|r|r|r|}
\hline 5. CNC Machining & 1 & 2 & 3 & 4 & 5 \\
\hline
\end{tabular}

a). Can you detail the steps involved in the process of CNC machining?

b). Can you weigh the capabilities and limitations in the process of CNC machining?

c). Can you recognize the necessity of this process in the manufacture of a particular product?

d). Can you communicate effectively in the terminology of this process?

e). Do you understand the placement of this process in the evolution of a product design?

f). Can you communicate the specifics of this process to a co-worker?

Rate your level of understanding, preparedness, and ability to converse on the subject of Casting. On a scale of 1 to 5 with $1=$ very well prepared and $5=$ very poorly prepared

\begin{tabular}{|l|l|l|l|l|l|}
\hline 6. Casting & $\mathbf{1}$ & $\mathbf{2}$ & $\mathbf{3}$ & $\mathbf{4}$ & $\mathbf{5}$ \\
\hline a). Can you detail the steps involved in the process of casting? & & & & & \\
\hline $\begin{array}{l}\text { b). Can you weigh the capabilities and limitations in the process of } \\
\text { casting? }\end{array}$ & & & & \\
\hline $\begin{array}{l}\text { c). Can you recognize the necessity of this process in the manufacture } \\
\text { of a particular product? }\end{array}$ & & & & \\
\hline $\begin{array}{l}\text { d). Can you communicate effectively in the terminology of this } \\
\text { process? }\end{array}$ & & & & & \\
\hline $\begin{array}{l}\text { e). Do you understand the placement of this process in the evolution of } \\
\text { a product design? }\end{array}$ & & & & \\
\hline \begin{tabular}{l} 
f). Can you communicate the specifics of this process to a co-worker? \\
\hline
\end{tabular} & & & & \\
\hline
\end{tabular}


Rate your level of understanding, preparedness, and ability to converse on the subject of Welding.

On a scale of 1 to 5 with $1=$ very well prepared and $\mathbf{5}=$ very poorly prepared

\section{Welding}

a). Can you detail the steps involved in the process of welding?

b). Can you weigh the capabilities and limitations in the process of welding?

c). Can you recognize the necessity of this process in the manufacture of a particular product?

d). Can you communicate effectively in the terminology of this process?

e). Do you understand the placement of this process in the evolution of a product design?

f). Can you communicate the specifics of this process to a co-worker?

\begin{tabular}{|r|r|r|r|r|r|}
\hline & 1 & 2 & 3 & 4 & 5 \\
\hline & & & & & \\
\hline & & & & & \\
\hline & & & & & \\
\hline & & & & & \\
\hline
\end{tabular}

Rate your level of understanding, preparedness, and ability to converse on the subject of Injection Molding.

On a scale of 1 to 5 with $1=$ very well prepared and $\mathbf{5}=$ very poorly prepared

8. Injection Molding

a). Can you detail the steps involved in the process of injection molding?

b). Can you weigh the capabilities and limitations in the process of injection molding?

c). Can you recognize the necessity of this process in the manufacture of a particular product?

d). Can you communicate effectively in the terminology of this process?

e). Do you understand the placement of this process in the evolution of a product design?

f). Can you communicate the specifics of this process to a co-worker?

Rate your level of understanding, preparedness, and ability to converse on the subject of Rapid Prototyping.

On a scale of 1 to 5 with $1=$ very well prepared and $5=$ very poorly prepared

9. Rapid Prototyping

a). Can you detail the steps involved in the process of Rapid Prototyping?

b). Can you weigh the capabilities and limitations in the process of Rapid Prototyping?

c). Can you recognize the necessity of this process in the manufacture of a particular product?

d). Can you communicate effectively in the terminology of this process?

e). Do you understand the placement of this process in the evolution of a product design?

f). Can you communicate the specifics of this process to a co-worker? g). Do you understand the effect of Rapid Prototyping on the speed of product development? 
Rate your level of understanding, preparedness, and ability to converse on the subject of Metallography.

On a scale of 1 to 5 with $1=$ very well prepared and $\mathbf{5}=$ very poorly prepared

10. Metallography

a). Can you define the purpose and function of Metallography?

b). Can you list the capabilities of this process?

c). Can you recognize the necessity of this process in the manufacture of a particular product?

d). Can you communicate effectively the value and purpose of this process to someone else?

e). Do you understand the function of this process in quality control

and failure diagnosis?

Rate your level of interest and enthusiasm for this course.

On a scale of 1 to 5 with $1=$ very interested and $5=$ not very interested

\begin{tabular}{|l|r|r|r|r|r|}
\hline 11. The project & $\mathbf{1}$ & $\mathbf{2}$ & $\mathbf{3}$ & $\mathbf{4}$ & $\mathbf{5}$ \\
\hline a). Rate your overall interest in the lab course & & & & & \\
\hline b). Rate your interest in the cannon project & & & & & \\
\hline
\end{tabular}

For the following questions answer yes or no

12. Do you feel the project can be effectively integrated in the course format?

13. Do you anticipate that the project will result in more effort on your part?

14. Will it help you as an engineer to manufacture and test the cannon?

15. Do you foresee potential problems with this new lab?

16. These questions cannot be all encompassing. Please write a few short sentences about your overall impression of the new course. 


\section{Non-Cannon Lab Initial Survey}

Name:

Student I.D.

Rate your level of understanding, preparedness, and ability to converse on the subject of Metrology and Tolerance.

On a scale of 1 to 5 with $1=$ very well prepared and $\mathbf{5}=$ very poorly prepared 1. Metrology and Tolerance

a). Can you define the function of metrology and tolerance in design?

b). Can you identify the criteria necessary to specify a particular dimension or tolerance in design?

c). Can you effectively reverse engineer a product?

d). Do you have the ability to issue a design drawing suitable for manufacture?

e). Can you place the subject of metrology and tolerance in a step-bystep product development?

Rate your level of understanding, preparedness, and ability to converse on the subjects of Fatigue testing, Impact testing, Tensile testing and Hardness testing.

On a scale of 1 to 5 with $1=$ very well prepared and $5=$ very poorly prepared

2. Fatigue, Impact, tensile test, and Hardness Testing

a). Can you define the specific process of the listed materials tests?

b). Do you understand the importance of these tests in evaluating material properties?

c). Do you feel you could choose a particular test for a specific design situation?

d). Can you communicate the process and capabilities of these tests

to someone else?

Rate your level of understanding, preparedness, and ability to converse on the subjects of

Precipitation Hardening and Heat Treatment of Steel.

On a scale of 1 to 5 with $1=$ very well prepared and $5=$ very poorly prepared

3. Precipitation Hardening and Heat Treatment of Steel

a). Can you define the processes of Precipitation Hardening and Heat Treatment of Steel?

b). Can you list the material properties effected by these two material treatments?

c). Can you place the location of the process in the step-by-step manufacture of a product?

d). Do you know the materials that these processes can be applied to?

e). Can you communicate your knowledge of the process and its capabilities to someone else?

f). Do you feel you could suggest one of these processes for a

particular design situation? 
Rate your level of understanding, preparedness, and ability to converse on the subject of CNC On a scale of 1 to 5 with $1=$ very well prepared and $5=$ very poorly prepared

5. CNC Machining

a). Can you detail the steps involved in the process of CNC machining?

b). Can you weigh the capabilities and limitations in the process of CNC machining?

c). Can you recognize the necessity of this process in the manufacture of a particular product?

d). Can you communicate effectively in the terminology of this process?

e). Do you understand the placement of this process in the evolution of a product design?

f). Can you communicate the specifics of this process to a co-worker?

Rate your level of understanding, preparedness, and ability to converse on the subject of Casting. On a scale of 1 to 5 with $1=$ very well prepared and $5=$ very poorly prepared

\begin{tabular}{|c|c|c|c|c|c|}
\hline 6. Casting & 1 & 2 & 3 & 4 & \\
\hline a). Can you detail the steps involved in the process of casting? & & & & & \\
\hline $\begin{array}{l}\text { b). Can you weigh the capabilities and limitations in the process of } \\
\text { casting? }\end{array}$ & & & & & \\
\hline $\begin{array}{l}\text { c). Can you recognize the necessity of this process in the manufacture } \\
\text { of a particular product? }\end{array}$ & & & & & \\
\hline $\begin{array}{l}\text { d). Can you communicate effectively in the terminology of this } \\
\text { process? }\end{array}$ & & & & & \\
\hline $\begin{array}{l}\text { e). Do you understand the placement of this process in the evolution of } \\
\text { a product design? }\end{array}$ & & & & & \\
\hline f). Can you communicate the specifics of this process to a co-worker? & & & & & \\
\hline
\end{tabular}

Rate your level of understanding, preparedness, and ability to converse on the subject of Welding. On a scale of 1 to 5 with $1=$ very well prepared and $5=$ very poorly prepared

7. Welding

a). Can you detail the steps involved in the process of welding?

b). Can you weigh the capabilities and limitations in the process of welding?

c). Can you recognize the necessity of this process in the manufacture of a particular product?

d). Can you communicate effectively in the terminology of this process?

e). Do you understand the placement of this process in the evolution of a product design?

f). Can you communicate the specifics of this process to a co-worker? 
Rate your level of understanding, preparedness, and ability to converse on the subject of Injection On a scale of 1 to 5 with $1=$ very well prepared and $5=$ very poorly prepared

8. Injection Molding

a). Can you detail the steps involved in the process of injection molding?

b). Can you weigh the capabilities and limitations in the process of injection molding?

c). Can you recognize the necessity of this process in the manufacture of a particular product?

d). Can you communicate effectively in the terminology of this process?

e). Do you understand the placement of this process in the evolution of a product design?

f). Can you communicate the specifics of this process to a co-worker?

Rate your level of understanding, preparedness, and ability to converse on the subject of Rapid On a scale of 1 to 5 with $\mathbf{1}=$ very well prepared and $5=$ very poorly prepared

\begin{tabular}{|l|r|r|r|r|r|}
\hline 9. Rapid Prototyping & 1 & 2 & 3 & 4 & 5 \\
\hline
\end{tabular}

a). Can you detail the steps involved in the process of Rapid Prototyping?

b). Can you weigh the capabilities and limitations in the process of Rapid Prototyping?

c). Can you recognize the necessity of this process in the manufacture of a particular product?

d). Can you communicate effectively in the terminology of this process?

e). Do you understand the placement of this process in the evolution o a product design?

f). Can you communicate the specifics of this process to a co-worker? g). Do you understand the effect of Rapid Prototyping on the speed of product development?

Rate your level of understanding, preparedness, and ability to converse on the subject of On a scale of 1 to 5 with $\mathbf{1}=$ very well prepared and $\mathbf{5}=$ very poorly prepared

\begin{tabular}{|c|c|c|c|c|c|}
\hline 10. Metallography & 1 & 2 & 2 & & 4 \\
\hline a). Can you define the purpose and function of Metallography? & & & & & \\
\hline b). Can you list the capabilities of this process? & & & & & \\
\hline $\begin{array}{l}\text { c). Can you recognize the necessity of this process in the manufacture } \\
\text { of a particular product? }\end{array}$ & & & & & \\
\hline $\begin{array}{l}\text { d). Can you communicate effectively the value and purpose of this } \\
\text { process to someone else? }\end{array}$ & & & & & \\
\hline $\begin{array}{l}\text { e). Do you understand the function of this process in quality control } \\
\text { and failure diagnosis? }\end{array}$ & & & & & \\
\hline
\end{tabular}

16. These questions cannot be all encompassing. Please write a few short sentences about relating your feeling about course content and format. 


\section{Mid-Semester Survey}

\section{Name:}

\section{Metrology}

1. Could you apply the techniques used in this assignment to a potential engineering career? How?

2. Can you relate a potential benefit of measuring a cannon part as opposed to a non-functional measurement fixture? Can you name a drawback?

3. Please write a sentence or two on how you might change the metrology assignment.

\section{Charpy Impact, Tensile Test, Hardness Test, Fatigue Test}

1. Please name one instance in which all these tests might be applied in a design, not a cannon. Explain briefly.

2. Did giving the tests a context such as "testing potential cannon materials" help lend importance to the lab? How?

3. Please write a sentence or two on how you might change the materials testing assignment. 


\section{Aging of Aluminum, Hardening of Steel}

1. What value, to your career as an engineer, do you see in performing this lab?

2. Do you believe there is greater benefit in treating a part that will be used in a product as opposed to simply treating a lab specimen? Why?

3. Please write a sentence or two on how you might change the heat treatment assignment. 


\section{Cannon Lab Final Survey}

Name:

Student I.D.

Rate your level of understanding, preparedness, and ability to converse on the subject of Metrology and Tolerance.

On a scale of 1 to 5 with $1=$ very well prepared and $5=$ very poorly prepared 1. Metrology and Tolerance

a). Can you define the function of metrology and tolerance in design?

b). Can you identify the criteria necessary to specify a particular dimension or tolerance in design?

c). Can you effectively reverse engineer a product?

d). Do you have the ability to issue a design drawing suitable for manufacture?

e). Can you place the subject of metrology and tolerance in a step-bystep product development?

Rate your level of understanding, preparedness, and ability to converse on the subjects of Fatigue testing, Impact testing, Tensile testing and Hardness testing.

On a scale of 1 to 5 with $1=$ very well prepared and $5=$ very poorly prepared

2. Fatigue, Impact, Tensile, and Hardness Testing

a). Can you define the specific process of the listed materials tests?

b). Do you understand the importance of these tests in evaluating material properties?

c). Do you feel you could choose a particular test for a specific design situation?

d). Can you communicate the process and capabilities of these tests to someone else?

Rate your level of understanding, preparedness, and ability to converse on the subjects of

Precipitation Hardening and Heat Treatment of Steel.

On a scale of 1 to 5 with $1=$ very well prepared and $5=$ very poorly prepared

3. Precipitation Hardening and Heat Treatment of Steel

a). Can you define the processes of Precipitation Hardening and Heat Treatment of Steel?

b). Can you list the material properties effected by these two material treatments?

c). Can you place the location of the process in the step-by-step manufacture of a product?

d). Do you know the materials that these processes can be applied to?

e). Can you communicate your knowledge of the process and its capabilities to someone else?

f). Do you feel you could suggest one of these processes for a

particular design situation? 
Rate your level of understanding, preparedness, and ability to converse on the subject of Manual Machining.

On a scale of 1 to 5 with $1=$ very well prepared and $5=$ very poorly prepared

4. Manual Machining

a). Can you detail the steps involved in the process of manual machining?

b). Can you weigh the capabilities and limitations in the process of manual machining?

c). Can you recognize the necessity of this process in the manufacture of a particular product?

d). Can you communicate effectively in the terminology of this process?

e). Do you understand the placement of this process in the evolution of a product design?

f). Can you communicate the specifics of this process to a co-worker?

Rate your level of understanding, preparedness, and ability to converse on the subject of CNC Machining.

On a scale of 1 to 5 with $1=$ very well prepared and $5=$ very poorly prepared

\begin{tabular}{|l|r|r|r|r|r|}
\hline 5. CNC Machining & 1 & 2 & 3 & 4 & 5 \\
\hline
\end{tabular}

a). Can you detail the steps involved in the process of CNC machining?

b). Can you weigh the capabilities and limitations in the process of CNC machining?

c). Can you recognize the necessity of this process in the manufacture of a particular product?

d). Can you communicate effectively in the terminology of this process?

e). Do you understand the placement of this process in the evolution of a product design?

f). Can you communicate the specifics of this process to a co-worker?

Rate your level of understanding, preparedness, and ability to converse on the subject of Casting. On a scale of 1 to 5 with $\mathbf{1}=$ very well prepared and $\mathbf{5}=$ very poorly prepared

\begin{tabular}{|l|l|l|l|l|l|}
\hline 6. Casting & $\mathbf{1}$ & $\mathbf{2}$ & $\mathbf{3}$ & $\mathbf{4}$ & $\mathbf{5}$ \\
\hline a). Can you detail the steps involved in the process of casting? & & & & & \\
\hline $\begin{array}{l}\text { b). Can you weigh the capabilities and limitations in the process of } \\
\text { casting? }\end{array}$ & & & & \\
\hline $\begin{array}{l}\text { c). Can you recognize the necessity of this process in the manufacture } \\
\text { of a particular product? }\end{array}$ & & & & \\
\hline $\begin{array}{l}\text { d). Can you communicate effectively in the terminology of this } \\
\text { process? }\end{array}$ & & & & & \\
\hline $\begin{array}{l}\text { e). Do you understand the placement of this process in the evolution of } \\
\text { a product design? }\end{array}$ & & & & \\
\hline \begin{tabular}{l} 
f). Can you communicate the specifics of this process to a co-worker? \\
\hline
\end{tabular} & & & & \\
\hline
\end{tabular}


Rate your level of understanding, preparedness, and ability to converse on the subject of Welding. On a scale of 1 to 5 with $1=$ very well prepared and $\mathbf{5}=$ very poorly prepared

\section{Welding}

a). Can you detail the steps involved in the process of welding?

b). Can you weigh the capabilities and limitations in the process of welding?

c). Can you recognize the necessity of this process in the manufacture of a particular product?

d). Can you communicate effectively in the terminology of this process?

e). Do you understand the placement of this process in the evolution of a product design?

f). Can you communicate the specifics of this process to a co-worker?

\begin{tabular}{|l|l|l|l|l|l|}
\hline & 1 & 2 & 3 & 4 & 5 \\
\hline & & & & & \\
\hline & & & & & \\
\hline & & & & & \\
\hline
\end{tabular}

Rate your level of understanding, preparedness, and ability to converse on the subject of Injection Molding.

On a scale of 1 to 5 with $1=$ very well prepared and $5=$ very poorly prepared

8. Injection Molding

a). Can you detail the steps involved in the process of injection molding?

b). Can you weigh the capabilities and limitations in the process of injection molding?

c). Can you recognize the necessity of this process in the manufacture of a particular product?

d). Can you communicate effectively in the terminology of this process?

e). Do you understand the placement of this process in the evolution of a product design?

f). Can you communicate the specifics of this process to a co-worker?

\begin{tabular}{|l|l|l|l|l|l|}
\hline & 1 & 2 & 3 & 4 & 5 \\
\hline & & & & & \\
\hline & & & & & \\
\hline & & & & & \\
\hline
\end{tabular}

Rate your level of understanding, preparedness, and ability to converse on the subject of Rapid Prototyping.

On a scale of 1 to 5 with $1=$ very well prepared and $5=$ very poorly prepared

9. Rapid Prototyping

a). Can you detail the steps involved in the process of Rapid Prototyping?

b). Can you weigh the capabilities and limitations in the process of Rapid Prototyping?

c). Can you recognize the necessity of this process in the manufacture of a particular product?

d). Can you communicate effectively in the terminology of this process?

e). Do you understand the placement of this process in the evolution of a product design?

f). Can you communicate the specifics of this process to a co-worker? g). Do you understand the effect of Rapid Prototyping on the speed of product development? 
Rate your level of understanding, preparedness, and ability to converse on the subject of Metallography.

\begin{tabular}{|c|c|c|c|c|c|}
\hline 10. Metallography & 1 & 2 & 3 & 4 & 5 \\
\hline a). Can you define the purpose and function of Metallography? & & & & & \\
\hline b). Can you list the capabilities of this process? & & & & & \\
\hline $\begin{array}{l}\text { c). Can you recognize the necessity of this process in the manufactu } \\
\text { of a particular product? }\end{array}$ & & & & & \\
\hline $\begin{array}{l}\text { d). Can you communicate effectively the value and purpose of this } \\
\text { process to someone else? }\end{array}$ & & & & & \\
\hline $\begin{array}{l}\text { e). Do you understand the function of this process in quality control } \\
\text { and failure diagnosis? }\end{array}$ & & & & & \\
\hline
\end{tabular}

Rate your level of interest and enthusiasm for this course.

On a scale of 1 to 5 with $1=$ very interested and $5=$ not very interested

\begin{tabular}{|l|r|r|r|r|r|}
\hline 11. The project & 1 & $\mathbf{2}$ & $\mathbf{3}$ & $\mathbf{4}$ & $\mathbf{5}$ \\
\hline a). Rate your overall interest in the lab course & & & & & \\
\hline b). Rate your interest in the cannon project & & & & & \\
\hline
\end{tabular}

For the following questions answer yes or no

12. Do you feel the project was effectively integrated in the course format?

13. Do you feel that the project resulted in more effort on your part?

14. Will it help you as an engineer to have manufactured and tested the cannon?

15. Do you feel that the experience provided by this lab is of sufficient value that

the format should be continued

16. These questions cannot be all encompassing. Please write a few short sentences about your overall impression of the new course. 


\section{APPENDIX D}

\section{OPEN ENDED QUALITATIVE ESSAYS}




\section{Open-Ended Qualitative Essay 1}

Name:

\section{Problem Statement:}

You have been given the task of selecting a material for a petrochemical pipeline that will be installed in Alaska. The pipeline will operate at temperature extremes of $-40^{\circ} \mathrm{F}$ to well above $212^{\circ} \mathrm{F}$. The pipeline will also be subject to pressures from atmospheric to $2000 \mathrm{psi}$. These pressures and temperatures will fluctuate throughout installation and operation.

\section{Questions:}

1. Given the preceding information, list the different mechanical properties of materials that must be taken into account for such an application. Explain what each property you listed quantifies.

2. You have listed a number of mechanical properties of materials. List the corresponding test, which is used to determine each particular property.

3. Given your list of properties select two properties, which you feel would be most important for material selection in this application and explain why you selected them. 
4. How would you use these properties to determine the suitability of a particular material or class of materials.

5. Materials are commonly broken into three groups: metals, polymers, and ceramics. Using your background in materials, select a particular group of materials to fulfill this application. Explain your reasoning by addressing how your particular class of material is superior in this application to the other two classes.

6. What sources of information would you address to finally select a specific material for this application.

7. Are there any potential material properties that you feel are called for in this application, but were not clearly indicated by the problem statement. Why are these properties important. 


\section{Open-Ended Qualitative Essay 2}

Name:

\section{Background:}

Automobile wheels have been built from a variety of materials through the years, but all wheels seem to serve the same functional requirements.

\section{Questions:}

8. List what you believe are the functional requirements of an automotive wheel. For each function list the material property that applies

9. The given list is representative of a number of materials that have been chosen for use as wheel materials through the preceding century. Select one material you might use for an automobile wheel. How does the material you chose meet the functional requirements of a wheel. Beyond just the listed functional requirements, what other properties make your selection superior. Explain the importance of these properties.

10. Pick a material from the list and explain why it is not suitable for use as an automobile wheel. 
11. I need to manufacturer eight wheels. What manufacturing process is suitable for this task? Explain your reasoning for choosing this process. Is your selected material suitable for this process? Explain why your material is suitable or why it is not.

12. I need to manufacture 1000 wheels. What manufacturing process is suitable for this task. Explain your reasoning for choosing this process. Is your selected material suitable for this process. Explain why your material is suitable or why it is not.

13. I need to manufacture 1000000 wheels. What manufacturing process is suitable for this task. Explain your reasoning for choosing this process. Is your selected material suitable for this process. Explain why your material is suitable or why it is not. 
14. Select an alternate material either from the list or from your experience and develop a situation where this alternate material might be more suitable than the material you selected in \#2.

15. Are there any potential material properties that you feel are called for in this application, but were not clearly indicated by the problem statement. Why are these properties important.

Materials List

\begin{tabular}{|c|c|c|c|c|c|c|c|c|c|}
\hline & & $\begin{array}{l}\text { Young's } \\
\text { Modulus }\end{array}$ & \begin{tabular}{|l} 
Yied \\
Strength \\
\end{tabular} & $\begin{array}{l}\text { Ultimate } \\
\text { Strength } \\
\end{array}$ & $\%$ Elongation & $\begin{array}{l}\text { Endurance } \\
\text { Limit }\end{array}$ & \begin{tabular}{|l|} 
Fracture \\
Toughness \\
\end{tabular} & Density & Price \\
\hline Material & & $10^{\wedge} 6 \mathrm{psi}$ & ksi & ksi & & ksi & ksi.in^1/2 & $\mathrm{lb} / \mathrm{in}^{\wedge} 3$ & USD/lb \\
\hline & & & & & & & & & \\
\hline 6061-T6 & Aluminum & 9.427 & 27.99 & 34.95 & 5 & 13.05 & 30.03 & 0.0965 & 0.4963 \\
\hline A356-T6 & Aluminum & 10.2 & 22.05 & 32.05 & 2 & 8.702 & 16.38 & 0.0965 & \begin{tabular}{|l|}
0.8074 \\
\end{tabular} \\
\hline \begin{tabular}{|l|} 
Hickory \\
\end{tabular} & wood & 0.2611 & 10.47 & 20.56 & 2.02 & 6.628 & 8.372 & 0.0332 & 1.324 \\
\hline \multicolumn{2}{|c|}{ Carbon fibre and epoxy composite } & 6.42 & 65.22 & 65.22 & 0.84 & 35.87 & 5.57 & 0.06 & 25.65 \\
\hline Cast Iron & & 12.76 & 26.83 & 40.61 & 3.00 & 18.85 & 32.76 & 0.27 & 0.30 \\
\hline ZC71A-T6 & Magnesium & 6.24 & 44.96 & 48.59 & 4.00 & 25.38 & 14.56 & 0.07 & 1.85 \\
\hline 1020 & Steel & 25.38 & 52.94 & 72.52 & 43.00 & 38.29 & 61.88 & 0.29 & 0.30 \\
\hline
\end{tabular}


APPENDIX E ESSAY RUBRICS 


\section{Rubric Essay 1}

\section{Evaluation Rubric for MEEN-360, Fall 2002, Quiz 1}

Given:

You have been given the task of selecting a material for a petrochemical pipeline that will be installed in Alaska. The pipeline will operate at temperature extremes of $-40 \mathrm{oF}$ to well above $212 \mathrm{oF}$. The pipeline will also be subject to pressures from atmospheric to $2000 \mathrm{psi}$. These pressures and temperatures will fluctuate throughout installation and operation.

Question 1:

Given the preceding information, list the different mechanical properties of materials that must be taken into account for such an application. Explain what each property you listed quantifies.

\begin{tabular}{|c|c|c|c|c|c|}
\hline Criteria & $\begin{array}{c}\text { Beginning } \\
1\end{array}$ & $\begin{array}{c}\text { Developing } \\
2\end{array}$ & $\begin{array}{c}\text { Accomplished } \\
3\end{array}$ & $\begin{array}{c}\text { Exemplary } \\
4\end{array}$ & Score \\
\hline $\begin{array}{l}\text { List mechanical } \\
\text { properties that are } \\
\text { required in the design } \\
\text { of the pipeline. }\end{array}$ & $\begin{array}{l}\text { Important mechanical } \\
\text { properties are } \\
\text { neglected and the } \\
\text { majority of properties } \\
\text { listed occupy other } \\
\text { categories. }\end{array}$ & $\begin{array}{l}\text { At least one of: yield } \\
\text { strength and fracture } \\
\text { toughness must be } \\
\text { listed with additional } \\
\text { properties. }\end{array}$ & $\begin{array}{l}\text { At least four important } \\
\text { mechanical properties } \\
\text { should be listed with } \\
\text { two of: yield strength, } \\
\text { fracture toughness, or } \\
\text { fatigue strength. }\end{array}$ & $\begin{array}{l}\text { Five important mechanical } \\
\text { properties should be } \\
\text { listed:yield strength, fracture } \\
\text { toughness, ultimate tensile } \\
\text { strength, fatigue strength, } \\
\text { creep resistance, or DBTT. }\end{array}$ & \\
\hline $\begin{array}{l}\text { Explain what each } \\
\text { property you listed } \\
\text { quantifies. }\end{array}$ & $\begin{array}{l}\text { Properties are } \\
\text { incorrectly defined, or } \\
\text { undefined }\end{array}$ & $\begin{array}{l}\text { Properties are defined } \\
\text { poorly }\end{array}$ & $\begin{array}{l}\text { Properties are defined } \\
\text { correctly without } \\
\text { reference to proper } \\
\text { design criteria. }\end{array}$ & $\begin{array}{l}\text { Each property is defined } \\
\text { correctly with relation to proper } \\
\text { design criteria. }\end{array}$ & \\
\hline
\end{tabular}

Question 2:

You have listed a number of mechanical properties of materials. List the corresponding test, which is used to determine each particular property.

\begin{tabular}{|c|c|c|c|c|c|}
\hline Criteria & $\begin{array}{c}\text { Beginning } \\
1\end{array}$ & $\begin{array}{l}\text { Developing } \\
2\end{array}$ & $\begin{array}{c}\text { Accomplished } \\
3\end{array}$ & $\begin{array}{c}\text { Exemplary } \\
4\end{array}$ & Score \\
\hline $\begin{array}{l}\text { List the tests used to } \\
\text { determine the } \\
\text { mechanical } \\
\text { properties. }\end{array}$ & $\begin{array}{l}\text { Fails to correctly list } \\
\text { even common tests. }\end{array}$ & $\begin{array}{l}\text { Only a portion of the } \\
\text { tests are correctly } \\
\text { listed and named. }\end{array}$ & $\begin{array}{l}\text { All tests are listed but } \\
\text { some are named with } \\
\text { the incorrect } \\
\text { terminology. }\end{array}$ & $\begin{array}{l}\text { All tests are correctly named } \\
\text { and matched to the } \\
\text { corresponding properties, with } \\
\text { descriptions of the tests } \\
\text { outside of course content }\end{array}$ & \\
\hline
\end{tabular}

Question 3:

Given your list of properties select two properties, which you feel would be most

important for material selection in this application and explain why you selected them.

\begin{tabular}{|c|c|c|c|c|c|}
\hline Criteria & $\begin{array}{c}\text { Beginning } \\
1\end{array}$ & $\begin{array}{l}\text { Developing } \\
2\end{array}$ & $\begin{array}{c}\text { Accomplished } \\
3\end{array}$ & $\begin{array}{c}\text { Exemplary } \\
4\end{array}$ & Score \\
\hline $\begin{array}{l}\text { Select two properties } \\
\text { which you feel would } \\
\text { be most important }\end{array}$ & \begin{tabular}{|l|} 
selected no \\
mechanical properties \\
which can be used for \\
failsafe design based \\
on the given criteria.
\end{tabular} & $\begin{array}{l}\text { Selected properties } \\
\text { which can be used for } \\
\text { failsafe design based } \\
\text { on the given criteria. }\end{array}$ & \begin{tabular}{|l|} 
Selected at least one \\
yield strength, fracture \\
toughness, or fatigue \\
strength and one \\
other, both of which \\
could be used for \\
failure analysis.
\end{tabular} & $\begin{array}{l}\text { Selected two of yield strength, } \\
\text { fracture toughness, and fatigue } \\
\text { strength }\end{array}$ & \\
\hline $\begin{array}{l}\text { Explain what each } \\
\text { property you listed } \\
\text { quantifies. }\end{array}$ & \begin{tabular}{|l|}
$\begin{array}{l}\text { Fails to relate selected } \\
\text { properties to design } \\
\text { methodologies. }\end{array}$ \\
\end{tabular} & $\begin{array}{l}\text { Outlines potentially } \\
\text { useful design } \\
\text { methodology, but not } \\
\text { the best. }\end{array}$ & $\begin{array}{l}\text { Uses a design criteria } \\
\text { comparison in at least } \\
\text { one case and some } \\
\text { other acceptable } \\
\text { explanation in the } \\
\text { second. }\end{array}$ & $\begin{array}{l}\text { Correctly outlines the } \\
\text { methodology by which the two } \\
\text { selected parameter could be } \\
\text { used for design based on } \\
\text { given criteria. }\end{array}$ & \\
\hline
\end{tabular}


Question 4:

How would you use these properties to determine the suitability of a particular material or class of materials.

Analysis:
\begin{tabular}{|l|l|l|l|l|l|}
\hline \multicolumn{1}{|c|}{ Criteria } & \multicolumn{1}{|c|}{ Beginning } & \multicolumn{1}{c|}{ Developing } & \multicolumn{1}{c|}{ Accomplished } & \multicolumn{1}{c|}{ Exemplary } & \multicolumn{1}{c|}{ Score } \\
\hline $\begin{array}{l}\text { propose methodology } \\
\text { for selecting the } \\
\text { correct group of } \\
\text { materials given } \\
\text { previous properties. }\end{array}$ & $\begin{array}{l}\text { Fails to establish a } \\
\text { clear easy to follow } \\
\text { method by which the } \\
\text { properties of one set } \\
\text { of materials can be } \\
\text { weighed against the } \\
\text { next. }\end{array}$ & $\begin{array}{l}\text { Proposes limited and } \\
\text { poorly defined process } \\
\text { without methodology } \\
\text { of comparison to } \\
\text { determine selection. }\end{array}$ & $\begin{array}{l}\text { Proposes a logical } \\
\text { process of selection } \\
\text { without methodology } \\
\text { of comparison. }\end{array}$ & $\begin{array}{l}\text { Establishes a clearly defined, } \\
\text { functional, method of } \\
\text { comparison by which materials } \\
\text { maybe evaluated. }\end{array}$ & \\
& & & & \\
\hline
\end{tabular}

Question 5:

Materials are commonly broken into three groups: metals, polymer, and ceramics.

Using your background in materials, select a particular group of materials to fulfill this application. Explain your reasoning by addressing how your particular class of material is superior in this application to the other two classes.

\begin{tabular}{|c|c|c|c|c|c|}
\hline Criteria & $\begin{array}{c}\text { Beginning } \\
1\end{array}$ & $\begin{array}{l}\text { Developing } \\
2\end{array}$ & $\begin{array}{l}\text { Accomplished } \\
3\end{array}$ & $\begin{array}{c}\text { Exemplary } \\
4\end{array}$ & Score \\
\hline $\begin{array}{l}\text { Select a group of } \\
\text { Materials } \\
\end{array}$ & \begin{tabular}{|l} 
Failed to select a \\
group of materials
\end{tabular} & & & Selected a group of materials & \\
\hline $\begin{array}{l}\text { Explain what each } \\
\text { property you listed } \\
\text { quantifies. }\end{array}$ & $\begin{array}{l}\text { Fails to correctly relate } \\
\text { the differences in } \\
\text { properties between } \\
\text { the three classes of } \\
\text { materials or present } \\
\text { suitable methodology } \\
\text { of selection. }\end{array}$ & $\begin{array}{l}\text { Properties are not } \\
\text { correctly identified and } \\
\text { methodology is not } \\
\text { evidenced. }\end{array}$ & \begin{tabular}{|l|} 
Property differences \\
are not necessarily \\
identified correctly, but \\
methodology of \\
selection is sound, or \\
the opposite is true.
\end{tabular} & $\begin{array}{l}\text { Correctly identifies the } \\
\text { differences in properties } \\
\text { between material groups and } \\
\text { effectively weighs them to } \\
\text { select a particular class. }\end{array}$ & \\
\hline
\end{tabular}

Question 6:

What sources of information would you address to finally select a specific material for this application.

\begin{tabular}{|c|c|c|c|c|c|}
\hline Criteria & $\begin{array}{c}\text { Beginning } \\
1\end{array}$ & $\begin{array}{l}\text { Developing } \\
2\end{array}$ & $\begin{array}{c}\text { Accomplished } \\
3\end{array}$ & $\begin{array}{c}\text { Exemplary } \\
4\end{array}$ & Score \\
\hline $\begin{array}{l}\text { List available material } \\
\text { information sources. }\end{array}$ & $\begin{array}{l}\text { Fails to list any } \\
\text { sources. }\end{array}$ & $\begin{array}{l}\text { Lists only non- } \\
\text { professional non- } \\
\text { specific sources such } \\
\text { as textbooks and the } \\
\text { internet. }\end{array}$ & $\begin{array}{l}\text { Lists at least one } \\
\text { specific and or a } \\
\text { variety of non-specific } \\
\text { resources. }\end{array}$ & \begin{tabular}{|l|} 
Lists 3 specific: Standards \\
organizations, Software, \\
textbooks, internet, \\
experienced professionals, and \\
manufacturers.
\end{tabular} & \\
\hline
\end{tabular}

Question 7:

Are there any potential material properties that you feel are called for in this application,

but were not clearly indicated by the problem statement. Why are these properties important?

\begin{tabular}{|c|c|c|c|c|c|}
\hline Criteria & $\begin{array}{c}\text { Beginning } \\
1\end{array}$ & $\begin{array}{l}\text { Developing } \\
2\end{array}$ & $\begin{array}{c}\text { Accomplished } \\
3\end{array}$ & $\begin{array}{c}\text { Exemplary } \\
4\end{array}$ & Score \\
\hline \begin{tabular}{|l|} 
List important non- \\
mechanical properties
\end{tabular} & $\begin{array}{l}\text { Lists no additional } \\
\text { properties or lists } \\
\text { properties that should } \\
\text { have been addressed } \\
\text { in the previous } \\
\text { sections. } \\
\end{array}$ & \begin{tabular}{|l|} 
Lists a variety of \\
properties specific and \\
unspecific, but not \\
germane to the \\
question.
\end{tabular} & \begin{tabular}{|l|} 
Lists important but \\
non-specific properties \\
ex. Corrosion, Cost \\
etc.
\end{tabular} & $\begin{array}{l}\text { Lists a variety of specific } \\
\text { important non-mechanical } \\
\text { properties ex. Material Cost, } \\
\text { Atmospheric Corrosion } \\
\text { Resistance, Coefficient of } \\
\text { Thermal Expansion, etc. } \\
\end{array}$ & \\
\hline $\begin{array}{l}\text { Importance of } \\
\text { properties? }\end{array}$ & $\begin{array}{l}\text { No explanation is } \\
\text { provided or the } \\
\text { explanation provided } \\
\text { is scientifically } \\
\text { implausible }\end{array}$ & $\begin{array}{l}\text { Provides poorly } \\
\text { defined analysis with } \\
\text { wrong or no design } \\
\text { criteria. }\end{array}$ & $\begin{array}{l}\text { Explains alternate } \\
\text { design methodology } \\
\text { without reference to } \\
\text { specific criteria. }\end{array}$ & $\begin{array}{l}\text { Clear explanation of the } \\
\text { importance of the property as } \\
\text { related to potential design } \\
\text { criteria }\end{array}$ & \\
\hline
\end{tabular}




\section{Rubric Essay 2}

\section{Evaluation Rubric for MEEN-360, Fall 2002, Quiz 2}

Given:

Automobile wheels have been built from a variety of materials through the years, but all wheels seem to serve the same functional requirements.

Question 1:

List what you believe are the functional requirements of an automotive wheel.

For each function list the material property that applies.

Analysis:
\begin{tabular}{|l|l|l|l|l|l|}
\hline \multicolumn{1}{|c|}{ Criteria } & \multicolumn{1}{|c|}{$\begin{array}{c}\text { Beginning } \\
1\end{array}$} & \multicolumn{1}{c|}{ Developing } & \multicolumn{1}{c|}{ Accomplished } & \multicolumn{1}{c|}{ Exemplary } & \multicolumn{1}{c|}{ Score } \\
\hline $\begin{array}{l}\text { List what you believe } \\
\text { are the functional } \\
\text { requirements of an } \\
\text { automotive wheel. }\end{array}$ & $\begin{array}{l}\text { No functions or wrong } \\
\text { functions }\end{array}$ & $\begin{array}{l}\text { Functional } \\
\text { requirements listed } \\
\text { are general and non- } \\
\text { specific in nature. }\end{array}$ & $\begin{array}{l}\text { Lists a number of specific } \\
\text { functional requirements } \\
\text { without one being: } \\
\text { transmit load. }\end{array}$ & $\begin{array}{l}\text { lists a number of specific } \\
\text { one of which must be: } \\
\text { transmit load. }\end{array}$ & \\
\hline $\begin{array}{l}\text { For each function list } \\
\text { the material property } \\
\text { that applies. }\end{array}$ & $\begin{array}{l}\text { No properties listed or } \\
\text { the properties listed } \\
\text { are wrong. }\end{array}$ & $\begin{array}{l}\text { Poor matching and } \\
\text { naming of properties. }\end{array}$ & $\begin{array}{l}\text { Correct properties are } \\
\text { matched to each } \\
\text { function. }\end{array}$ & $\begin{array}{l}\text { Correct properties are } \\
\text { matched to each function, } \\
\text { preferable more than one. }\end{array}$ & \\
\hline
\end{tabular}

Question 2:

The given list is representative of a number of materials that have been chosen for use as wheel materials through the preceding century. Select one material you might use for an automobile wheel. How does the material you chose meet the functional requirements of a wheel. Beyond just the listed functional requirements, what other properties make your selection superior. Explain the importance of these properties.

\begin{tabular}{|c|c|c|c|c|c|}
\hline Criteria & $\begin{array}{c}\text { Beginning } \\
1 \\
\end{array}$ & $\begin{array}{c}\text { Developing } \\
2 \\
\end{array}$ & $\begin{array}{c}\text { Accomplished } \\
3 \\
\end{array}$ & \begin{tabular}{|c|} 
Exemplary \\
4 \\
\end{tabular} & Score \\
\hline $\begin{array}{l}\text { Select one material } \\
\text { you might use for an } \\
\text { automobile wheel. }\end{array}$ & no material selected & & & material selected & \\
\hline $\begin{array}{l}\text { How does the } \\
\text { material you chose } \\
\text { meet the functional } \\
\text { requirements of a } \\
\text { wheel. }\end{array}$ & $\begin{array}{l}\text { None or incorrect } \\
\text { relation of properties } \\
\text { to functions. }\end{array}$ & \begin{tabular}{|l|} 
Poorly relates material \\
properties to \\
functional \\
requirements.
\end{tabular} & $\begin{array}{l}\text { Makes general reference } \\
\text { to satisfaction of } \\
\text { functions. }\end{array}$ & $\begin{array}{l}\text { Names specific properties } \\
\text { as related to listed } \\
\text { functions. }\end{array}$ & \\
\hline $\begin{array}{l}\text { Other properties that } \\
\text { make the selection } \\
\text { superior. }\end{array}$ & $\begin{array}{l}\text { No properties or the } \\
\text { properties referenced } \\
\text { are incorrect. }\end{array}$ & $\begin{array}{l}\text { Poor correlation } \\
\text { between selected } \\
\text { properties and } \\
\text { application. } \\
\end{array}$ & $\begin{array}{l}\text { General reference to } \\
\text { properties. }\end{array}$ & $\begin{array}{l}\text { Names specific properties } \\
\text { of the material that make it } \\
\text { superior. }\end{array}$ & \\
\hline $\begin{array}{l}\text { Explain the } \\
\text { importance of these } \\
\text { properties. }\end{array}$ & $\begin{array}{l}\text { The importance of the } \\
\text { property is not } \\
\text { explained or the } \\
\text { explanation is wrong. }\end{array}$ & \begin{tabular}{|l|} 
Selected some \\
appropriate but not the \\
best methodology.
\end{tabular} & $\begin{array}{l}\text { Makes limited use of } \\
\text { proper design criteria. }\end{array}$ & $\begin{array}{l}\text { Explains the importance of } \\
\text { the property by relating it to } \\
\text { specific design criteria. }\end{array}$ & \\
\hline
\end{tabular}

Question 3:

Pick a material from the list and explain why it is not suitable for use as an automotive wheel.

Analysis:
\begin{tabular}{|l|l|l|l|l|l|}
\hline \multicolumn{1}{|c|}{ Criteria } & \multicolumn{1}{|c|}{$\begin{array}{c}\text { Beginning } \\
1\end{array}$} & \multicolumn{1}{c|}{$\begin{array}{c}\text { Developing } \\
2\end{array}$} & \multicolumn{1}{c|}{$\begin{array}{c}\text { Accomplished } \\
3\end{array}$} & \multicolumn{1}{c|}{$\begin{array}{c}\text { Exemplary } \\
4\end{array}$} & Score \\
\hline $\begin{array}{l}\text { Pick a material from } \\
\text { the list. }\end{array}$ & $\begin{array}{l}\text { No Material is } \\
\text { Selected. }\end{array}$ & & Material Selected. & \\
\hline $\begin{array}{l}\text { Explain why it is not } \\
\text { suitable for use as an } \\
\text { automotive wheel }\end{array}$ & $\begin{array}{l}\text { No explanation is } \\
\text { made or the } \\
\text { explanation presented } \\
\text { is wrong. }\end{array}$ & $\begin{array}{l}\text { Makes general } \\
\text { commentary, without } \\
\text { comparison, and } \\
\text { displays poor } \\
\text { reasoning. }\end{array}$ & $\begin{array}{l}\text { Selection is good and } \\
\text { proper reasoning is } \\
\text { evident, but properties } \\
\text { are not related well to } \\
\text { proper design criteria. }\end{array}$ & $\begin{array}{l}\text { Names specific properties } \\
\text { related to functional needs } \\
\text { which display how the } \\
\text { material will not work. }\end{array}$ & . \\
\hline
\end{tabular}


Question 4:

I need to manufacturer eight wheels. What manufacturing process is suitable for this task. Explain your reasoning for choosing this process. Is your selected material suitable for this process. Explain why your material is suitable or why it is not.

\begin{tabular}{|c|c|c|c|c|c|}
\hline Criteria & $\begin{array}{c}\text { Beginning } \\
1\end{array}$ & $\begin{array}{c}\text { Developing } \\
2\end{array}$ & $\begin{array}{c}\text { Accomplished } \\
3\end{array}$ & $\begin{array}{c}\text { Exemplary } \\
4\end{array}$ & Score \\
\hline $\begin{array}{l}\text { What manufacturing } \\
\text { process is suitable for } \\
\text { this task? }\end{array}$ & $\begin{array}{l}\text { No process is selected } \\
\text { of the wrong process } \\
\text { is selected. }\end{array}$ & $\begin{array}{l}\text { Poorly describes the } \\
\text { applicable process. }\end{array}$ & $\begin{array}{l}\text { Names the process in } \\
\text { general terms ex. } \\
\text { Casting. }\end{array}$ & $\begin{array}{l}\text { Names the process in } \\
\text { specific terms ex. Sand } \\
\text { Casting. }\end{array}$ & \\
\hline $\begin{array}{l}\text { Explain your } \\
\text { reasoning for } \\
\text { choosing this process. }\end{array}$ & $\begin{array}{l}\text { The explanation is non } \\
\text { existent or blatantly } \\
\text { incorrect. }\end{array}$ & $\begin{array}{l}\text { The process } \\
\text { description is limited } \\
\text { and fails to completely } \\
\text { answer the question. }\end{array}$ & $\begin{array}{l}\text { Indicates general details } \\
\text { of the process which lend } \\
\text { itself to manufacture. }\end{array}$ & $\begin{array}{l}\text { Indicates specific details of } \\
\text { the process which lend } \\
\text { itself to manufacture. }\end{array}$ & \\
\hline $\begin{array}{l}\text { Is your selected } \\
\text { material suitable for } \\
\text { this process. }\end{array}$ & $\begin{array}{l}\text { incorrectly identifies } \\
\text { the suitability of the } \\
\text { selected material. }\end{array}$ & & & $\begin{array}{l}\text { correctly identifies the } \\
\text { suitability of the selected } \\
\text { material. }\end{array}$ & \\
\hline $\begin{array}{l}\text { Explain why your } \\
\text { material is suitable or } \\
\text { why it is not. }\end{array}$ & $\begin{array}{l}\text { no explanation given } \\
\text { or the explanation } \\
\text { given is wrong. }\end{array}$ & $\begin{array}{l}\text { limited and or poor } \\
\text { explanation. }\end{array}$ & $\begin{array}{l}\text { Makes suitable } \\
\text { explanation which lacks } \\
\text { detail. }\end{array}$ & $\begin{array}{l}\text { Indicates specific material } \\
\text { properties or } \\
\text { characteristics which } \\
\text { demonstrate suitability. }\end{array}$ & \\
\hline
\end{tabular}

Question 5:

I need to manufacture 1000 wheels. What manufacturing process is suitable for this task. Explain your reasoning for choosing this process. Is your selected material suitable for this process. Explain why your material is suitable or why it is not.

\begin{tabular}{|c|c|c|c|c|c|}
\hline Criteria & $\begin{array}{c}\text { Beginning } \\
1\end{array}$ & $\begin{array}{c}\text { Developing } \\
2\end{array}$ & $\begin{array}{c}\text { Accomplished } \\
3\end{array}$ & $\begin{array}{c}\text { Exemplary } \\
4\end{array}$ & Score \\
\hline $\begin{array}{l}\text { What manufacturing } \\
\text { process is suitable for } \\
\text { this task? }\end{array}$ & $\begin{array}{l}\text { No process is selected } \\
\text { of the wrong process } \\
\text { is selected. }\end{array}$ & $\begin{array}{l}\text { Poorly describes the } \\
\text { applicable process. }\end{array}$ & $\begin{array}{l}\text { Names the process in } \\
\text { general terms ex. } \\
\text { Casting. }\end{array}$ & $\begin{array}{l}\text { Names the process in } \\
\text { specific terms ex. Sand } \\
\text { Casting. }\end{array}$ & \\
\hline $\begin{array}{l}\text { Explain your } \\
\text { reasoning for } \\
\text { choosing this process. }\end{array}$ & $\begin{array}{l}\text { The explanation is non } \\
\text { existent or blatantly } \\
\text { incorrect. }\end{array}$ & $\begin{array}{l}\text { The process } \\
\text { description is limited } \\
\text { and fails to completely } \\
\text { answer the question. }\end{array}$ & $\begin{array}{l}\text { Indicates general details } \\
\text { of the process which lend } \\
\text { itself to manufacture. }\end{array}$ & $\begin{array}{l}\text { Indicates specific details of } \\
\text { the process which lend } \\
\text { itself to manufacture. }\end{array}$ & \\
\hline $\begin{array}{l}\text { Is your selected } \\
\text { material suitable for } \\
\text { this process. }\end{array}$ & $\begin{array}{l}\text { incorrectly identifies } \\
\text { the suitability of the } \\
\text { selected material. }\end{array}$ & & & $\begin{array}{l}\text { correctly identifies the } \\
\text { suitability of the selected } \\
\text { material. }\end{array}$ & \\
\hline $\begin{array}{l}\text { Explain why your } \\
\text { material is suitable or } \\
\text { why it is not. }\end{array}$ & $\begin{array}{l}\text { no explanation given } \\
\text { or the explanation } \\
\text { given is wrong. }\end{array}$ & $\begin{array}{l}\text { limited and or poor } \\
\text { explanation. }\end{array}$ & $\begin{array}{l}\text { Makes suitable } \\
\text { explanation which lacks } \\
\text { detail. }\end{array}$ & $\begin{array}{l}\text { Indicates specific material } \\
\text { properties or } \\
\text { characteristics which } \\
\text { demonstrate suitability. }\end{array}$ & \\
\hline
\end{tabular}


Question 6:

I need to manufacture 1000000 wheels. What manufacturing process is suitable for this task. Explain your reasoning for choosing this process. Is your selected material suitable for this process. Explain why your material is suitable or why it is not.

\begin{tabular}{|c|c|c|c|c|c|}
\hline Criteria & $\begin{array}{c}\text { Beginning } \\
1\end{array}$ & $\begin{array}{c}\text { Developing } \\
2\end{array}$ & $\begin{array}{c}\text { Accomplished } \\
3\end{array}$ & $\begin{array}{c}\text { Exemplary } \\
4\end{array}$ & Score \\
\hline $\begin{array}{l}\text { What manufacturing } \\
\text { process is suitable for } \\
\text { this task? }\end{array}$ & $\begin{array}{l}\text { No process is selected } \\
\text { of the wrong process } \\
\text { is selected. }\end{array}$ & $\begin{array}{l}\text { Poorly describes the } \\
\text { applicable process. }\end{array}$ & $\begin{array}{l}\text { Names the process in } \\
\text { general terms ex. } \\
\text { Casting. }\end{array}$ & $\begin{array}{l}\text { Names the process in } \\
\text { specific terms ex. Sand } \\
\text { Casting. }\end{array}$ & \\
\hline $\begin{array}{l}\text { Explain your } \\
\text { reasoning for } \\
\text { choosing this process. }\end{array}$ & $\begin{array}{l}\text { The explanation is non } \\
\text { existent or blatantly } \\
\text { incorrect. }\end{array}$ & $\begin{array}{l}\text { The process } \\
\text { description is limited } \\
\text { and fails to completely } \\
\text { answer the question. }\end{array}$ & $\begin{array}{l}\text { Indicates general details } \\
\text { of the process which lend } \\
\text { itself to manufacture. }\end{array}$ & $\begin{array}{l}\text { Indicates specific details of } \\
\text { the process which lend } \\
\text { itself to manufacture. }\end{array}$ & \\
\hline $\begin{array}{l}\text { Is your selected } \\
\text { material suitable for } \\
\text { this process. }\end{array}$ & $\begin{array}{l}\text { incorrectly identifies } \\
\text { the suitability of the } \\
\text { selected material. }\end{array}$ & & & $\begin{array}{l}\text { correctly identifies the } \\
\text { suitability of the selected } \\
\text { material. }\end{array}$ & \\
\hline $\begin{array}{l}\text { Explain why your } \\
\text { material is suitable or } \\
\text { why it is not. }\end{array}$ & $\begin{array}{l}\text { no explanation given } \\
\text { or the explanation } \\
\text { given is wrong. }\end{array}$ & $\begin{array}{l}\text { limited and or poor } \\
\text { explanation. }\end{array}$ & $\begin{array}{l}\text { Makes suitable } \\
\text { explanation which lacks } \\
\text { detail. }\end{array}$ & $\begin{array}{l}\text { Indicates specific material } \\
\text { properties or } \\
\text { characteristics which } \\
\text { demonstrate suitability. }\end{array}$ & \\
\hline
\end{tabular}

Question 7:

Select an alternate material either from the list or from your experience and develop a situation where this alternate material might be more suitable than the material you selected in \#2.

\begin{tabular}{|c|c|c|c|c|c|}
\hline Criteria & $\begin{array}{c}\text { Beginning } \\
1\end{array}$ & $\begin{array}{c}\text { Developing } \\
2\end{array}$ & $\begin{array}{c}\text { Accomplished } \\
3\end{array}$ & $\begin{array}{c}\text { Exemplary } \\
4\end{array}$ & Score \\
\hline $\begin{array}{l}\text { Select an alternate } \\
\text { material either from } \\
\text { the list or from your } \\
\text { experience. }\end{array}$ & $\begin{array}{l}\text { No Material is } \\
\text { Selected. }\end{array}$ & & & Material Selected. & \\
\hline $\begin{array}{l}\text { Develop a situation } \\
\text { where this alternate } \\
\text { material might be } \\
\text { more suitable than the } \\
\text { material you selected } \\
\text { in \#2. }\end{array}$ & \begin{tabular}{|l|} 
Fails to indicate a \\
design situation or \\
incorrectly justifies the \\
use of the material.
\end{tabular} & $\begin{array}{l}\text { Establishes a special } \\
\text { design situation and } \\
\text { selects general } \\
\text { material properties } \\
\text { which indicate } \\
\text { suitability. }\end{array}$ & $\begin{array}{l}\text { Establishes a special } \\
\text { design situation, } \\
\text { develops separate } \\
\text { situation specific } \\
\text { functions, and selects } \\
\text { general material } \\
\text { properties which indicate } \\
\text { suitability. }\end{array}$ & $\begin{array}{l}\text { Establishes a special } \\
\text { design situation, develops } \\
\text { separate situation specific } \\
\text { functions, and selects } \\
\text { specific material properties } \\
\text { which indicate suitability. }\end{array}$ & \\
\hline
\end{tabular}


APPENDIX F

SURVEY RESULTS 


\section{Section 502 Initial Survey Results}

Rate your level of understanding, preparedness, and ability to converse on the subject of Metrology and Tolerance.

On a scale of 1 to 5 with $\mathbf{1}=$ very well prepared and $\mathbf{5}=$ very poorly prepared \# of resp. avg. 1. Metrology and Tolerance

a). Can you define the function of metrology and tolerance in design?

b). Can you identify the criteria necessary to specify a particular dimension or tolerance in design?

c). Can you effectively reverse engineer a product?

d). Do you have the ability to issue a design drawing suitable for manufacture?

e). Can you place the subject of metrology and tolerance in a step-bystep product development?

\begin{tabular}{|l|l|r|r|r|r|}
\hline 1 & 2 & 3 & 4 & 5 \\
\hline & & 1 & 5 & 4 & 2 \\
\hline & & 1 & 7 & 4 & \\
\hline & & 3 & 3 & 5 & 1 \\
\hline & & 1 & 4 & 5 & 2 \\
\hline
\end{tabular}

Rate your level of understanding, preparedness, and ability to converse on the subjects of Fatigue testing, Impact testing, Tensile testing and Hardness testing.

On a scale of 1 to 5 with $\mathbf{1}=$ very well prepared and $\mathbf{5}=$ very poorly prepared \# of resp. avg.

2. Fatigue, Impact, Tensile, and Hardness Testing

a). Can you define the specific process of the listed materials tests?

b). Do you understand the importance of these tests in evaluating material properties?

c). Do you feel you could choose a particular test for a specific design situation?

d). Can you communicate the process and capabilities of these tests

\begin{tabular}{|l|l|r|r|r|}
\hline 1 & 2 & 3 & 4 & 5 \\
\hline 1 & 2 & 2 & 5 & 2 \\
\hline 2 & 4 & 4 & 1 & 1 \\
\hline & 2 & 6 & 3 & 1 \\
\hline & & 5 & 4 & 1 \\
\hline
\end{tabular}

12

to someone else?

Rate your level of understanding, preparedness, and ability to converse on the subjects of Precipitation Hardening and Heat Treatment of Steel.

On a scale of 1 to 5 with $\mathbf{1}=$ very well prepared and $\mathbf{5}=$ very poorly prepared \# of resp. avg.

3. Precipitation Hardening and Heat Treatment of Steel

a). Can you define the processes of Precipitation Hardening and Heat Treatment of Steel?

b). Can you list the material properties effected by these two material treatments?

c). Can you place the location of the process in the step-by-step manufacture of a product?

d). Do you know the materials that these processes can be applied to?

e). Can you communicate your knowledge of the process and its capabilities to someone else?

f). Do you feel you could suggest one of these processes for a particular design situation?

\begin{tabular}{|l|l|l|r|r|r}
\hline 1 & $\mathbf{2}$ & $\mathbf{3}$ & $\mathbf{4}$ & $\mathbf{5}$ \\
\hline & & 1 & 5 & 5 & 1 \\
\hline & & 1 & 4 & 6 & 1 \\
\hline & & 2 & 2 & 7 & 1 \\
\hline & & 2 & 8 & \\
\hline & & 1 & 3 & 7 & 1 \\
\hline
\end{tabular}


Rate your level of understanding, preparedness, and ability to converse on the subject of Manual Machining.

On a scale of 1 to 5 with $1=$ very well prepared and $\mathbf{5}=$ very poorly prepared \# of resp. avg.

4. Manual Machining

a). Can you detail the steps involved in the process of manual machining?

b). Can you weigh the capabilities and limitations in the process of manual machining?

c). Can you recognize the necessity of this process in the manufacture of a particular product?

d). Can you communicate effectively in the terminology of this process?

e). Do you understand the placement of this process in the evolution of a product design?

f). Can you communicate the specifics of this process to a co-worker?

\begin{tabular}{|r|r|r|r|r|r|}
\hline & 1 & 2 & 3 & $\mathbf{4}$ & $\mathbf{5}$ \\
\hline & & 2 & 1 & 5 & 4 \\
\hline & & 1 & 2 & 6 & 3 \\
\hline
\end{tabular}

12

12

12

12

12

Rate your level of understanding, preparedness, and ability to converse on the subject of CNC Machining.

On a scale of 1 to 5 with $1=$ very well prepared and $5=$ very poorly prepared \# of resp. avg.

5. CNC Machining

a). Can you detail the steps involved in the process of CNC machining?

b). Can you weigh the capabilities and limitations in the process of

CNC machining?

c). Can you recognize the necessity of this process in the manufacture of a particular product?

d). Can you communicate effectively in the terminology of this process?

e). Do you understand the placement of this process in the evolution of a product design?

f). Can you communicate the specifics of this process to a co-worker?

\begin{tabular}{|r|r|r|r|r|r|}
\hline & 1 & 2 & 3 & 4 & 5 \\
\hline & & & 2 & 3 & 7 \\
\hline of & & & 2 & 3 & 7 \\
\hline & & & 1 & 2 & 7 \\
\hline & & & 2 & 3 & 7 \\
\hline
\end{tabular}

12

Rate your level of understanding, preparedness, and ability to converse on the subject of Casting.

On a scale of 1 to 5 with $1=$ very well prepared and $\mathbf{5}=$ very poorly prepared \# of resp. avg.

6. Casting

a). Can you detail the steps involved in the process of casting?

b). Can you weigh the capabilities and limitations in the process of casting?

c). Can you recognize the necessity of this process in the manufacture of a particular product?

d). Can you communicate effectively in the terminology of this process?

e). Do you understand the placement of this process in the evolution of a product design?

\begin{tabular}{|r|r|r|r|r|r|}
\hline & 1 & 2 & 3 & 4 & 5 \\
\hline & & 1 & 2 & 4 & 4 \\
\hline & & & 3 & 4 & 5 \\
\hline of & & & 3 & 2 & 5 \\
\hline & & 1 & 2 & 4 & 5 \\
\hline
\end{tabular}


Rate your level of understanding, preparedness, and ability to converse on the subject of Welding.

On a scale of 1 to 5 with $1=$ very well prepared and $5=$ very poorly prepared \# of resp. avg.

7. Welding

a). Can you detail the steps involved in the process of welding?

b). Can you weigh the capabilities and limitations in the process of welding?

c). Can you recognize the necessity of this process in the manufacture

of a particular product?

d). Can you communicate effectively in the terminology of this process?

e). Do you understand the placement of this process in the evolution of a product design?

f). Can you communicate the specifics of this process to a co-worker?

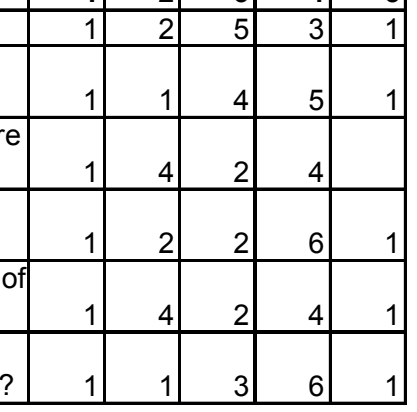

Rate your level of understanding, preparedness, and ability to converse on the subject of Injection Molding.

8. Injection Molding

On a scale of 1 to 5 with $\mathbf{1}=$ very well prepared and $\mathbf{5}=$ very poorly prepared \# of resp. avg.

a). Can you detail the steps involved in the process of injection molding?

b). Can you weigh the capabilities and limitations in the process of injection molding?

c). Can you recognize the necessity of this process in the manufacture of a particular product?

d). Can you communicate effectively in the terminology of this process?

e). Do you understand the placement of this process in the evolution of a product design?

f). Can you communicate the specifics of this process to a co-worker?

\begin{tabular}{|l|l|l|l|r|r|}
\hline & 1 & 2 & 3 & $\mathbf{4}$ & $\mathbf{5}$ \\
\hline & & & & 8 & 4 \\
\hline & & & & 7 & 5 \\
\hline of & & & & 7 & 5 \\
\hline & & & & 6 & 6 \\
\hline
\end{tabular}

Rate your level of understanding, preparedness, and ability to converse on the subject of Rapid Prototyping.

\begin{tabular}{|c|c|c|c|c|c|}
\hline 9. Rapid Prototyping & 1 & 2 & 3 & 4 & 5 \\
\hline $\begin{array}{l}\text { a). Can you detail the steps involved in the process of Rapid } \\
\text { Prototyping? }\end{array}$ & & 1 & 2 & 5 & 4 \\
\hline $\begin{array}{l}\text { b). Can you weigh the capabilities and limitations in the process of } \\
\text { Rapid Prototyping? }\end{array}$ & & 1 & 4 & 2 & \\
\hline $\begin{array}{l}\text { c). Can you recognize the necessity of this process in the manufacture } \\
\text { of a particular product? }\end{array}$ & 1 & 1 & 4 & 1 & 5 \\
\hline $\begin{array}{l}\text { d). Can you communicate effectively in the terminology of this } \\
\text { process? }\end{array}$ & & 1 & 1 & 5 & 5 \\
\hline $\begin{array}{l}\text { e). Do you understand the placement of this process in the evolution of } \\
\text { a product design? }\end{array}$ & & 3 & 4 & 1 & 4 \\
\hline f). Can you communicate the specifics of this process to a co-worker? & & 1 & 2 & 5 & 4 \\
\hline $\begin{array}{l}\text { g). Do you understand the effect of Rapid Prototyping on the speed of } \\
\text { product development? }\end{array}$ & 1 & 2 & 4 & 1 & \\
\hline
\end{tabular}


Rate your level of understanding, preparedness, and ability to converse on the subject of Metallography.

10. Metallography

On a scale of 1 to 5 with $1=$ very well prepared and $\mathbf{5}=$ very poorly prepared \# of resp. avg.

a). Can you define the purpose and function of Metallography?

b). Can you list the capabilities of this process?

c). Can you recognize the necessity of this process in the manufacture of a particular product?

d). Can you communicate effectively the value and purpose of this process to someone else?

e). Do you understand the function of this process in quality control

and failure diagnosis?

\begin{tabular}{|l|r|r|r|r|r|}
\hline & 1 & 2 & 3 & $\mathbf{4}$ & $\mathbf{5}$ \\
\hline & & 1 & 3 & 4 & 4 \\
\hline & & 1 & 3 & 3 & 5 \\
\hline & & & & & \\
& & 1 & 4 & 4 & 3 \\
\hline & & & & 3 & 5 \\
\hline
\end{tabular}

12

3.92

124.00

12

Rate your level of interest and enthusiasm for this course.

On a scale of 1 to 5 with $1=$ very interested and $5=$ not very interested \# of resp. avg.

11. The project

\begin{tabular}{|l|r|r|r|r|r|} 
& 1 & 2 & 3 & 4 & 5 \\
\hline
\end{tabular}

a). Rate your overall interest in the lab course

b). Rate your interest in the cannon project

11

1

12

12

1.50

For the following questions answer yes or no

12. Do you feel the project can be effectively integrated in the course format?

yes no

13. Do you anticipate that the project will result in more effort on your part?

14. Will it help you as an engineer to manufacture and test the cannon?

15. Do you foresee potential problems with this new lab?

\# of resp.

12

12

12

16. These questions cannot be all encompassing. Please write a few short sentences about your overall impression of the new course. 


\section{Section 504 Initial Survey Results}

Rate your level of understanding, preparedness, and ability to converse on the subject of Metrology and Tolerance.

On a scale of 1 to 5 with $1=$ very well prepared and $\mathbf{5}=$ very poorly prepared \# of resp. avg. 1. Metrology and Tolerance

a). Can you define the function of metrology and tolerance in design?

b). Can you identify the criteria necessary to specify a particular dimension or tolerance in design?

c). Can you effectively reverse engineer a product?

d). Do you have the ability to issue a design drawing suitable for manufacture?

e). Can you place the subject of metrology and tolerance in a step-bystep product development?

\begin{tabular}{|l|r|r|r|r|}
\hline 1 & 2 & 3 & $\mathbf{4}$ & $\mathbf{5}$ \\
\hline & 3 & 11 & 1 & 2 \\
\hline & 4 & 8 & 5 & \\
\hline 2 & 4 & 6 & 4 & 1 \\
\hline 3 & 7 & 4 & 2 & 1 \\
\hline 1 & 1 & 6 & 5 & 4 \\
\hline
\end{tabular}

Rate your level of understanding, preparedness, and ability to converse on the subjects of Fatigue testing, Impact testing, Tensile testing and Hardness testing.

On a scale of 1 to 5 with 1 = very well prepared and $5=$ very poorly prepared \# of resp. avg.

2. Fatigue, Impact, Tensile, and Hardness Testing

a). Can you define the specific process of the listed materials tests?

b). Do you understand the importance of these tests in evaluating material properties?

c). Do you feel you could choose a particular test for a specific design situation?

d). Can you communicate the process and capabilities of these tests to someone else?

\begin{tabular}{|l|l|r|r|r|r|}
\hline 1 & 2 & 3 & 4 & $\mathbf{5}$ \\
\hline & 2 & 3 & 2 & 9 & 1 \\
\hline & 3 & 9 & 4 & 1 & \\
\hline & 1 & 3 & 9 & 4 & \\
\hline & & 5 & 7 & 5 & \\
\hline
\end{tabular}

$17 \quad 3.235294$

$17 \quad 2.176471$

$17 \quad 2.941176$

Rate your level of understanding, preparedness, and ability to converse on the subjects of Precipitation Hardening and Heat Treatment of Steel.

On a scale of 1 to 5 with $1=$ very well prepared and $5=$ very poorly prepared \# of resp. avg.

3. Precipitation Hardening and Heat Treatment of Steel

a). Can you define the processes of Precipitation Hardening and Heat Treatment of Steel?

b). Can you list the material properties effected by these two material treatments?

c). Can you place the location of the process in the step-by-step manufacture of a product?

d). Do you know the materials that these processes can be applied to?

e). Can you communicate your knowledge of the process and its capabilities to someone else?

f). Do you feel you could suggest one of these processes for a particular design situation?

\begin{tabular}{|r|r|r|r|r|r|}
\hline & 1 & $\mathbf{2}$ & $\mathbf{3}$ & $\mathbf{4}$ & $\mathbf{5}$ \\
\hline at & & 2 & 11 & 3 & 1 \\
\hline & 1 & 2 & 7 & 5 & 2 \\
\hline & 1 & 2 & 4 & 6 & 4 \\
\hline & 1 & 1 & 11 & 3 & 1 \\
\hline & 1 & 1 & 7 & 5 & 3 \\
\hline & 1 & & 6 & 5 & 3 \\
\hline
\end{tabular}


Rate your level of understanding, preparedness, and ability to converse on the subject of Welding.

On a scale of 1 to 5 with $1=$ very well prepared and $\mathbf{5}=$ very poorly prepared \# of resp. avg.

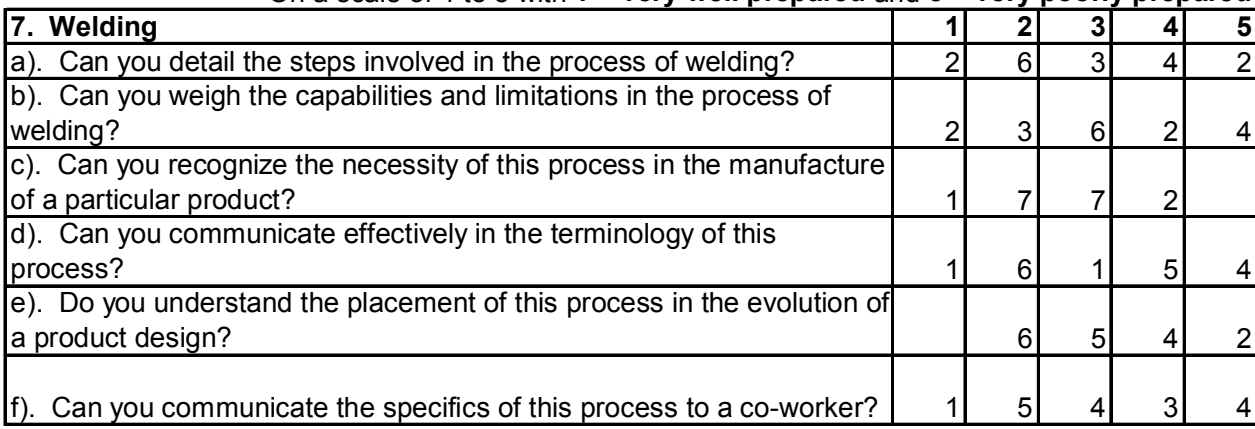

$17 \quad 2.882353$

$17 \quad 3.176471$

$17 \quad 2.588235$

$17 \quad 3.294118$

$17 \quad 3.117647$

$17 \quad 3.235294$

Rate your level of understanding, preparedness, and ability to converse on the subject of Injection Molding.

On a scale of 1 to 5 with $1=$ very well prepared and $\mathbf{5}=$ very poorly prepared \# of resp. avg.

8. Injection Molding

a). Can you detail the steps involved in the process of injection

molding?

b). Can you weigh the capabilities and limitations in the process of injection molding?

c). Can you recognize the necessity of this process in the manufacture of a particular product?

d). Can you communicate effectively in the terminology of this process?

e). Do you understand the placement of this process in the evolution of a product design?

f). Can you communicate the specifics of this process to a co-worker?

\begin{tabular}{|r|r|r|r|r|r|}
\hline & 1 & 2 & 3 & 4 & $\mathbf{5}$ \\
\hline & 1 & 2 & 4 & 4 & 6 \\
\hline & & 3 & 3 & 3 & 8 \\
\hline & 2 & 1 & 1 & 6 & 7 \\
\hline ore & & 4 & 4 & 6 & 3 \\
\hline
\end{tabular}

$17 \quad 3.705882$

$17 \quad 3.941176$

$17 \quad 3.470588$

$17 \quad 3.882353$

$17 \quad 3.764706$

$17 \quad 3.941176$

Rate your level of understanding, preparedness, and ability to converse on the subject of Rapid Prototyping.

On a scale of 1 to 5 with $\mathbf{1}=$ very well prepared and $\mathbf{5}=$ very poorly prepared \# of resp. avg.

9. Rapid Prototyping

a). Can you detail the steps involved in the process of Rapid

Prototyping?

b). Can you weigh the capabilities and limitations in the process of Rapid Prototyping?

c). Can you recognize the necessity of this process in the manufacture of a particular product?

d). Can you communicate effectively in the terminology of this process?

e). Do you understand the placement of this process in the evolution o a product design?

\begin{tabular}{|l|r|r|r|r|}
\hline 1 & 2 & 3 & 4 & 5 \\
\hline 2 & 1 & 2 & 4 & 8 \\
\hline 1 & 2 & 3 & 2 & 9 \\
\hline 2 & 4 & 1 & 4 & 6 \\
\hline 2 & 1 & 1 & 4 & 9 \\
\hline 1 & 4 & 2 & 2 & 8 \\
\hline 1 & 3 & 3 & 1 & 9 \\
\hline 3 & 4 & 1 & 2 & 7 \\
\hline
\end{tabular}

$17 \quad 3.882353$

$17 \quad 3.941176$

$17 \quad 3.470588$

17

f). Can you communicate the specifics of this process to a co-worker?

g). Do you understand the effect of Rapid Prototyping on the speed of product development?
$17 \quad 3.705882$
$17 \quad 3.823529$
$17 \quad 3.352941$ 
Rate your level of understanding, preparedness, and ability to converse on the subject of Manual Machining.

4. Manual Machining

On a scale of 1 to 5 with $1=$ very well prepared and $5=$ very poorly prepared \# of resp. avg.

a). Can you detail the steps involved in the process of manual

machining?

b). Can you weigh the capabilities and limitations in the process of

manual machining?

c). Can you recognize the necessity of this process in the manufacture

of a particular product?

d). Can you communicate effectively in the terminology of this process?

e). Do you understand the placement of this process in the evolution of a product design?

f). Can you communicate the specifics of this process to a co-worker?

\begin{tabular}{|r|r|r|r|r|r|}
\hline & 1 & 2 & 3 & $\mathbf{4}$ & $\mathbf{5}$ \\
\hline & 1 & 4 & 3 & 6 & 3 \\
\hline & 1 & 3 & 3 & 5 & 5 \\
\hline & 1 & 5 & 2 & 5 & 3 \\
\hline & 1 & 3 & 4 & 4 & 5 \\
\hline
\end{tabular}

$17 \quad 3.352941$

$17 \quad 3.588235$

$16 \quad 3.25$

$17 \quad 3.529412$

$17 \quad 3.235294$

$17 \quad 3.411765$

Rate your level of understanding, preparedness, and ability to converse on the subject of CNC Machining.

5. CNC Machining

On a scale of 1 to 5 with $1=$ very well prepared and $5=$ very poorly prepared \# of resp. avg.

a). Can you detail the steps involved in the process of CNC

machining?

b). Can you weigh the capabilities and limitations in the process of

CNC machining?

c). Can you recognize the necessity of this process in the manufacture

of a particular product?

d). Can you communicate effectively in the terminology of this

process?

e). Do you understand the placement of this process in the evolution of

a product design?

f). Can you communicate the specifics of this process to a co-worker?

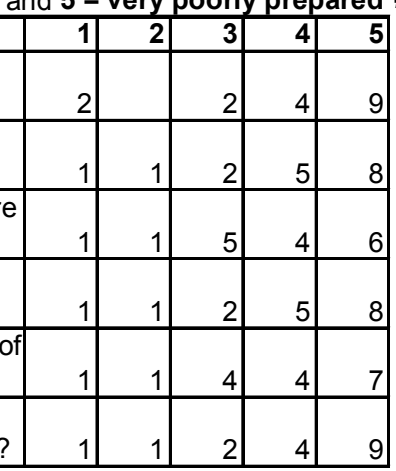

$17 \quad 4.058824$

$17 \quad 4.058824$

$17 \quad 3.764706$

$17 \quad 4.058824$

$17 \quad 3.882353$

$17 \quad 4.117647$

Rate your level of understanding, preparedness, and ability to converse on the subject of Casting.

On a scale of 1 to 5 with $1=$ very well prepared and $\mathbf{5}=$ very poorly prepared \# of resp. avg.

\begin{tabular}{|c|c|c|c|c|c|}
\hline 6. Casting & 1 & 2 & 3 & 4 & 5 \\
\hline a). Can you detail the steps involved in the process of casting? & 2 & 2 & 5 & 4 & 4 \\
\hline $\begin{array}{l}\text { b). Can you weigh the capabilities and limitations in the process of } \\
\text { casting? }\end{array}$ & 2 & & 6 & 2 & 7 \\
\hline $\begin{array}{l}\text { c). Can you recognize the necessity of this process in the manufacture } \\
\text { of a particular product? }\end{array}$ & 2 & 2 & 4 & 4 & 5 \\
\hline $\begin{array}{l}\text { d). Can you communicate effectively in the terminology of this } \\
\text { process? }\end{array}$ & 2 & & 4 & 6 & 5 \\
\hline $\begin{array}{l}\text { e). Do you understand the placement of this process in the evolution of } \\
\text { a product design? }\end{array}$ & 2 & 2 & 2 & 6 & 5 \\
\hline f). Can you communicate the specifics of this process to a co-worker? & 2 & 1 & 4 & 4 & 6 \\
\hline
\end{tabular}

$17 \quad 3.352941$

$17 \quad 3.705882$

$17 \quad 3.470588$

$17 \quad 3.705882$

$17 \quad 3.588235$

$17 \quad 3.647059$ 
Rate your level of understanding, preparedness, and ability to converse on the subject of Metallography.

\begin{tabular}{|c|c|c|c|c|c|c|c|}
\hline 10. Metallography & 1 & 2 & 3 & 4 & 5 & & \\
\hline a). Can you define the purpose and function of Metallography? & & & 6 & 4 & 7 & 17 & 4.058824 \\
\hline b). Can you list the capabilities of this process? & 1 & & 3 & 6 & 7 & 17 & 4.058824 \\
\hline $\begin{array}{l}\text { c). Can you recognize the necessity of this process in the manufacture } \\
\text { of a particular product? }\end{array}$ & & 1 & 6 & 3 & 7 & 17 & 3.941176 \\
\hline $\begin{array}{l}\text { d). Can you communicate effectively the value and purpose of this } \\
\text { process to someone else? }\end{array}$ & & 1 & 3 & 6 & 7 & 17 & 4.117647 \\
\hline $\begin{array}{l}\text { e). Do you understand the function of this process in quality control } \\
\text { and failure diagnosis? }\end{array}$ & & 1 & 5 & 4 & 7 & 17 & \\
\hline
\end{tabular}

Rate your level of interest and enthusiasm for this course.

On a scale of 1 to 5 with $1=$ very interested and $5=$ not very interested \# of resp. avg.

11. The project

a). Rate your overall interest in the lab course

b). Rate your interest in the cannon project

\begin{tabular}{r|r|r|r|r|}
\hline & $\mathbf{2}$ & 3 & $\mathbf{4}$ & $\mathbf{5}$ \\
\hline 13 & 1 & 3 & & 1 \\
\hline
\end{tabular}

For the following questions answer yes or no yes no

12. Do you feel the project can be effectively integrated in the course format?

\# of resp. avg.

13. Do you anticipate that the project will result in more effort on your part?

14. Will it help you as an engineer to manufacture and test the cannon?

15. Do you foresee potential problems with this new lab?

16. These questions cannot be all encompassing. Please write a few short sentences about your overall impression of the new course. 


\section{MEEN 360-502 first survey Written Responses}

1. Is it safe to give some of these guys a cannon that can shoot a .50 caliber bullet? I think this will be one of the best labs I've had.

2. The only real problem that I see is if a group has completed their project, and it doesn't work. Other than a large shot to their pride, the lab seems extremely beneficial.

3. I was excited about this lab when I signed up. I like hands on work and I feel like I learn a lot more from hands on work.

4. I'm very excited about the cannon project because it will be a real test of how much we learn in this course. My uncle has welded all his life and knows a lot about materials. He actually built a much larger cannon than the one we will build. It will be interesting to see how things turn out. I can't wait. I will definitely gain a lot from this lab.

5. Even though it may potential be more time consuming to work on the cannon project. I believe that / hope that it will be a valuable experience since we will be actually incorporating all the concepts learned into a single unit and applying the knowledge of the course in an engineering formatted manner.

6. It's about time we had a lab like this. All previous labs have been in the format where each week is a new experience. Encompassing all the experiments of this course into one ultimate goal and larger experiment should be beneficial.

7. I appreciate the idea of getting some actual hands on experience, and anticipate working on this lab. So far this looks to be one of the best labs so far in my education here. The only problem I foresee teaching everyone how to use all the equipment and processes effectively enough to complete this lab.

8. I think it is a really good idea to incorporate all subjects in this lab to build one object.

9. Really I have very little knowledge or experience with the subjects listed above, but I am very interested in learning them. I think the cannon is a good idea and it will be nice to have something to work toward rather than just a series of different lab experiments.

10. I would simply like to state that my background is very limited in the topics we will be discussing this semester and to that end I hope this will be a focused learning experience. 
11. It seems like a very good idea. Labs are always quite boring but this lab seems like it may be a bit more realistic and therefore more interesting.

12. I am interested in this project and will be much more motivated for this lab than for others.

13. I see this lab is the most interesting and exciting because we get to practice with many machines that are use by few people in the world. This was a great idea. 


\section{MEEN 360-504 first survey Written Responses}

1. I'll let you know later

2. Although I know very little about welding, CNC machining, etc. I have taken technical classes before and am excited about learning actual practical knowledge (something I don't think my classes stress enough). My only concern is that, as a female my knowledge and capabilities will be underestimated and I will not be allowed to participate.

3. I am very excited about finally being able to build something real. And at the same time, use knowledge learned in this course.

4. I feel this course will teach me things. They will be interesting. They will be useful.

5. Being able to see and fire the finished product should help motivate students and make them feel responsibility for the project

6. Looks like a lot of work and learning, but fun.

7. The project seems like a very good idea. Something real to show for my efforts will definitely cause me to put more effort into the course.

8. I like hands on stuff and the work material we will be covering interests me and will be helpful in the work environment that I will be seeking.

9. I have experience as a design engineer. I am happy that I will have a chance to see the manufacturing side of engineering.

10. Learning all of these machining skills is great, but being able to apply it to an actual project will illustrate the usefulness of the skills. Great idea of the cannon.

11. I Think a lot can be learned from this course.

12. It seems like writing the reports will require an enormous amount of work.

13. The idea sounds very interesting. Not only will we learn a lot, but it should be very enjoyable. To have something to show for your work at the end of the semester will give us a feeling of accomplishment.

14. I think that exposure to metallography and machining techniques will enhance my design ability. 


\section{Section 506 Initial Survey Responses}

Rate your level of understanding, preparedness, and ability to converse on the subject of Metrology and Tolerance.

On a scale of 1 to 5 with $\mathbf{1}=$ very well prepared and $\mathbf{5}=$ very poorly prepared \# of resp. avg. 1. Metrology and Tolerance

a). Can you define the function of metrology and tolerance in design?

b). Can you identify the criteria necessary to specify a particular dimension or tolerance in design?

c). Can you effectively reverse engineer a product?

d). Do you have the ability to issue a design drawing suitable for manufacture?

e). Can you place the subject of metrology and tolerance in a step-bystep product development?

\begin{tabular}{|r|r|r|r|r|r|}
\hline 1 & 2 & 3 & 4 & 5 \\
\hline & & 2 & 4 & 5 & 4 \\
\hline & & 3 & 11 & 1 & \\
\hline & & 2 & 6 & 5 & 2 \\
\hline & & 5 & 6 & 4 & \\
\hline
\end{tabular}

$15 \quad 3.733333$

$15 \quad 2.866667$

$15 \quad 3.466667$

$15 \quad 2.933333$

$14 \quad 3.857143$

Rate your level of understanding, preparedness, and ability to converse on the subjects of Fatigue testing, Impact testing, Tensile testing and Hardness testing. On a scale of 1 to 5 with $1=$ very well prepared and $5=$ very poorly prepared \# of resp. avg. 2. Fatigue, Impact, Tensile, and Hardness Testing

a). Can you define the specific process of the listed materials tests? b). Do you understand the importance of these tests in evaluating material properties?

c). Do you feel you could choose a particular test for a specific design situation?

d). Can you communicate the process and capabilities of these tests to someone else?

\begin{tabular}{|r|r|r|r|r|r|}
\hline 1 & 2 & 3 & 4 & $\mathbf{5}$ \\
\hline & 2 & 6 & 6 & 1 & \\
\hline & 2 & 11 & 2 & & \\
\hline & 2 & 6 & 6 & 1 & \\
\hline & 2 & 6 & 6 & 1 & \\
\hline
\end{tabular}

15

Rate your level of understanding, preparedness, and ability to converse on the subjects of Precipitation Hardening and Heat Treatment of Steel.

On a scale of 1 to 5 with 1 = very well prepared and $5=$ very poorly prepared \# of resp. avg.

3. Precipitation Hardening and Heat Treatment of Steel

a). Can you define the processes of Precipitation Hardening and Heat Treatment of Steel?

b). Can you list the material properties effected by these two material treatments?

c). Can you place the location of the process in the step-by-step manufacture of a product?

\begin{tabular}{|r|r|r|r|r|r|}
\hline 1 & 2 & 3 & 4 & 5 \\
\hline & & 7 & 8 & & \\
\hline & 5 & 7 & 1 & \\
\hline & & 2 & 7 & 4 & 1 \\
\hline & & 2 & 8 & 3 & 2 \\
\hline & & 5 & 4 & 6 & \\
\hline & & 3 & 4 & 6 & 2 \\
\hline
\end{tabular}

$15 \quad 2.533333$

$15 \quad 2.466667$

$14 \quad 3.285714$

d). Do you know the materials that these processes can be applied to? e). Can you communicate your knowledge of the process and its capabilities to someone else?

f). Do you feel you could suggest one of these processes for a particular design situation?

$15 \quad 3.333333$

$15 \quad 3.066667$

$15 \quad 3.466667$ 
Rate your level of understanding, preparedness, and ability to converse on the subject of CNC Machining.

5. CNC Machining

On a scale of 1 to 5 with $1=$ very well prepared and $5=$ very poorly prepared \# of resp. avg.

a). Can you detail the steps involved in the process of CNC

machining?

b). Can you weigh the capabilities and limitations in the process of

CNC machining?

c). Can you recognize the necessity of this process in the manufacture

of a particular product?

d). Can you communicate effectively in the terminology of this

process?

e). Do you understand the placement of this process in the evolution of

a product design?

f). Can you communicate the specifics of this process to a co-worker?

\begin{tabular}{|r|r|r|r|r|r|}
\hline & 1 & 2 & 3 & 4 & 5 \\
\hline & 1 & 5 & 3 & 5 \\
\hline & & 2 & 3 & 5 & 5 \\
\hline & 1 & 4 & 3 & 2 & 5 \\
\hline & & 1 & 2 & 7 & 5 \\
\hline & 1 & 1 & 1 & 7 & 5 \\
\hline
\end{tabular}

$15 \quad 3.666667$

$15 \quad 3.866667$

15

$15 \quad 3.933333$

$15 \quad 4.066667$

Rate your level of understanding, preparedness, and ability to converse on the subject of Casting.

On a scale of 1 to 5 with $1=$ very well prepared and $5=$ very poorly prepared \# of resp. avg.

\begin{tabular}{|c|c|c|c|c|c|c|c|}
\hline 6. Casting & 1 & 2 & 3 & 4 & 5 & & \\
\hline a). Can you detail the steps involved in the process of casting? & & & 3 & 8 & 4 & 15 & 4.066667 \\
\hline $\begin{array}{l}\text { b). Can you weigh the capabilities and limitations in the process of } \\
\text { casting? }\end{array}$ & & & 4 & 7 & 4 & 15 & ( \\
\hline $\begin{array}{l}\text { c). Can you recognize the necessity of this process in the manufacture } \\
\text { of a particular product? }\end{array}$ & & 2 & 5 & 4 & 4 & 15 & 3.666667 \\
\hline $\begin{array}{l}\text { d). Can you communicate effectively in the terminology of this } \\
\text { process? }\end{array}$ & & & 1 & 10 & 4 & 15 & 4.2 \\
\hline $\begin{array}{l}\text { e). Do you understand the placement of this process in the evolution of } \\
\text { a product design? }\end{array}$ & & 1 & 1 & 8 & 5 & 15 & 4.133333 \\
\hline f). Can you communicate the specifics of this process to a co-worker? & & & 1 & 9 & 5 & 15 & 4.266667 \\
\hline
\end{tabular}

Rate your level of understanding, preparedness, and ability to converse on the subject of Welding.

On a scale of 1 to 5 with $1=$ very well prepared and $5=$ very poorly prepared \# of resp. avg.

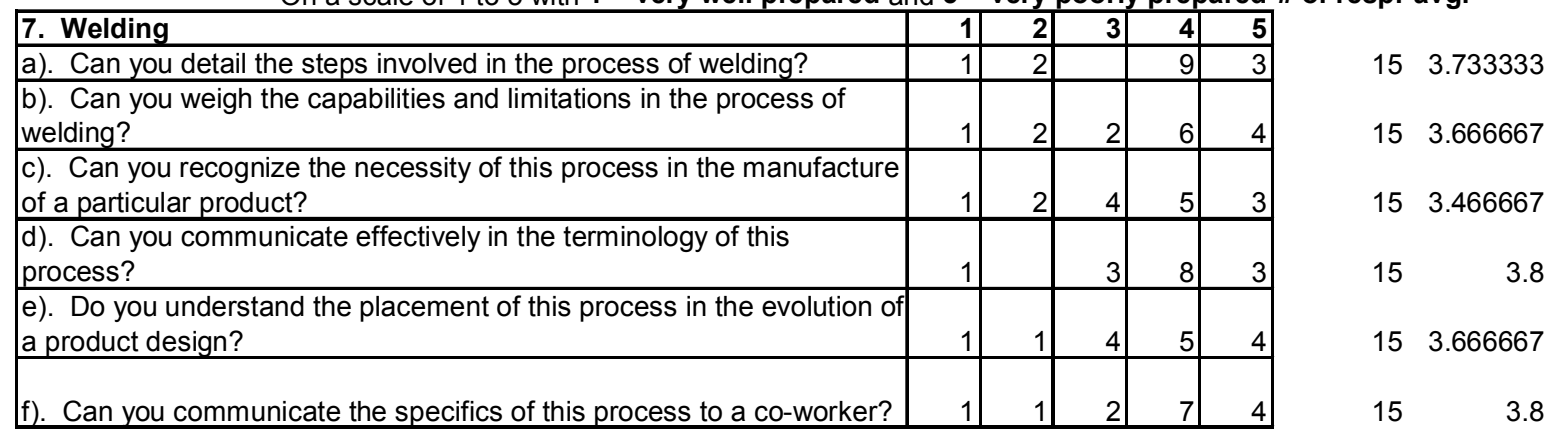


Rate your level of understanding, preparedness, and ability to converse on the subject of Injection Molding.

8. Injection Molding

On a scale of 1 to 5 with $1=$ very well prepared and $5=$ very poorly prepared \# of resp. avg.

a). Can you detail the steps involved in the process of injection

molding?

b). Can you weigh the capabilities and limitations in the process of injection molding?

c). Can you recognize the necessity of this process in the manufacture

of a particular product?

d). Can you communicate effectively in the terminology of this process?

e). Do you understand the placement of this process in the evolution of a product design?

f). Can you communicate the specifics of this process to a co-worker?

\begin{tabular}{|l|l|l|l|r|r|}
\hline & 1 & 2 & 3 & 4 & 5 \\
\hline & & 5 & 2 & 1 \\
\hline & & 3 & 6 & 3 & 3 \\
\hline & & 6 & 2 & 2 \\
\hline & & 1 & 9 & 3 & 2 \\
\hline & & 4 & 4 & 6 & 1 \\
\hline & & & & 3 \\
\hline
\end{tabular}

$15 \quad 2.933333$

15

$15 \quad 3.066667$

$15 \quad 3.4$

$15 \quad 3.266667$

$15 \quad 3.266667$

Rate your level of understanding, preparedness, and ability to converse on the subject of Rapid Prototyping.

9. Rapid Prototyping

On a scale of 1 to 5 with $1=$ very well prepared and $5=$ very poorly prepared \# of resp. avg.

a). Can you detail the steps involved in the process of Rapid

Prototyping?

b). Can you weigh the capabilities and limitations in the process of

Rapid Prototyping?

c). Can you recognize the necessity of this process in the manufacture

of a particular product?

d). Can you communicate effectively in the terminology of this process?

e). Do you understand the placement of this process in the evolution of a product design?

f). Can you communicate the specifics of this process to a co-worker?

\begin{tabular}{|r|r|r|r|r|r|}
\hline & 1 & 2 & 3 & 4 & 5 \\
\hline & & 3 & 3 & 5 \\
\hline & & 3 & 4 & 4 & 4 \\
\hline & & 4 & 2 & 4 & 5 \\
\hline of & & 5 & 4 & 5 \\
\hline & & 2 & 4 & 4 & 5 \\
\hline
\end{tabular}

15

g). Do you understand the effect of Rapid Prototyping on the speed of

product development?

Rate your level of understanding, preparedness, and ability to converse on the subject of Metallography.

$15 \quad 3.066667$

\begin{tabular}{|c|c|c|c|c|c|c|c|}
\hline 10. Metallography & 1 & 2 & 3 & 4 & 5 & & \\
\hline a). Can you define the purpose and function of Metallography? & & & 2 & 7 & 6 & 15 & 4.266667 \\
\hline b). Can you list the capabilities of this process? & & & & 9 & 6 & 15 & 4.4 \\
\hline $\begin{array}{l}\text { c). Can you recognize the necessity of this process in the manufacture } \\
\text { of a particular product? }\end{array}$ & & & 1 & 8 & 6 & 15 & 4.333333 \\
\hline $\begin{array}{l}\text { d). Can you communicate effectively the value and purpose of this } \\
\text { process to someone else? }\end{array}$ & & & 1 & 8 & 6 & 15 & 4.333333 \\
\hline $\begin{array}{l}\text { e). Do you understand the function of this process in quality control } \\
\text { and failure diagnosis? }\end{array}$ & & 1 & & 7 & 7 & 15 & 4.333333 \\
\hline
\end{tabular}




\section{Section 502 Final Survey Results}

Rate your level of understanding, preparedness, and ability to converse on the subject of Metrology and Tolerance.

On a scale of 1 to 5 with $1=$ very well prepared and $\mathbf{5}=$ very poorly prepared \# of resp. avg. 1. Metrology and Tolerance

a). Can you define the function of metrology and tolerance in design?

b). Can you identify the criteria necessary to specify a particular dimension or tolerance in design?

c). Can you effectively reverse engineer a product?

d). Do you have the ability to issue a design drawing suitable for manufacture?

e). Can you place the subject of metrology and tolerance in a step-bystep product development?

\begin{tabular}{|c|c|c|c|c|}
\hline 1 & 2 & 3 & 4 & 5 \\
\hline 3 & 7 & 2 & & \\
\hline 2 & 7 & 2 & 1 & \\
\hline 4 & 6 & 2 & & \\
\hline 4 & 5 & 2 & 1 & \\
\hline 2 & 6 & 4 & & \\
\hline
\end{tabular}

$12 \quad 1.916667$

$\begin{array}{ll}12 & 2.166667\end{array}$

121.833333

12

$12 \quad 2.166667$

Rate your level of understanding, preparedness, and ability to converse on the subjects of Fatigue testing, Impact testing, Tensile testing and Hardness testing.

On a scale of 1 to 5 with $1=$ very well prepared and $5=$ very poorly prepared \# of resp. avg.

2. Fatigue, Impact, Tensile, and Hardness Testing

a). Can you define the specific process of the listed materials tests?

b). Do you understand the importance of these tests in evaluating material properties?

c). Do you feel you could choose a particular test for a specific design situation?

d). Can you communicate the process and capabilities of these tests

to someone else?

\begin{tabular}{|l|r|r|r|r|r|}
\hline 1 & 2 & 3 & $\mathbf{4}$ & $\mathbf{5}$ \\
\hline 6 & 5 & 1 & & \\
\hline & 5 & 1 & & \\
\hline 4 & 7 & 1 & & \\
\hline 2 & 7 & 3 & & \\
\hline
\end{tabular}

121.583333

121.583333

12

Rate your level of understanding, preparedness, and ability to converse on the subjects of Precipitation Hardening and Heat Treatment of Steel.

On a scale of 1 to 5 with $1=$ very well prepared and $5=$ very poorly prepared \# of resp. avg.

3. Precipitation Hardening and Heat Treatment of Steel

a). Can you define the processes of Precipitation Hardening and Heat Treatment of Steel?

b). Can you list the material properties effected by these two material treatments?

c). Can you place the location of the process in the step-by-step manufacture of a product?

\begin{tabular}{|r|r|r|r|r|r|}
\hline & 1 & 2 & 3 & 4 & $\mathbf{5}$ \\
\hline & 1 & 9 & 2 & & \\
\hline & 6 & 4 & & \\
\hline & 1 & 9 & 2 & & \\
\hline & & 6 & 5 & 1 & \\
\hline & 1 & 7 & 4 & & \\
\hline & 1 & 8 & 3 & & \\
\hline
\end{tabular}

$12 \quad 2.083333$

$12 \quad 2.166667$

$12 \quad 2.083333$

d). Do you know the materials that these processes can be applied to?

e). Can you communicate your knowledge of the process and its capabilities to someone else?

f). Do you feel you could suggest one of these processes for a particular design situation?

$12 \quad 2.583333$ 
Rate your level of understanding, preparedness, and ability to converse on the subject of Manual Machining.

On a scale of 1 to 5 with $1=$ very well prepared and $5=$ very poorly prepared \# of resp. avg.

4. Manual Machining

a). Can you detail the steps involved in the process of manual machining?

b). Can you weigh the capabilities and limitations in the process of manual machining?

c). Can you recognize the necessity of this process in the manufacture

of a particular product?

d). Can you communicate effectively in the terminology of this process?

e). Do you understand the placement of this process in the evolution of a product design?

f). Can you communicate the specifics of this process to a co-worker?

\begin{tabular}{|r|r|r|r|r|r|}
\hline & 1 & 2 & 3 & 4 & 5 \\
\hline & 5 & 4 & & \\
\hline & 1 & 8 & 3 & & \\
\hline 7 & 3 & 2 & & \\
\hline of & 2 & 6 & 3 & 1 & \\
\hline & 2 & 7 & 3 & & \\
\hline & 1 & 7 & 4 & & \\
\hline
\end{tabular}

$12 \quad 2.083333$

$12 \quad 2.166667$

121.583333

$12 \quad 2.25$

122.083333

$12 \quad 2.25$

Rate your level of understanding, preparedness, and ability to converse on the subject of CNC

Machining.

5. CNC Machining

On a scale of 1 to 5 with $1=$ very well prepared and $5=$ very poorly prepared \# of resp. avg.

a). Can you detail the steps involved in the process of CNC machining?

b). Can you weigh the capabilities and limitations in the process of CNC machining?

c). Can you recognize the necessity of this process in the manufacture of a particular product?

d). Can you communicate effectively in the terminology of this process?

e). Do you understand the placement of this process in the evolution of a product design?

f). Can you communicate the specifics of this process to a co-worker?

\begin{tabular}{|l|l|l|l|l|l|}
\hline & 1 & 2 & 3 & 4 & $\mathbf{5}$ \\
\hline & & 7 & 5 & & \\
\hline & 2 & 7 & 3 & & \\
\hline & 3 & 5 & 4 & & \\
\hline & 1 & 6 & 4 & 1 & \\
\hline of & 1 & 7 & 4 & & \\
\hline & & 6 & 4 & 1 & \\
\hline
\end{tabular}

$12 \quad 2.416667$

$12 \quad 2.083333$

$12 \quad 2.083333$

$12 \quad 2.416667$

$12 \quad 2.25$

$12 \quad 2.416667$

Rate your level of understanding, preparedness, and ability to converse on the subject of Casting. On a scale of 1 to 5 with $1=$ very well prepared and $5=$ very poorly prepared \# of resp. avg.

6. Casting

a). Can you detail the steps involved in the process of casting?

b). Can you weigh the capabilities and limitations in the process of casting?

c). Can you recognize the necessity of this process in the manufacture of a particular product?

d). Can you communicate effectively in the terminology of this process?

e). Do you understand the placement of this process in the evolution of a product design?

f). Can you communicate the specifics of this process to a co-worker?

\begin{tabular}{|l|r|r|r|r|}
1 & 2 & 3 & 4 & 5 \\
\hline 3 & 6 & 2 & & \\
\hline 3 & 7 & 2 & & \\
\hline 3 & 6 & 3 & & \\
\hline 4 & 4 & 4 & & \\
\hline 2 & 7 & 3 & & \\
\hline 4 & 4 & 4 & & \\
\hline
\end{tabular}

111.909091

121.916667

$12 \quad 2$

12

122.083333

12 
Rate your level of understanding, preparedness, and ability to converse on the subject of Welding.

On a scale of 1 to 5 with 1 = very well prepared and $5=$ very poorly prepared \# of resp. avg.

\begin{tabular}{|c|c|c|c|c|c|}
\hline 7. Welding & 1 & 2 & 3 & 4 & \\
\hline a). Can you detail the steps involved in the process of welding? & 3 & 7 & 2 & & \\
\hline $\begin{array}{l}\text { b). Can you weigh the capabilities and limitations in the process of } \\
\text { welding? }\end{array}$ & 4 & 6 & 2 & & \\
\hline $\begin{array}{l}\text { c). Can you recognize the necessity of this process in the manufacture } \\
\text { of a particular product? }\end{array}$ & 2 & 8 & 1 & 1 & \\
\hline $\begin{array}{l}\text { d). Can you communicate effectively in the terminology of this } \\
\text { process? }\end{array}$ & 2 & 6 & 4 & & \\
\hline $\begin{array}{l}\text { e). Do you understand the placement of this process in the evolution of } \\
\text { a product design? }\end{array}$ & 3 & 7 & 2 & & \\
\hline f). Can you communicate the specifics of this process to a co-wo & 2 & 7 & 3 & & \\
\hline
\end{tabular}

121.916667

121.833333

$12 \quad 2.083333$

$12 \quad 2.166667$

121.916667

$12 \quad 2.083333$

Rate your level of understanding, preparedness, and ability to converse on the subject of Injection Molding.

On a scale of 1 to 5 with $1=$ very well prepared and $\mathbf{5}=$ very poorly prepared \# of resp. avg.

8. Injection Molding

a). Can you detail the steps involved in the process of injection molding?

b). Can you weigh the capabilities and limitations in the process of injection molding?

c). Can you recognize the necessity of this process in the manufacture of a particular product?

d). Can you communicate effectively in the terminology of this process?

e). Do you understand the placement of this process in the evolution of a product design?

\begin{tabular}{|r|r|r|r|r|r|}
\hline & 1 & 2 & 3 & 4 & 5 \\
\hline & 1 & 3 & 7 & & \\
\hline & & 7 & 4 & & \\
\hline & 1 & 5 & 5 & & \\
\hline of & & 7 & 4 & & \\
\hline & & 7 & 3 & & \\
\hline
\end{tabular}

$11 \quad 2.545455$

112.363636

112.363636

112.363636

112.181818

f). Can you communicate the specifics of this process to a co-worker?

$11 \quad 2.454545$

Rate your level of understanding, preparedness, and ability to converse on the subject of Rapid Prototyping.

On a scale of 1 to 5 with $1=$ very well prepared and $\mathbf{5}=$ very poorly prepared \# of resp. avg.

9. Rapid Prototyping

a). Can you detail the steps involved in the process of Rapid

Prototyping?

b). Can you weigh the capabilities and limitations in the process of Rapid Prototyping?

c). Can you recognize the necessity of this process in the manufacture of a particular product?

d). Can you communicate effectively in the terminology of this process?

e). Do you understand the placement of this process in the evolution of a product design?

f). Can you communicate the specifics of this process to a co-worker?

g). Do you understand the effect of Rapid Prototyping on the speed of product development?

\begin{tabular}{|r|r|r|r|r|r|}
\hline & 1 & 2 & 3 & 4 & 5 \\
\hline & 4 & 4 & 3 & 1 & \\
\hline 3 & 6 & 3 & & \\
\hline & 3 & 7 & 2 & & \\
\hline & 2 & 5 & 3 & 2 & \\
\hline of & 4 & 3 & 5 & & \\
\hline & 1 & 7 & 2 & 2 & \\
\hline
\end{tabular}

122.083333

12

121.916667

$12 \quad 2.416667$

$12 \quad 2.083333$

$12 \quad 2.416667$

121.833333 
Rate your level of understanding, preparedness, and ability to converse on the subject of Metallography.

\begin{tabular}{|c|c|c|c|c|c|c|c|}
\hline 10. Metallography & 1 & 2 & 3 & 4 & 5 & & \\
\hline a). Can you define the purpose and function of Metallography? & 5 & 6 & 1 & & & 12 & 1.666667 \\
\hline b). Can you list the capabilities of this process? & 3 & 6 & 3 & & & 12 & \\
\hline $\begin{array}{l}\text { c). Can you recognize the necessity of this process in the manufacture } \\
\text { of a particular product? }\end{array}$ & 3 & 7 & 2 & & & 12 & 1.916667 \\
\hline $\begin{array}{l}\text { d). Can you communicate effectively the value and purpose of this } \\
\text { process to someone else? }\end{array}$ & 3 & 7 & 2 & & & 12 & 1.916667 \\
\hline $\begin{array}{l}\text { e). Do you understand the function of this process in quality control } \\
\text { and failure diagnosis? }\end{array}$ & 5 & 3 & 4 & & & 12 & 1.916667 \\
\hline
\end{tabular}

Rate your level of interest and enthusiasm for this course.

On a scale of 1 to 5 with $1=$ very interested and $5=$ not very interested \# of resp. avg.

11. The project

in the lab course

\begin{tabular}{l} 
a). Rate your overall interest in the lab course \\
\hline b). Rate your interest in the cannon project
\end{tabular}

121.833333

$12 \quad 1.583333$

For the following questions answer yes or no

12. Do you feel the project was effectively integrated in the course format?

13. Do you feel that the project resulted in more effort on your part?

14. Will it help you as an engineer to have manufactured and tested the cannon? 15. Do you feel that the experience provided by this lab is of sufficient value that the format should be continued

yes no

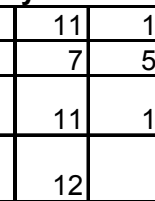

16. These questions cannot be all encompassing. Please write a few short sentences about your overall impression of the new course. 


\section{Section 504 Final Survey Results}

Rate your level of understanding, preparedness, and ability to converse on the subject of Metrology and Tolerance.

On a scale of 1 to 5 with $\mathbf{1}=$ very well prepared and $\mathbf{5}=$ very poorly prepared \# of resp. avg. 1. Metrology and Tolerance

a). Can you define the function of metrology and tolerance in design? b). Can you identify the criteria necessary to specify a particular dimension or tolerance in design?

c). Can you effectively reverse engineer a product?

d). Do you have the ability to issue a design drawing suitable for manufacture?

e). Can you place the subject of metrology and tolerance in a step-bystep product development?

\begin{tabular}{|r|r|r|r|r|r|}
\hline & 1 & 2 & 3 & $\mathbf{4}$ & $\mathbf{5}$ \\
\hline & 5 & 11 & 2 & & \\
\hline & 7 & 9 & 2 & & \\
\hline & 8 & 5 & 5 & & \\
\hline & 4 & 8 & 6 & & \\
\hline & 2 & 12 & 4 & & \\
\hline
\end{tabular}

$18 \quad 1.833333$

$18 \quad 1.722222$

$18 \quad 1.833333$

$18 \quad 2.111111$

$18 \quad 2.111111$

Rate your level of understanding, preparedness, and ability to converse on the subjects of Fatigue testing, Impact testing, Tensile testing and Hardness testing.

On a scale of 1 to 5 with $1=$ very well prepared and $5=$ very poorly prepared \# of resp. avg.

2. Fatigue, Impact, Tensile, and Hardness Testing

a). Can you define the specific process of the listed materials tests?

b). Do you understand the importance of these tests in evaluating material properties?

c). Do you feel you could choose a particular test for a specific design situation?

d). Can you communicate the process and capabilities of these tests

to someone else?

\begin{tabular}{|r|r|r|r|r|r|}
\hline 1 & 2 & 3 & $\mathbf{4}$ & $\mathbf{5}$ \\
\hline & 8 & 8 & 2 & & \\
\hline 10 & 8 & & & \\
\hline & 10 & 7 & 1 & & \\
\hline & 7 & 2 & & \\
\hline
\end{tabular}

181.666667

$18 \quad 1.444444$

18

Rate your level of understanding, preparedness, and ability to converse on the subjects of Precipitation Hardening and Heat Treatment of Steel.

On a scale of 1 to 5 with $1=$ very well prepared and $5=$ very poorly prepared \# of resp. avg.

3. Precipitation Hardening and Heat Treatment of Steel

a). Can you define the processes of Precipitation Hardening and Heat Treatment of Steel?

b). Can you list the material properties effected by these two material treatments?

c). Can you place the location of the process in the step-by-step manufacture of a product?

\begin{tabular}{|r|r|r|r|r|r|}
\hline & 1 & 2 & 3 & $\mathbf{4}$ & $\mathbf{5}$ \\
\hline & 6 & 12 & & & \\
\hline & 8 & 9 & 1 & & \\
\hline & 5 & 11 & 2 & & \\
\hline & & 13 & 5 & & \\
\hline & 5 & 9 & 3 & & \\
\hline & 5 & 9 & 3 & 1 & \\
\hline
\end{tabular}

181.666667

$18 \quad 1.611111$

181.833333

d). Do you know the materials that these processes can be applied to?

e). Can you communicate your knowledge of the process and its capabilities to someone else?

f). Do you feel you could suggest one of these processes for a particular design situation?

$18 \quad 2.277778$

$17 \quad 1.882353$ 
Rate your level of understanding, preparedness, and ability to converse on the subject of Manual Machining.

On a scale of 1 to 5 with $1=$ very well prepared and $5=$ very poorly prepared \# of resp. avg.

4. Manual Machining

a). Can you detail the steps involved in the process of manual machining?

b). Can you weigh the capabilities and limitations in the process of manual machining?

c). Can you recognize the necessity of this process in the manufacture

of a particular product?

d). Can you communicate effectively in the terminology of this process?

e). Do you understand the placement of this process in the evolution of a product design?

f). Can you communicate the specifics of this process to a co-worker?

\begin{tabular}{|r|r|r|r|r|r|}
\hline 1 & 2 & 3 & 4 & $\mathbf{5}$ \\
\hline & 4 & 13 & 1 & & \\
\hline 5 & 12 & 1 & & \\
\hline 11 & 7 & & & \\
\hline of & 3 & 8 & 7 & & \\
\hline & 6 & 12 & & & \\
\hline & 4 & 9 & 5 & & \\
\hline
\end{tabular}

$18 \quad 1.833333$

$18 \quad 1.777778$

181.388889

$18 \quad 2.222222$

$18 \quad 1.666667$

$18 \quad 2.055556$

Rate your level of understanding, preparedness, and ability to converse on the subject of CNC

Machining.

On a scale of 1 to 5 with $1=$ very well prepared and $5=$ very poorly prepared \# of resp. avg.

5. CNC Machining

a). Can you detail the steps involved in the process of CNC

machining?

b). Can you weigh the capabilities and limitations in the process of

CNC machining?

c). Can you recognize the necessity of this process in the manufacture

of a particular product?

d). Can you communicate effectively in the terminology of this process?

e). Do you understand the placement of this process in the evolution of a product design?

f). Can you communicate the specifics of this process to a co-worker?

\begin{tabular}{|r|r|r|r|r|r|}
\hline & 1 & 2 & 3 & $\mathbf{4}$ & $\mathbf{5}$ \\
\hline & 2 & 10 & 5 & 1 & \\
\hline & 3 & 12 & 3 & & \\
\hline & 5 & 13 & & & \\
\hline & 2 & 9 & 5 & 2 & \\
\hline
\end{tabular}

$18 \quad 2.277778$

18

$18 \quad 2.388889$

181.888889

18

Rate your level of understanding, preparedness, and ability to converse on the subject of Casting.

On a scale of 1 to 5 with $1=$ very well prepared and $\mathbf{5}=$ very poorly prepared \# of resp. avg.

6. Casting

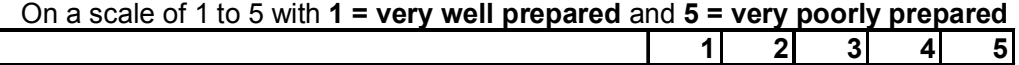

a). Can you detail the steps involved in the process of casting?

b). Can you weigh the capabilities and limitations in the process of casting?

c). Can you recognize the necessity of this process in the manufacture of a particular product?

d). Can you communicate effectively in the terminology of this process?

e). Do you understand the placement of this process in the evolution of a product design?

f). Can you communicate the specifics of this process to a co-worker?

\begin{tabular}{|r|r|r|r|r|}
\hline $\mathbf{1}$ & $\mathbf{2}$ & $\mathbf{3}$ & $\mathbf{4}$ & $\mathbf{5}$ \\
\hline 9 & 9 & & & \\
\hline 8 & 10 & & & \\
\hline 11 & 7 & & & \\
\hline 4 & 13 & 1 & & \\
\hline 5 & 13 & & & \\
\hline 4 & 13 & 1 & & \\
\hline
\end{tabular}


Rate your level of understanding, preparedness, and ability to converse on the subject of Welding.

On a scale of 1 to 5 with 1 = very well prepared and $5=$ very poorly prepared \# of resp. avg.

\begin{tabular}{|c|c|c|c|c|c|}
\hline 7. Welding & 1 & 2 & 3 & 4 & \\
\hline a). Can you detail the steps involved in the process of welding? & 5 & 10 & 2 & & \\
\hline $\begin{array}{l}\text { b). Can you weigh the capabilities and limitations in the process of } \\
\text { welding? }\end{array}$ & 4 & 10 & 4 & & \\
\hline $\begin{array}{l}\text { c). Can you recognize the necessity of this process in the manufacture } \\
\text { of a particular product? }\end{array}$ & 7 & 11 & & & \\
\hline $\begin{array}{l}\text { d). Can you communicate effectively in the terminology of this } \\
\text { process? }\end{array}$ & 4 & 9 & 4 & 1 & \\
\hline $\begin{array}{l}\text { e). Do you understand the placement of this process in the evolution of } \\
\text { a product design? }\end{array}$ & 4 & 14 & & & \\
\hline f). Can you communicate the specifics of this process to a co-wo & 2 & 12 & 4 & & \\
\hline
\end{tabular}

171.823529

$18 \quad 2$

$18 \quad 1.611111$

$18 \quad 2.111111$

$18 \quad 1.777778$

$18 \quad 2.111111$

Rate your level of understanding, preparedness, and ability to converse on the subject of Injection Molding.

On a scale of 1 to 5 with $1=$ very well prepared and $\mathbf{5}=$ very poorly prepared \# of resp. avg.

8. Injection Molding

a). Can you detail the steps involved in the process of injection molding?

b). Can you weigh the capabilities and limitations in the process of injection molding?

c). Can you recognize the necessity of this process in the manufacture of a particular product?

d). Can you communicate effectively in the terminology of this process?

e). Do you understand the placement of this process in the evolution of a product design?

\begin{tabular}{|l|r|r|r|r|}
\hline 1 & 2 & 3 & 4 & $\mathbf{5}$ \\
\hline 2 & 13 & 3 & & \\
\hline & 13 & 5 & & \\
\hline 4 & 12 & 2 & & \\
\hline 2 & 10 & 6 & & \\
\hline 3 & 12 & 3 & & \\
\hline 2 & 12 & 4 & & \\
\hline
\end{tabular}

$18 \quad 2.055556$

$18 \quad 2.277778$

$18 \quad 1.888889$

$18 \quad 2.222222$

18

2

f). Can you communicate the specifics of this process to a co-worker?

$18 \quad 2.111111$

Rate your level of understanding, preparedness, and ability to converse on the subject of Rapid Prototyping.

On a scale of 1 to 5 with $1=$ very well prepared and $5=$ very poorly prepared \# of resp. avg.

9. Rapid Prototyping

a). Can you detail the steps involved in the process of Rapid

Prototyping?

b). Can you weigh the capabilities and limitations in the process of Rapid Prototyping?

c). Can you recognize the necessity of this process in the manufacture of a particular product?

d). Can you communicate effectively in the terminology of this process?

e). Do you understand the placement of this process in the evolution of a product design?

f). Can you communicate the specifics of this process to a co-worker? g). Do you understand the effect of Rapid Prototyping on the speed of product development?

$18 \quad 1.666667$

$18 \quad 1.777778$

$18 \quad 1.277778$

$18 \quad 1.944444$

$17 \quad 1.529412$

$18 \quad 1.833333$

$18 \quad 1.333333$ 
Rate your level of understanding, preparedness, and ability to converse on the subject of Metallography.

10. Metallography On a scale of 1 to 5 with $1=$ very well prepared and $5=$ very poorly prepared \# of resp. avg.

a). Can you define the purpose and function of Metallography?

b). Can you list the capabilities of this process?

c). Can you recognize the necessity of this process in the manufacture

of a particular product?

d). Can you communicate effectively the value and purpose of this process to someone else?

e). Do you understand the function of this process in quality control and failure diagnosis?

$18 \quad 1.611111$

$18 \quad 2.277778$

182.055556

$18 \quad 2.055556$

181.722222

Rate your level of interest and enthusiasm for this course.

On a scale of 1 to 5 with $1=$ very interested and $5=$ not very interested \# of resp. avg.

11. The project

in the lab course

a). Rate your overall interest in the lab cours
b). Rate your interest in the cannon project

$\begin{array}{ll}17 & 1.529412\end{array}$

12

\begin{tabular}{|l|l|l|l|}
$\mathbf{2}$ & $\mathbf{3}$ & $\mathbf{4}$ & $\mathbf{5}$ \\
\hline 7 & 1 & & \\
\hline 5 & 1 & & \\
\hline
\end{tabular}

$18 \quad 1.388889$

For the following questions answer yes or no

12. Do you feel the project was effectively integrated in the course format?

13. Do you feel that the project resulted in more effort on your part?

14. Will it help you as an engineer to have manufactured and tested the cannon?

15. Do you feel that the experience provided by this lab is of sufficient value that

yes no

16. These questions cannot be all encompassing. Please write a few short sentences about your overall impression of the new course. 


\section{MEEN 360-502 \\ Final Commentary}

This process was much better than any other lab where experiments are carried out with no interesting results. The continual process on a finished product made this lab a continuous learning experience where it was demonstrated how each lab contributed to the whole. I enjoyed this lab much more than any other I've done.

I am pleased with the integration of the lab material with the project. It was much more motivating to work on the project

I was nice to have something to relate mechanical properties to, and have an ultimate goal.

Good course. Very interesting lab. A refreshing change. Need a little fine tuning.

Good to see how all processes lead to a final part (cannon) rather than just doing test on scrap pieces of metal that didn't matter.

Fun and Interesting (Best lab experience ever).

I'm glad I was a part of it because I feel like we got to actually see how all these processes are applied and do something with them. Forming a product is of more value than just seeing every process done separately.

Very helpful to learn techniques and apply them to a real application. This made things more interesting and I think I learned more from it.

There was extra work involved, but it was worth it.

This lab was actually something I looked forward to doing on Tuesdays. This cannot be said for many of my other classes. 


\section{MEEN 360-504 \\ Final Commentary}

Overall it meets its objectives. More instruction could be provided about the whys of materials.

I enjoyed actually making something while learning different manufacturing processes.

This course gave more meaning to the lab course. It gave me something to look forward to at the end of the semester. We got to see the processes involved in the manufacturing of a metal cannon. It kept my interest up throughout the semester.

The whole processes (reverse engineering, manufacturing, testing, and analysis) made me much more interested in this course than I would have been had we just worked with random pieces of metal and plastic. I definitely put more effort into the course because of it.

The course went well because we actually got all the different kind of material testing and shaping processes to build a product.

It's a good idea to manufacture a product using each lab to produce a component for the product helps to keep people's interest.

The lab needs to be more hands on.

The material offered is interesting and resulted in a good lab.

I thought the course was good. It definitely encompassed all the subject this lab intends to cover. The cannon project gives the test and processes a purpose, aside from just doing random tests.

This lab is full of interesting and useful information. I have enjoyed this class.

This was my favorite lab that I have ever been enrolled in. I liked tying all of the labs together with the cannon project, although it seemed to be more work for the instructors. It definitely helped pull the concepts together to see how they fit into the process of making the cannon.

It was good to actually have a goal to build on. This gave each individual lab more importance.

This was the only lab where I feel like I have learned a lot. No one liked the fact we had to do an extra formal report. Also, I think we should make 2 cannon barrels, one to cut up and one to keep. 
I enjoyed applying all of this to a cannon. Working toward a project make the class more interesting.

I believe lab groups be smaller it is hard to get hands on experience with so many teammates.

The only thing tht I did not like about the course was that you only got one chance at everything. One more try at everything would set in what we learned. I realize that there is no time for this but it would be nice. Maybe an out of class time to try to make a part better.

The cannon-building addition to the lab was definitely a great idea. This added much interest/enthusiasm to the learning process without losing (to my knowledge) any of the benefits of the lab with its original structure.

I feel that making the cannon while focusing on the course material is much better than not actually making something. I enjoyed this lab more than any other lab I have had at A\&M. 


\section{Section 506 Final Survey Results}

Rate your level of understanding, preparedness, and ability to converse on the subject of Metrology and Tolerance.

On a scale of 1 to 5 with $1=$ very well prepared and $\mathbf{5}=$ very poorly prepared \# of resp. avg. 1. Metrology and Tolerance

a). Can you define the function of metrology and tolerance in design?

b). Can you identify the criteria necessary to specify a particular dimension or tolerance in design?

c). Can you effectively reverse engineer a product?

d). Do you have the ability to issue a design drawing suitable for manufacture?

e). Can you place the subject of metrology and tolerance in a step-bystep product development?

\begin{tabular}{|c|c|c|c|c|}
\hline 1 & 2 & 3 & 4 & 5 \\
\hline 1 & 7 & 8 & 1 & \\
\hline 1 & 7 & 8 & 1 & \\
\hline 1 & 10 & 5 & 1 & \\
\hline & 10 & 4 & 3 & \\
\hline & 5 & 8 & 4 & \\
\hline
\end{tabular}

$17 \quad 2.529412$

$17 \quad 2.529412$

$17 \quad 2.352941$

172.588235

$17 \quad 2.941176$

Rate your level of understanding, preparedness, and ability to converse on the subjects of Fatigue testing, Impact testing, Tensile testing and Hardness testing

On a scale of 1 to 5 with $1=$ very well prepared and $5=$ very poorly prepared \# of resp. avg.

2. Fatigue, Impact, Tensile, and Hardness Testing

a). Can you define the specific process of the listed materials tests?

b). Do you understand the importance of these tests in evaluating material properties?

c). Do you feel you could choose a particular test for a specific design situation?

d). Can you communicate the process and capabilities of these tests

to someone else?

\begin{tabular}{|l|r|r|r|r|r|}
\hline 1 & 2 & 3 & 4 & 5 \\
\hline & 8 & 7 & 2 & & \\
\hline & 8 & 8 & 1 & & \\
\hline & 5 & 10 & 1 & 1 & \\
\hline & 2 & 14 & 1 & & \\
\hline
\end{tabular}

171.647059

171.588235

171.882353

171.941176

Rate your level of understanding, preparedness, and ability to converse on the subjects of Precipitation Hardening and Heat Treatment of Steel.

On a scale of 1 to 5 with $1=$ very well prepared and $5=$ very poorly prepared \# of resp. avg.

3. Precipitation Hardening and Heat Treatment of Steel

a). Can you define the processes of Precipitation Hardening and Heat Treatment of Steel?

b). Can you list the material properties effected by these two material treatments?

c). Can you place the location of the process in the step-by-step manufacture of a product?

\begin{tabular}{|r|r|r|r|r|r|}
\hline & 1 & 2 & 3 & 4 & $\mathbf{5}$ \\
\hline & 2 & 10 & 5 & & \\
\hline & 1 & 4 & 1 & \\
\hline & 1 & 9 & 6 & 1 & \\
\hline & & 8 & 8 & 1 & \\
\hline & & 12 & 5 & & \\
\hline & 1 & 8 & 7 & 1 & \\
\hline
\end{tabular}

$17 \quad 2.176471$

$17 \quad 2.294118$

$17 \quad 2.411765$

d). Do you know the materials that these processes can be applied to?

e). Can you communicate your knowledge of the process and its capabilities to someone else?

f). Do you feel you could suggest one of these processes for a particular design situation? 
Rate your level of understanding, preparedness, and ability to converse on the subject of CNC Machining.

5. CNC Machining

On a scale of 1 to 5 with $1=$ very well prepared and $5=$ very poorly prepared \# of resp. avg.

a). Can you detail the steps involved in the process of CNC

machining?

b). Can you weigh the capabilities and limitations in the process of

CNC machining?

c). Can you recognize the necessity of this process in the manufacture

of a particular product?

d). Can you communicate effectively in the terminology of this process?

e). Do you understand the placement of this process in the evolution of a product design?

f). Can you communicate the specifics of this process to a co-worker?

\begin{tabular}{|r|r|r|r|r|r|}
\hline & 1 & 2 & 3 & 4 & 5 \\
\hline & 1 & 9 & 6 & 1 & \\
\hline & 1 & 9 & 7 & & \\
\hline of & 2 & 10 & 3 & 2 & \\
\hline & & 3 & 11 & 3 & \\
\hline & & & 6 & 1 & \\
\hline
\end{tabular}

$17 \quad 2.411765$

$17 \quad 2.352941$

$17 \quad 2.294118$

17

$17 \quad 2.470588$

$17 \quad 2.588235$

Rate your level of understanding, preparedness, and ability to converse on the subject of Casting.

On a scale of 1 to 5 with $1=$ very well prepared and $5=$ very poorly prepared \# of resp. avg.

\begin{tabular}{|c|c|c|c|c|c|c|c|}
\hline 6. Casting & 1 & 2 & 3 & 4 & 5 & & \\
\hline a). Can you detail the steps involved in the process of casting? & 8 & 8 & 1 & & & 17 & 1.588235 \\
\hline $\begin{array}{l}\text { b). Can you weigh the capabilities and limitations in the process of } \\
\text { casting? }\end{array}$ & 6 & 9 & 2 & & & 17 & 1.764706 \\
\hline $\begin{array}{l}\text { c). Can you recognize the necessity of this process in the manufacture } \\
\text { of a particular product? }\end{array}$ & 6 & 9 & 1 & 1 & & 17 & 1.823529 \\
\hline $\begin{array}{l}\text { d). Can you communicate effectively in the terminology of this } \\
\text { process? }\end{array}$ & 3 & 10 & 4 & & & 17 & 2.058824 \\
\hline $\begin{array}{l}\text { e). Do you understand the placement of this process in the evolution of } \\
\text { a product design? }\end{array}$ & 6 & 6 & 5 & & & 17 & 1.941176 \\
\hline f). Can you communicate the specifics of this process to a co-worker? & 4 & 10 & 3 & & & 17 & 1.941176 \\
\hline
\end{tabular}

Rate your level of understanding, preparedness, and ability to converse on the subject of Welding.

On a scale of 1 to 5 with $1=$ very well prepared and $5=$ very poorly prepared \# of resp. avg.

\begin{tabular}{|c|c|c|c|c|c|c|c|}
\hline 7. Welding & 1 & 2 & 3 & 4 & 5 & & \\
\hline a). Can you detail the steps involved in the process of welding? & 2 & 11 & 4 & & & 17 & 2.117647 \\
\hline $\begin{array}{l}\text { b). Can you weigh the capabilities and limitations in the process of } \\
\text { welding? }\end{array}$ & 3 & 8 & 6 & & & 17 & 2.176471 \\
\hline $\begin{array}{l}\text { c). Can you recognize the necessity of this process in the manufacture } \\
\text { of a particular product? }\end{array}$ & 4 & 11 & 2 & & & 17 & 1.882353 \\
\hline $\begin{array}{l}\text { d). Can you communicate effectively in the terminology of this } \\
\text { process? }\end{array}$ & 1 & 9 & 7 & & & 17 & 2.352941 \\
\hline $\begin{array}{l}\text { e). Do you understand the placement of this process in the evolution of } \\
\text { a product design? }\end{array}$ & 4 & 11 & 2 & & & 17 & 1.882353 \\
\hline f). Can you communicate the specifics of this process to a co-worker? & 2 & 10 & 5 & & & 17 & 2.176471 \\
\hline
\end{tabular}


Rate your level of understanding, preparedness, and ability to converse on the subject of Injection Molding.

8. Injection Molding

On a scale of 1 to 5 with 1 = very well prepared and $5=$ very poorly prepared \# of resp. avg.

a). Can you detail the steps involved in the process of injection

molding?

b). Can you weigh the capabilities and limitations in the process of injection molding?

c). Can you recognize the necessity of this process in the manufacture

of a particular product?

d). Can you communicate effectively in the terminology of this process?

e). Do you understand the placement of this process in the evolution of a product design?

f). Can you communicate the specifics of this process to a co-worker?

\begin{tabular}{|r|r|r|r|r|r|}
\hline 1 & 2 & 3 & 4 & $\mathbf{5}$ \\
\hline & 5 & 8 & & \\
\hline 1 & 9 & 6 & 1 & \\
\hline & 3 & 10 & 3 & 1 & \\
\hline of & 2 & 4 & 10 & 1 & \\
\hline & 3 & 8 & 5 & 1 & \\
\hline & 3 & 2 & 11 & 1 & \\
\hline
\end{tabular}

$17 \quad 2.235294$

$17 \quad 2.411765$

$17 \quad 2.117647$

$17 \quad 2.588235$

$17 \quad 2.235294$

$17 \quad 2.588235$

Rate your level of understanding, preparedness, and ability to converse on the subject of Rapid Prototyping.

9. Rapid Prototyping

On a scale of 1 to 5 with $1=$ very well prepared and $\mathbf{5}=$ very poorly prepared \# of resp. avg.

a). Can you detail the steps involved in the process of Rapid

Prototyping?

b). Can you weigh the capabilities and limitations in the process of

Rapid Prototyping?

c). Can you recognize the necessity of this process in the manufacture

of a particular product?

d). Can you communicate effectively in the terminology of this process?

e). Do you understand the placement of this process in the evolution of a product design?

f). Can you communicate the specifics of this process to a co-worker? g). Do you understand the effect of Rapid Prototyping on the speed of product development?

\begin{tabular}{|r|r|r|r|r|r|}
\hline & 1 & 2 & 3 & 4 & 5 \\
\hline & 3 & 10 & 4 & & \\
\hline & 2 & 11 & 3 & 1 & \\
\hline & 3 & 10 & 4 & & \\
\hline & 1 & 7 & 8 & 1 & \\
\hline & 4 & 9 & 3 & 1 & \\
\hline of & 2 & 8 & 6 & 1 & \\
\hline & 6 & 8 & 2 & 1 & \\
\hline
\end{tabular}

$17 \quad 2.058824$

$17 \quad 2.176471$

$17 \quad 2.058824$

$17 \quad 2.529412$

$17 \quad 2.058824$

$17 \quad 2.352941$

171.882353

Rate your level of understanding, preparedness, and ability to converse on the subject of Metallography.

10. Metallography

On a scale of 1 to 5 with $\mathbf{1}=$ very well prepared and $\mathbf{5}=$ very poorly prepared \# of resp. avg.

a). Can you define the purpose and function of Metallography?

b). Can you list the capabilities of this process?

c). Can you recognize the necessity of this process in the manufacture of a particular product?

d). Can you communicate effectively the value and purpose of this process to someone else?

e). Do you understand the function of this process in quality control

\begin{tabular}{|r|r|r|r|r|}
\hline 1 & $\mathbf{2}$ & $\mathbf{3}$ & $\mathbf{4}$ & $\mathbf{5}$ \\
\hline 3 & 12 & 1 & 1 & \\
\hline 2 & 9 & 5 & 1 & \\
\hline 1 & 11 & 4 & 1 & \\
\hline 1 & 10 & 5 & 1 & \\
\hline & 9 & 4 & 1 & \\
\hline
\end{tabular}

17

$17 \quad 2.294118$

and failure diagnosis?

$17 \quad 2.294118$

$17 \quad 2.352941$

$17 \quad 2.176471$ 


\section{MEEN 360-506 \\ Final Commentary}

I enjoyed this course. A lot of information was covered, although most briefly, I felt I retained most information presented.

The lab was very educational in a sense that there was a lot of hands on activity which helped my personal learning process (ability). Doing a lot experiments increased my awareness of the manufacturing of materials.

Pretty sound overall introduction to many concepts. I thought lab write ups were appropriate.

Good, interesting lab. Helped my understanding of material.

This lab is an excellent learning tool. I learn far more by "hands-on" approach. I feel more comfortable learning in lab than in lecture.

Regarding the lab, I feel it tremendously assisted in understanding class material. The hands-on approach along with Dr. Wolfenden's knowledge and experience made it very easy to stay interested and learn.

I very much enjoyed the hands-on approach to this course. I learned a lot and I know Dr. Wolfeden will be missed.

Overall the lab was very interesting. It was nice to be able to gain some "hands-on" experience with rapid prototyping, injection molding, and welding. This lab provided an introduction to "real-world" methods. The only suggestion would be to go over the requirements of the technical report before it is due. We handed ours in before we were told what to put on it. 


\section{APPENDIX G}

\section{ESSAY ANALYSIS DATA}




\begin{tabular}{|c|c|c|c|c|c|c|c|c|c|c|c|c|c|c|c|}
\hline SEC & ETHNICITY & GENDER & SAT VERBAL & SAT TOTAL & EXP. GPR & ENGR 213 & \begin{tabular}{|l|} 
CBK GPA \\
\end{tabular} & A1 & B1 & C1 & D1 & D2 & E1 & E2 & E3 \\
\hline 501 & W & $\mathrm{M}$ & & & & $\mathrm{B}$ & 4.00 & 65.22 & 76.95 & 75.24 & 8.5 & 8.5 & 4 & 9 & 5.5 \\
\hline 501 & W & $\mathrm{M}$ & 650 & 1280 & 29 & $B$ & 2.74 & 61.00 & 72.44 & 75.00 & & & & & \\
\hline 501 & $\mathrm{~W}$ & $\mathrm{M}$ & 750 & 1520 & 32 & $\mathrm{~B}$ & 3.10 & 80.00 & 76.37 & 76.08 & 12.5 & 9 & 5 & 10.75 & 7.25 \\
\hline 501 & $\mathrm{~W}$ & $F$ & 490 & 1020 & 23 & $\mathrm{~A}$ & 2.80 & 37.00 & 67.85 & 72.31 & 6.5 & 4.5 & 3 & 9.25 & 5.75 \\
\hline 501 & W & $\mathrm{M}$ & & & & A & 4.00 & 52.00 & 79.35 & 83.48 & 13 & 11 & 4 & 9.75 & 10.5 \\
\hline 501 & W & $\mathrm{M}$ & & & & & & 77.00 & 63.43 & 74.70 & 8.5 & 9.5 & & & \\
\hline 501 & w & M & 640 & 1380 & 30 & $B$ & 3.60 & 70.00 & 70.57 & 74.86 & 13.5 & 7 & 7 & 9 & 8.5 \\
\hline 501 & $\mathrm{~W}$ & $F$ & 640 & 1390 & 32 & $A$ & 3.88 & 71.74 & 70.60 & 80.69 & 14 & 11 & & & \\
\hline 501 & $\mathrm{~W}$ & $F$ & 580 & 1230 & 28 & $B$ & 3.40 & 80.43 & 66.71 & 71.99 & 11.5 & 9 & 4 & 10 & 6 \\
\hline 501 & $\mathrm{~W}$ & $F$ & 550 & 1250 & 26 & C & 2.90 & 63.04 & 75.60 & 79.26 & 11.5 & 9.5 & 5 & 10.25 & 7.5 \\
\hline 501 & W & $\mathrm{F}$ & 700 & 1410 & 32 & C & 3.20 & 71.74 & 77.09 & 78.64 & 13.5 & 9.5 & 5 & 8.25 & 7.25 \\
\hline 501 & $\mathrm{H}$ & $\mathrm{M}$ & 580 & 1160 & 29 & $B$ & 2.90 & 67.39 & 79.43 & 81.15 & 12 & 9 & 5 & 11.5 & 8.5 \\
\hline 501 & $\mathrm{~W}$ & $\mathrm{M}$ & & & & $A$ & & 72.00 & 65.56 & 77.37 & 9 & 8.5 & 5 & 9.5 & 10 \\
\hline 501 & $\mathrm{~W}$ & $\mathrm{M}$ & 610 & 1240 & 30 & $B$ & 2.43 & 78.00 & 73.65 & 78.42 & 11.5 & 10 & 6 & 9.75 & 9 \\
\hline 501 & W & $\mathrm{M}$ & & & & $A$ & 2.67 & 80.00 & 78.19 & 83.58 & 12 & 9.5 & 5 & 9.25 & 9.25 \\
\hline 501 & w & $M$ & 610 & 1350 & 30 & A & 3.75 & 74.00 & 74.92 & 80.12 & \begin{tabular}{|l|}
13.5 \\
\end{tabular} & 10.5 & & & \\
\hline 501 & $\mathrm{~W}$ & $F$ & 660 & 1360 & 30 & $B$ & 3.10 & 52.00 & \begin{tabular}{|l|l}
60.48 \\
\end{tabular} & 71.67 & \begin{tabular}{l|}
5.5 \\
\end{tabular} & 8 & 4 & 10.75 & 8.75 \\
\hline 502 & $\mathrm{~W}$ & $M$ & 690 & 1330 & 28 & $A$ & 3.00 & & 71.20 & 70.36 & 11 & 9.5 & 6 & 10.25 & 6.75 \\
\hline 502 & $\mathrm{~W}$ & $\mathrm{M}$ & 610 & 1190 & 26 & C & 2.75 & 75.00 & 64.72 & 63.70 & \begin{tabular}{ll|}
11.5 \\
\end{tabular} & 10 & 4 & 10.75 & 9 \\
\hline 502 & W & $\mathrm{M}$ & 520 & 1120 & 26 & $B$ & 3.10 & 72.00 & 63.81 & 65.37 & 12 & \begin{tabular}{l|l}
6.5 \\
\end{tabular} & 7 & 9.25 & 6 \\
\hline 502 & W & $\mathrm{F}$ & 580 & 1150 & 29 & $B$ & 3.00 & 41.30 & 53.91 & 70.39 & 10.5 & 11 & 3 & 10 & 8.5 \\
\hline 502 & W & $\mathrm{M}$ & 660 & 1340 & 28 & $\mathrm{~A}$ & 2.70 & 34.78 & \begin{tabular}{|l|l|}
78.47 \\
\end{tabular} & 75.28 & $\begin{array}{l}9.5 \\
\end{array}$ & 8 & 6 & 11 & 10.25 \\
\hline 502 & W & $\mathrm{M}$ & 660 & 1210 & 28 & $A$ & 2.88 & 65.22 & 7.27 & 72.92 & 15 & 12 & 6 & 9 & 11 \\
\hline 502 & $\mathrm{~W}$ & $\mathrm{M}$ & & & & $A$ & & 80.00 & 76.47 & 78.92 & 14 & 10 & 5 & 9 & 7 \\
\hline 502 & W & $M$ & & & & B & & 78.00 & 73.78 & 73.09 & 13.5 & 7.5 & 5 & 7.75 & 4.5 \\
\hline 502 & W & M & 700 & 1440 & 32 & $\mathrm{C}$ & 3.00 & 70.00 & 60.20 & 69.04 & 12.5 & 5 & 4 & 10.25 & 8.25 \\
\hline 502 & W & $\mathrm{M}$ & 600 & 1280 & 25 & $A$ & 2.70 & 65.00 & 67.50 & 69.19 & 14 & 9 & 5 & 10.75 & 6.5 \\
\hline 503 & $\mathrm{~W}$ & $\mathrm{M}$ & & & & A & & 33.00 & 61.74 & 71.73 & & & 4 & 8.75 & 5.75 \\
\hline 503 & W & $\mathrm{M}$ & 700 & 1430 & 32 & $A$ & 4.00 & 48.00 & 85.52 & 88.37 & 11 & 12 & 5 & 11.25 & 9 \\
\hline 503 & $\mathrm{~W}$ & $\mathrm{~F}$ & 640 & 1380 & 32 & $B$ & 3.00 & 61.00 & 76.89 & 76.68 & 7 & 9 & & & \\
\hline 503 & $x$ & $\mathrm{M}$ & & & & $B$ & & & 62.01 & 72.42 & 11 & 10 & 4 & $\begin{array}{c}9.5 \\
\end{array}$ & 7.5 \\
\hline 503 & $X$ & $\mathrm{M}$ & 420 & 1080 & 20 & $A$ & 3.70 & 50.00 & \begin{tabular}{|l|}
69.85 \\
\end{tabular} & 74.06 & 11.5 & 9.5 & 4 & 8.25 & 4.25 \\
\hline 503 & $X$ & $\mathrm{M}$ & 450 & 1120 & 19 & $B$ & 3.60 & 34.78 & \begin{tabular}{|l|}
55.91 \\
\end{tabular} & 66.68 & 11.5 & 7.5 & 4 & 8.5 & 9 \\
\hline 503 & $X$ & $M$ & 610 & 1320 & 27 & $B$ & 2.75 & 69.57 & 64.74 & 71.41 & \begin{tabular}{c|}
9.5 \\
\end{tabular} & 6 & 6 & 9.25 & 7 \\
\hline 503 & $\mathrm{~W}$ & $\mathrm{M}$ & & & & $B$ & & 57.00 & 76.68 & 78.30 & 11 & 9 & 3 & 10.75 & 7.25 \\
\hline 503 & $\mathrm{~W}$ & $\mathrm{M}$ & 480 & 990 & 26 & $\mathrm{~A}$ & 2.90 & 71.74 & \begin{tabular}{|l|l|}
80.51 \\
\end{tabular} & 77.37 & 12.5 & 6.5 & & & \\
\hline 503 & $X$ & $\mathrm{M}$ & & & & $A$ & & 50.00 & 71.52 & 73.82 & 12 & 5 & 6 & 9.5 & 11.25 \\
\hline 503 & $\mathrm{~W}$ & $\bar{M}$ & 580 & 1340 & 31 & B & 2.90 & 73.91 & 81.68 & 77.69 & 11.5 & 6 & 5 & 10 & 10 \\
\hline 503 & $\mathrm{~W}$ & $\mathrm{M}$ & 740 & 1480 & 32 & $A$ & & 67.00 & 72.36 & 81.17 & $\begin{array}{l}14.5 \\
\end{array}$ & 10 & 6 & 8 & 7.25 \\
\hline 503 & W & M & 490 & 1040 & 26 & $B$ & 2.00 & 83.00 & 50.58 & 63.40 & 11 & 5 & & & \\
\hline 503 & $\mathrm{~W}$ & $\bar{M}$ & 640 & 1340 & 31 & $\mathrm{~A}$ & 4.00 & 67.00 & \begin{tabular}{|l|}
85.76 \\
\end{tabular} & 88.91 & 12.5 & 8 & 5 & 10.25 & 8.25 \\
\hline 503 & $\mathrm{~W}$ & $\mathrm{M}$ & 500 & 1100 & 26 & $B$ & 3.10 & 59.00 & \begin{tabular}{|l|l|}
75.39 \\
\end{tabular} & 80.19 & 111.5 & 8 & 5 & $\begin{array}{c}9.25 \\
\end{array}$ & 6 \\
\hline 504 & W & $\mathrm{M}$ & 0 & 0 & 27 & $B$ & 3.30 & 47.00 & 74.36 & 82.34 & 10.5 & 11 & 5 & 10.25 & 6.5 \\
\hline 504 & W & $\mathrm{M}$ & 610 & 1200 & 26 & $A$ & 3.00 & 60.87 & 80.35 & 82.57 & $\begin{array}{c}9.5 \\
\end{array}$ & 10 & 4 & 8.75 & 10.75 \\
\hline 504 & W & $\mathrm{F}$ & & & & & & 49.00 & 75.21 & 84.90 & 11.5 & \begin{tabular}{|c|}
9.5 \\
\end{tabular} & 5 & 10.75 & 9.75 \\
\hline 504 & $\mathrm{~W}$ & $\mathrm{M}$ & 530 & 1140 & 27 & $A$ & 2.90 & 35.00 & 57.74 & 78.72 & 9 & 11 & 5 & 9 & 7.25 \\
\hline 504 & $\mathrm{~W}$ & $\mathrm{M}$ & 580 & 1280 & 31 & $B$ & 3.10 & 39.00 & 76.13 & 81.80 & 11 & 8 & 6 & 10.5 & 7.5 \\
\hline 504 & W & M & & & & A & 2.83 & 59.00 & 66.69 & 84.07 & 9.5 & 12 & 5 & 9.25 & 8 \\
\hline 504 & W & M & & & & A & 3.00 & 39.00 & \begin{tabular}{|l|}
73.56 \\
\end{tabular} & 77.50 & & & 4 & 10.5 & 6.75 \\
\hline 504 & $\mathrm{~W}$ & $\mathrm{M}$ & & & & $\mathrm{B}$ & 3.00 & 69.57 & 63.14 & 75.90 & 12.5 & 12 & 4 & \begin{tabular}{|c|}
9.75 \\
\end{tabular} & 9.5 \\
\hline 504 & $\mathrm{~W}$ & $\mathrm{M}$ & 510 & 1090 & 25 & $B$ & 2.90 & 67.39 & \begin{tabular}{|l}
7.47 \\
\end{tabular} & 78.52 & 111.5 & 7 & 6 & 9 & 9.5 \\
\hline 504 & W & $\mathrm{M}$ & 630 & 1270 & 30 & & 2.80 & 67.39 & 74.44 & 78.62 & 11.5 & 5.5 & 6 & 8.5 & 9.25 \\
\hline 504 & W & $\mathrm{M}$ & & & & A & & 80.00 & 83.46 & 82.78 & 12.5 & 11 & 8 & 10.5 & 9 \\
\hline 504 & W & M & & & & A & & 67.00 & 67.50 & 80.78 & 10 & 8 & 4 & 10.75 & 7 \\
\hline 504 & W & M & 550 & 1220 & 30 & $A$ & 3.00 & 74.00 & 69.54 & 79.33 & 10 & 8 & 7 & 9.75 & 8.25 \\
\hline 504 & $\mathrm{~W}$ & $\bar{M}$ & 590 & 1200 & 28 & $B$ & 3.67 & 72.00 & 75.63 & 79.17 & \begin{tabular}{|l|}
11.5 \\
\end{tabular} & 10 & 5 & \begin{tabular}{l|}
9.25 \\
\end{tabular} & 10 \\
\hline 504 & $\mathrm{~W}$ & $\mathrm{M}$ & 690 & 1340 & 31 & $A$ & 4.00 & 85.00 & \begin{tabular}{|l}
87.20 \\
\end{tabular} & 85.89 & 13.5 & 12 & 5 & 9.75 & 9.25 \\
\hline 504 & W & $\mathrm{F}$ & 640 & 1260 & 34 & $B$ & 3.00 & 57.00 & \begin{tabular}{|l|}
59.53 \\
\end{tabular} & 68.22 & 11.5 & 5.5 & 5 & 9.5 & 9.5 \\
\hline 504 & W & M & 690 & 1370 & 30 & $\mathrm{~A}$ & 2.75 & 65.00 & \begin{tabular}{|l|l}
72.68 \\
\end{tabular} & \begin{tabular}{|c|}
79.75 \\
\end{tabular} & 12 & 12 & 3 & 10.25 & 7.5 \\
\hline 504 & W & $\mathrm{M}$ & 540 & 1110 & 29 & $A$ & 2.90 & 61.00 & \begin{tabular}{|l|}
62.11 \\
\end{tabular} & 78.10 & 8 & 10 & & 9.25 & 11.25 \\
\hline 505 & $\mathrm{~W}$ & $\mathrm{M}$ & 620 & 1200 & 29 & $\mathrm{~A}$ & 3.70 & 65.00 & \begin{tabular}{|l|}
89.65 \\
\end{tabular} & \begin{tabular}{|l|l|}
89.89 \\
\end{tabular} & 12.5 & 5.5 & 6 & \begin{tabular}{|c|}
9.75 \\
\end{tabular} & 5.75 \\
\hline 505 & W & M & 590 & 1270 & 27 & $B$ & 3.13 & 72.00 & 58.81 & 75.60 & 12 & 11 & 4 & $\begin{array}{r}8.5 \\
\end{array}$ & 8.75 \\
\hline 505 & $A$ & M & 600 & 1250 & 28 & $x$ & & 41.00 & 71.20 & 84.05 & 6 & 12 & 4 & 9.25 & 8.5 \\
\hline 505 & w & M & 590 & 1320 & 30 & $B$ & 3.00 & 54.00 & \begin{tabular}{|l|l|}
75.31 \\
\end{tabular} & 73.65 & 5 & 7.5 & 3 & $\begin{array}{l}11 \\
\end{array}$ & 10.25 \\
\hline 505 & $\mathrm{w}$ & $\mathrm{M}$ & 570 & 1180 & 25 & $\mathrm{~A}$ & 2.40 & & 51.13 & 76.61 & 10.5 & 12 & 4 & 8.75 & $\begin{array}{l}7.75 \\
\end{array}$ \\
\hline 505 & W & $\mathrm{M}$ & & & & $\mathrm{B}$ & 3.75 & 67.00 & 75.26 & 81.69 & $\begin{array}{r}7.5 \\
\end{array}$ & 6 & 6 & 9.75 & 6 \\
\hline 505 & W & $\mathrm{M}$ & 570 & 1220 & 30 & $\mathrm{D}$ & 2.90 & 70.00 & 67.42 & 70.17 & & & 0 & 8.5 & 5.25 \\
\hline 505 & $\mathrm{~W}$ & $\mathrm{M}$ & 600 & 1310 & 29 & C & 3.38 & 60.87 & 80.13 & \begin{tabular}{|l|l|}
79.02 \\
\end{tabular} & 10 & 11 & 5 & 10.25 & 8 \\
\hline 505 & W & M & 490 & 1040 & 23 & $\mathrm{~A}$ & 2.40 & 89.13 & \begin{tabular}{|l|}
68.98 \\
\end{tabular} & 77.35 & 7.5 & 5 & 3 & 9.5 & 7.5 \\
\hline 505 & $\mathrm{~W}$ & $F$ & 690 & 1390 & 32 & $B$ & 3.00 & 58.70 & \begin{tabular}{|l|}
67.91 \\
\end{tabular} & 81.14 & \begin{tabular}{l|l}
12.5 \\
\end{tabular} & 12 & 4 & 9 & 7 \\
\hline 505 & $\mathrm{~W}$ & $\mathrm{M}$ & 0 & 0 & 22 & $\mathrm{C}$ & 3.40 & 72.00 & 75.29 & 78.63 & \begin{tabular}{l|l}
10.5 \\
\end{tabular} & 8 & 7 & 10.25 & 10.5 \\
\hline 505 & W & $M$ & 760 & 1550 & 32 & $A$ & 2.50 & 70.00 & 68.99 & 69.42 & 14 & \begin{tabular}{|l|}
9.5 \\
\end{tabular} & 7 & 8.5 & 9.5 \\
\hline 505 & W & $\mathrm{M}$ & 540 & 1160 & & $\mathrm{~A}$ & 3.20 & 65.00 & 71.73 & 83.37 & 7 & 11 & 6 & \begin{tabular}{|c|}
10 \\
\end{tabular} & 8 \\
\hline 505 & W & $\mathrm{M}$ & 700 & 1410 & 32 & $A$ & 3.50 & 65.00 & 74.88 & \begin{tabular}{|l|l|}
82.98 \\
\end{tabular} & 12 & 10 & 4 & 10.5 & 9.75 \\
\hline
\end{tabular}




\section{VITA}

Jeremy L. Weinstein received his undergraduate degree from Texas Tech University in May of 1998. Since graduating with his B.S. in mechanical engineering he has had the opportunity to work in a variety of industries. His longest term of employment was with Thermon Manufacturing in San Marcos, Texas. While working at Thermon, he became proficient as a product development engineer, acquiring a number of skills in design, testing and manufacturing. After working for two years he decided that his career could be best developed by returning to school for a master's degree. After graduating in May of 2003 with a Master of Science in mechanical engineering, he will endeavor to continue to accrue knowledge in the area of mechanical design and manufacturing with hope of obtaining a professional license within the next year.

His Permanent Address is:

1019 Burning Tree

Kingwood, TX 77339 